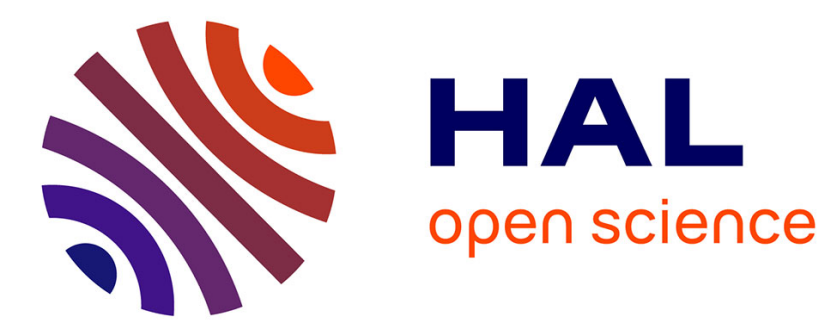

\title{
Enantioselective magnesium-catalyzed transformations
}

Helene Pellissier

\section{To cite this version:}

Helene Pellissier. Enantioselective magnesium-catalyzed transformations. Organic \& Biomolecular Chemistry, 2017, 15 (22), pp.4750-4782. 10.1039/C7OB00903H . hal-01612123

\section{HAL Id: hal-01612123 \\ https://hal.science/hal-01612123}

Submitted on 16 Apr 2018

HAL is a multi-disciplinary open access archive for the deposit and dissemination of scientific research documents, whether they are published or not. The documents may come from teaching and research institutions in France or abroad, or from public or private research centers.
L'archive ouverte pluridisciplinaire HAL, est destinée au dépôt et à la diffusion de documents scientifiques de niveau recherche, publiés ou non, émanant des établissements d'enseignement et de recherche français ou étrangers, des laboratoires publics ou privés. 


\title{
Enantioselective magnesium-catalyzed transformations
}

\author{
Hélène Pellissier (1) \\ This review updates the major progress in the field of enantioselective transformations promoted by chiral \\ magnesium catalysts, covering the literature since 2007, illustrating the power of these mild Lewis acid \\ catalysts to provide a wide variety of novel asymmetric reactions.
}

\section{Introduction}

Developed for several decades, organometallic chemistry is even today considered to be a very dynamic discipline. In particular, asymmetric transition-metal catalysis constitutes a powerful tool to perform highly enantioselective reactions. ${ }^{1}$ Unlike transition metals, alkaline earth metals, such as magnesium, have been well recognized owing to their vast abundance and being inexpensive and environmentally benign. Moreover, they have shown promising applications in the field of catalytic organic synthesis, due to their milder Lewis acidity in comparison with traditional transition metals. First reported in 1992 by Corey, ${ }^{2}$ ecological and economical magnesium-catalyzed enantioselective transformations have attracted continu-

Aix Marseille Univ., CNRS, Centrale Marseille, iSm2, Marseille, France. E-mail: h.pellissier@univ-amu.fr ous ever-growing attention in the last few decades, leading to fruitful research studies. Indeed, many chiral complexes of magnesium(II) have been designed and developed as mild Lewis acids to catalyze a wide variety of enantioselective transformations generally performed under mild reaction conditions. Among them, the first asymmetric magnesiumcatalyzed domino reactions have been only recently developed besides a number of novel highly enantioselective magnesiumcatalyzed cycloadditions, ring-opening reactions, Michael additions, 1,2-nucleophilic additions to carbonyl compounds and imines, $\alpha$-functionalizations of carbonyl compounds, hydroaminations of alkenes, etc. The goal of this review is to collect the major developments in enantioselective magnesium-catalyzed transformations published since 2007, because this field was most recently reviewed in 2008 by Hatano and Ishihara in a book chapter covering the literature up to 2006. ${ }^{3}$ Prior to 2008, this field was reviewed by Nishiyama and Motoyama in a book chapter, ${ }^{4}$ and by Afarinkia in a review article. ${ }^{5}$ It must be noted that a specific book chapter was dedicated by Kantam and Chintareddy in 2011 to their works and to those of Choudary on nanocrystalline magnesium oxide for asymmetric organic reactions. ${ }^{6}$ In 2013, Harder edited a book dealing with alkaline-earth metal compounds but it included only one example of enantioselective magnesium-catalyzed hydroamination. ${ }^{7}$ Moreover, a concept review dealing with homogeneous organomagnesium catalysis was recently published by Mashima and Tsurugi, but it included only one example of enantioselective hydroamination along with racemic reactions. ${ }^{8}$ It must be also noted that a recent book dealing with sustainable catalysis with nonendangered metals was edited by Michael North. ${ }^{9}$ The present review has been divided into eight principal sections, dealing successively with enantioselective magnesium-catalyzed cycloadditions, domino and tandem reactions, ring-opening reactions, Michael reactions, 1,2-nucleophilic additions to carbonyl compounds and imines, $\alpha$-functionalizations of carbonyl compounds, hydroamination reactions, and miscellaneous reactions. 


\section{Magnesium-catalyzed cycloadditions}

\section{1. (Hetero)-Diels-Alder cycloadditions}

The asymmetric Diels-Alder reaction constitutes a powerful tool to build up chiral cyclic six-membered rings. ${ }^{10}$ Since the pioneering work reported by Corey and Ishihara in $1992^{2}$ dealing with the enantioselective Diels-Alder cycloaddition of $\mathrm{N}$-acryloyloxazolidinone with cyclopentadiene catalyzed by chiral bis(oxazoline) magnesium catalysts achieved with enantioselectivities of up to $91 \%$ ee, a number of different chiral $\mathrm{Mg}$ (II) complexes have been successfully applied to promote this type of reaction. Even chiral magnesium complexes immobilized on silica supports have proved to be effective catalysts. Indeed, Hardacre et al. have developed the cycloaddition of $\mathrm{N}$-acryloyloxazolidinone $\mathbf{1}$ with cyclopentadiene catalyzed by bis(oxazoline) magnesium complex 2 immobilized on nanoporous silica SPA-15 through ionic liquids to give the corresponding cycloadduct 3 in $72 \%$ ee with complete conversion (Scheme 1). ${ }^{11}$

Chiral spirocyclic oxindoles are known to be pharmaceutically interesting compounds. ${ }^{12}$ In this context, Antilla et al. have reported a novel rapid route to these products based on the enantioselective magnesium-catalyzed Diels-Alder reaction of variously substituted 3-methyleneoxindoles 4 with Danishefsky's diene 5a $\left(\mathrm{R}^{5}=\mathrm{TBS}\right) .{ }^{13}$ As shown in Scheme 2, the process was promoted at room temperature by preformed the chiral magnesium phosphate complex 6 in diethyl ether as a solvent to afford the corresponding chiral six-membered spirooxindoles 7 exhibiting three contiguous stereocenters in high yields (85-99\%), high diastereoselectivities (80-98\% de) and remarkable enantioselectivities (95-99\% ee). In addition to tert-butyldimethylsilyl-protected Danishefsky's diene $\mathbf{5 a}$, the smaller trimethylsilyl-protected one $\mathbf{5 b}\left(\mathrm{R}^{5}=\mathrm{TMS}\right)$ gave comparable results ( $90 \%$ yield, $98 \%$ de, $99 \%$ ee). To explain the stereochemical outcome of the cycloaddition, a plausible transition state is depicted in Scheme 2 in which the imide group of the oxindole coordinates with $\mathrm{Mg}^{2+}$ to form a tetrahedral intermediate in which the top face of the $\mathrm{C}=\mathrm{C}$ bond is blocked by the 9-phenanthryl group of the ligand, while leaving the bottom open for Danishefsky's diene to form the preferred endo product. On the other hand, the Boc group
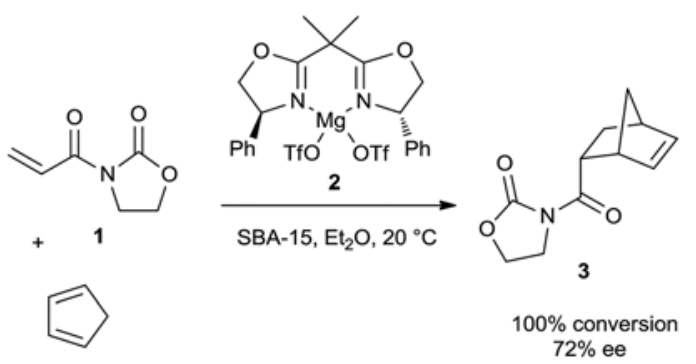

Scheme 1 Diels-Alder reaction of $N$-acryloyloxazolidinone with cyclopentadiene through supported ionic liquid phase catalysis.
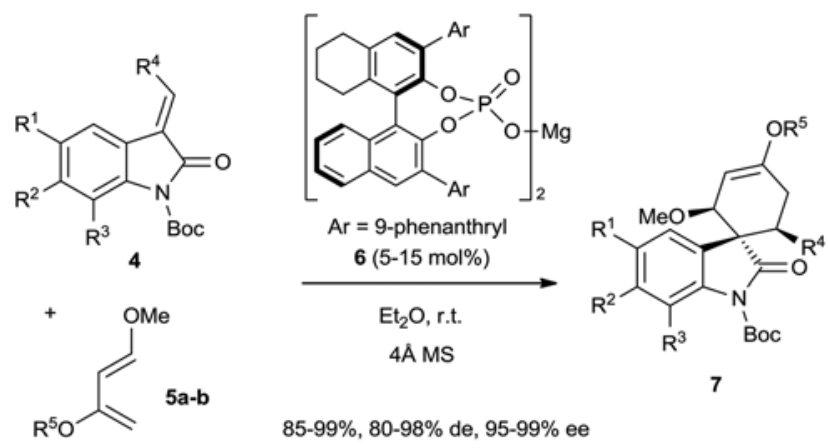

$85-99 \%, 80-98 \%$ de, $95-99 \%$ ee

$\mathrm{R}^{1}=\mathrm{H}, \mathrm{Me}, \mathrm{MeO}, \mathrm{F}, \mathrm{Cl}, \mathrm{Br}$

$\mathrm{R}^{2}=\mathrm{H}, \mathrm{Br}$

$\mathrm{R}^{3}=\mathrm{H}, \mathrm{Me}$

$\mathrm{R}^{4}=\mathrm{CN}, \mathrm{CO}_{2} \mathrm{Me}$

$\mathrm{R}^{5}=\mathrm{TBS}, \mathrm{TMS}$

proposed transition state:

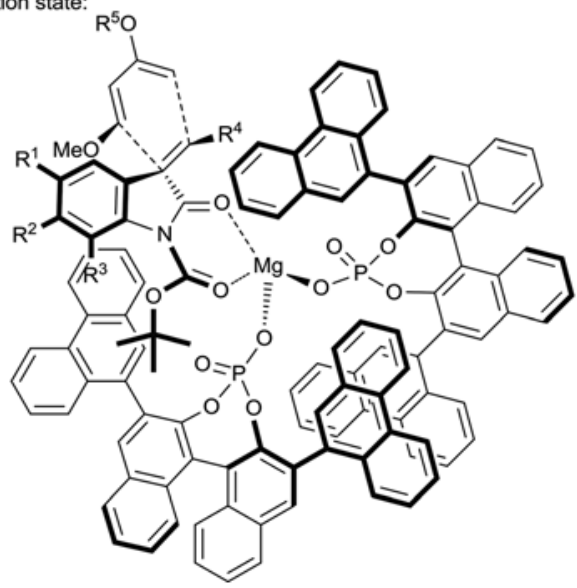

Scheme 2 Diels-Alder reaction of 3-methyleneoxindoles with Danishefsky's dienes.

holds one of the other 9-phenanthryl groups in position by steric hindrance.

The asymmetric hetero-Diels-Alder reaction is among the most powerful methodologies available for the construction of optically active six-membered heterocycles, with extensive synthetic applications in natural or unnatural products with a wide range of biological activities. ${ }^{14}$ In 1998, Whiting et al. described the first enantioselective aza-Diels-Alder cycloaddition which was catalyzed by a magnesium complex derived from chiral diphenylethylenediamine as ligand. ${ }^{15}$ The reaction occurred between Danishefsky's diene and methyl glyoxylate-derived aldimine, leading to the corresponding cycloadduct in $97 \%$ ee. Later in 2008 , Ding et al. reported the first asymmetric magnesium-catalyzed hetero-Diels-Alder reactions of aldehydes. ${ }^{16}$ Among a collection of BINOL- and TADDOL-derived ligands, $(R)-\mathrm{H}_{4}$-BINOL was selected as the most efficient to give at room temperature in combination with $\mathrm{MgBu}_{2}$ the best enantioselectivities (up to $99 \%$ ee) combined with excellent yields (91-99\%) for the cycloadducts 8 arising from the reactions of a variety of aromatic as well as aliphatic aldehydes with Danishefsky's diene 5b (Scheme 3). To 


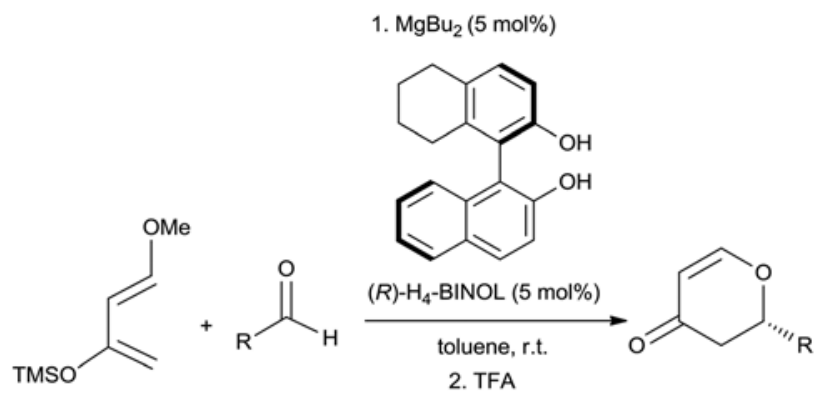

$5 b$

$91-99 \%, 80-99 \%$ ee

$\mathrm{R}=\mathrm{Ph}, p-\mathrm{MeOC}_{6} \mathrm{H}_{4}, p-\mathrm{Tol}, m-\mathrm{ClC}_{6} \mathrm{H}_{4}, p-\mathrm{BrC}_{6} \mathrm{H}_{4}, p-\mathrm{ClC}_{6} \mathrm{H}_{4}, o-\mathrm{BrC}_{6} \mathrm{H}_{4}$, o- $\mathrm{Tol}, 2,6-\mathrm{Cl}_{2} \mathrm{C}_{6} \mathrm{H}_{3}, \mathrm{BnCH}_{2},(E)-\mathrm{PhCH}=\mathrm{CH}, 2-\mathrm{Fu}$

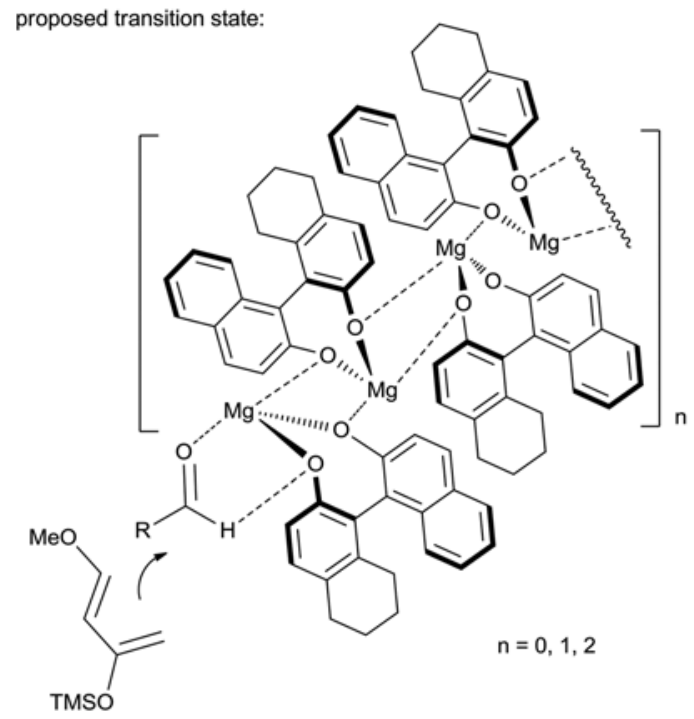<smiles>[R]C=O</smiles>

$5 b$

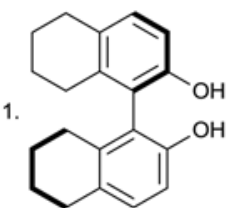

(R)- $\mathrm{H}_{8}$-BINOL (5 mol\%)

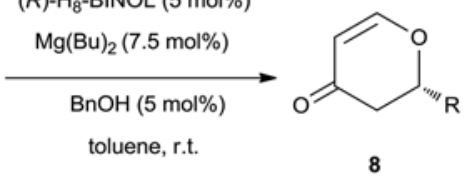

2. TFA
$\mathrm{R}=\mathrm{BnCH}_{2}: 93 \%, 96 \%$ ee $\mathrm{R}=n$-Pent: $72 \%, 96 \%$ ee $\mathrm{R}=\mathrm{Cy}: 47 \%, 97 \%$ ee

Scheme 3 Hetero-Diels-Alder reactions of aldehydes with Danishefsky's diene.

explain the stereoselectivity of the process, the authors have proposed the active catalyst species depicted in Scheme 3, possessing an oligomeric zigzag chain structure comprised of $\mathrm{Mg}_{2} \mathrm{O}_{2}$ cores from the $\mathrm{H}_{4}$-BINOL units and magnesium centers. Although the inner magnesium centers were not accessible to the reactants owing to steric hindrance, the mag-

nesium atom situated at the end of the chain could activate the aldehyde substrate through interaction with its oxygen atom. Moreover, a hydrogen-bonding interaction between the aldehyde hydrogen atom and one of the $\mathrm{H}_{4}$-BINOL oxygen atoms could also help in fixing the spatial position of the aldehyde. Finally, the preferential attack of the diene through the $S i$ face of the aldehyde led to the formation of the $(S)$-cycloadduct. In 2013, this type of reaction was reinvestigated by Ishihara et al. by using $(R)-\mathrm{H}_{8}-\mathrm{BINOL}$ as ligand in the presence of benzyl alcohol as an additive. ${ }^{17}$ As shown in Scheme 3, the reaction of aliphatic aldehydes with Danishefsky's diene $\mathbf{5 b}$ in toluene at room temperature led to the corresponding cycloadducts 8 in moderate to high yields (47-93\%) and excellent enantioselectivities (96-97\% ee).

The enantioselective hetero-Diels-Alder reaction of Brassard's dienes with carbonyl compounds is a classical approach to access chiral six-membered $\delta$-lactones, which are widely found in bioactive natural products. In 2014, Feng et al. reported the first catalytic asymmetric hetero-Diels-Alder reaction of Brassard's type dienes, such as $\mathbf{9}$, with isatins $10 .{ }^{18}$ As shown in Scheme 4, the process was promoted by a combination of $\mathrm{Mg}\left(\mathrm{ClO}_{4}\right)_{2}$ with chiral $N, N^{\prime}$-dioxide ligand 11 in dichloromethane at $35{ }^{\circ} \mathrm{C}$ to give the corresponding chiral spirolactones 12 in high to quantitative yields (90-99\%), high diastereoselectivities (84-98\% de) and remarkable enantioselectivities (96-99\% ee). Notably, neither electron-donating<smiles>C/C=C(\C=C(OC)OC)OC</smiles><smiles>NC(=O)[C@@H]1CCCC[N+]1([O-])CCC[N+]1(O)CCCCC1C(=O)N[14OH]</smiles>
$\mathrm{Ar}=2,6-\mathrm{Et}_{2}-4-\mathrm{MeC}_{0} \mathrm{H}_{2} \quad \mathrm{MeO}$ $11(10 \mathrm{~mol} \%)$ $\mathrm{Mg}\left(\mathrm{ClO}_{4}\right)_{2}(10 \mathrm{~mol} \%)$ $\mathrm{CH}_{2} \mathrm{Cl}_{2}, 35^{\circ} \mathrm{C}$ then TFA $90-99 \%, 84-98 \%$ de, $96-99 \%$ ee

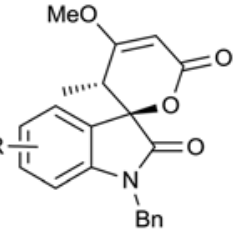

12 10 $\mathrm{R}=5-\mathrm{F}, 5-\mathrm{Cl}, 4-\mathrm{Br}, 5-\mathrm{Br}, 6-\mathrm{Br}, 5-\mathrm{I}, 5-\mathrm{Me}, 7-\mathrm{Me}, 5,7-\mathrm{Me}_{2}, 5-\mathrm{MeO}, 7-\mathrm{CF}_{3}$ proposed transition state:

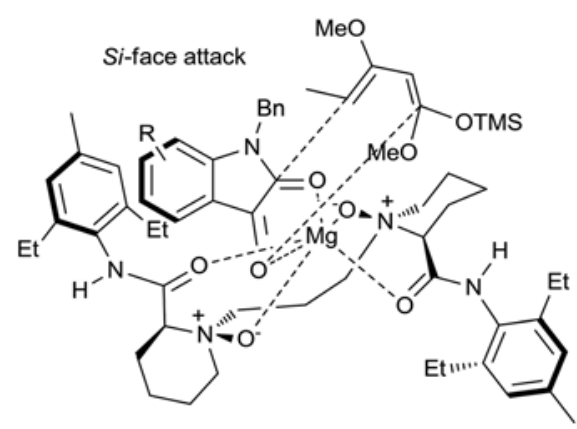

Scheme 4 Hetero-Diels-Alder reaction of isatins with Brassard's diene. 
nor electron-withdrawing substituents (R) on the aromatic ring of the isatins had an obvious impact on the outcomes of the reaction. The stereoselectivity of the cycloaddition was explained by the transition state depicted in Scheme 4 in which both oxygen atoms of the amide and $N$-oxides of the ligand were coordinated with the magnesium atom. Moreover, the isatin coordinated to the $\mathrm{Mg}$ (II) in a bidentate fashion with its dicarbonyl groups. The $R e$ face of the isatin was shielded by the neighboring 2,6-diethyl-4-methylphenyl group of the ligand, and consequently the diene attacked preferentially from the $S i$ face to afford the final product.

Later, these authors demonstrated that in the presence of only $0.1-0.5 \mathrm{~mol} \%$ of the same catalyst system, a range of $\alpha$-ketoesters 13 reacted with Danishefsky's diene $\mathbf{5 b}$ to afford the corresponding cycloadducts $\mathbf{1 4}$ in good to quantitative yields (76-99\%) with excellent enantioselectivities (97->99\% ee). ${ }^{19}$ Irrespective of the electron-donating or electron-withdrawing nature of the substituents on the meta- or para-position of the phenyl ring (R) of the $\alpha$-ketoesters, nearly optically pure products were obtained in all cases. Furthermore, the scope of the reaction was extended to ring-fused naphthyl-substituted substrate ( $\mathrm{R}=2$-Naph, $91 \%$ yield, $>99 \%$ ee), as well as to $\alpha$-ketoesters bearing alkynyl (79-99\% yield, $97-99 \%$ ee) or alkyl (76-81\% yield, $>99 \%$ ee) groups. Furthermore, a range of $\beta, \gamma$-unsaturated $\alpha$-ketoesters were proved to be excellent substrates, leading to the corresponding chiral lactones in high yields (88-98\%) with remarkable enantioselectivities (97->99\% ee). Encouraged by these excellent results, the authors applied the same reaction conditions to variously substituted isatins 15 which yielded the corresponding chiral spirooxindole 2,3dihydropyran-4-ones 16 in high to quantitative yields (90-99\%) with excellent enantioselectivities (95-98\% ee), as shown in Scheme 5. Even ring-fused isatins 15ab provided excellent yields (92-95\%) and enantioselectivities (97-98\% ee).

\subsection{1,3-Dipolar cycloadditions}

The 1,3-dipolar cycloaddition ${ }^{20}$ is a classic reaction in organic chemistry consisting of the reaction of a dipolarophile with a 1,3-dipolar compound that allows the production of various five-membered heterocycles. ${ }^{21}$ A wide variety of chiral catalysts have been applied to promote asymmetric versions of this reaction, providing chiral proline derivatives, which are key chiral building blocks found in a number of natural products and pharmaceutically important compounds. The first example of enantioselective magnesium-catalyzed 1,3-dipolar cycloaddition was described by Jørgensen et al. in $1996 .^{22}$ It occurred between nitrones and alkenes in the presence of a chiral bis(oxazoline) magnesium(II) catalyst with enantioselectivities of up to $82 \%$ ee. Ever since, other chiral magnesium complexes have been successfully applied to this type of reaction. For example, Yamamoto et al. reported the use of chiral pybox ligand 17 in combination with $\mathrm{MgBr}_{2}$ in the asymmetric 1,3-dipolar cycloaddition of 2-imidazolidinone-derived acrylamide 18 with benzonitrile oxide precursor 19 in dichloromethane at $-78{ }^{\circ} \mathrm{C} .{ }^{23}$ As shown in Scheme 6, the corresponding cycloadduct 20 was achieved in moderate yield (53\%)
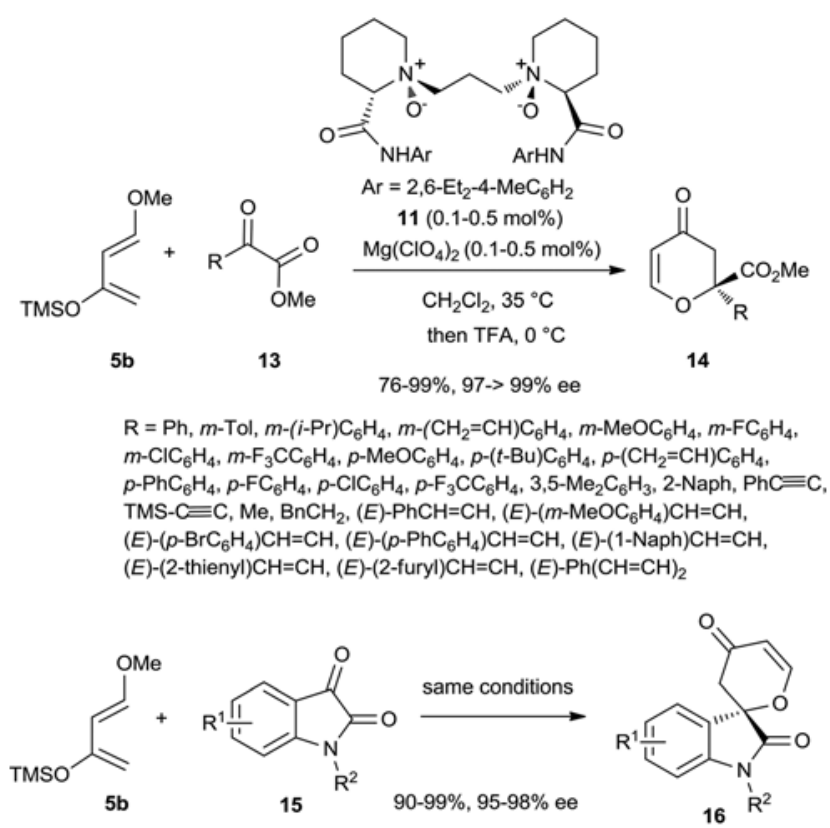

$\mathrm{R}^{1}=\mathrm{H}, 5-\mathrm{F}, 5-\mathrm{Cl}, 4-\mathrm{Br}, 5-\mathrm{Br}, 6-\mathrm{Br}, 7-\mathrm{Br}, 5-\mathrm{I}, 5-\mathrm{Me}, 5,7-\mathrm{Me}_{2}, 5-\mathrm{MeO}$ $\mathrm{R}^{2}=\mathrm{Bn}, \mathrm{Me}$, allyl, $\mathrm{PMB}$
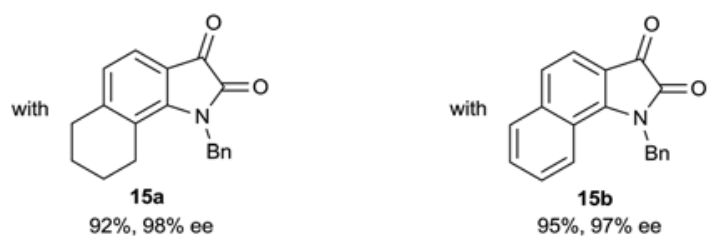

Scheme 5 Hetero-Diels-Alder reactions of $\alpha$-ketoesters and isatins with Danishefsky's diene.

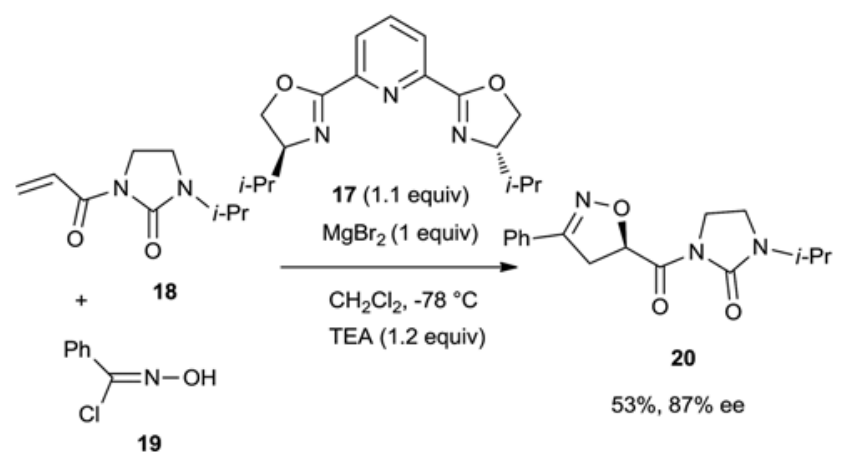

Scheme 6 1,3-Dipolar cycloaddition of a 2-imidazolidinone-derived acrylamide with benzohydroximoyl chloride.

with good enantioselectivity ( $87 \%$ ee). It is important to note that this process employed stoichiometric amounts of the catalyst system.

On the other hand, Johnson et al. have developed the synthesis of chiral tetrahydrofurans on the basis of the asymmetric magnesium-catalyzed $[3+2]$ cycloaddition of cyclopropanes with aldehydes occurring through dynamic kinetic resolution. ${ }^{24}$ Indeed, the catalyst, in situ generated from $\mathrm{MgI}_{2}$ 
and chiral pybox ligand 21, was found to promote the cycloaddition of aldehydes with one enantiomer of methyl malonate cyclopropanes $\mathbf{2 2}$ and promote the interconversion of the cyclopropane enantiomers, providing the corresponding 2,5cis-disubstituted tetrahydrofurans 23 in good yields (64-92\%), overall excellent diastereoselectivity ( $>96 \%$ de) and good to high enantioselectivities (82-94\% ee). As shown in Scheme 7, aryl, cinnamyl and aliphatic aldehydes underwent cycloadditions with a variety of cyclopropanes bearing electron-rich donor groups.

A closely related chiral ligand $\mathbf{2 4}$ was later applied by the same authors to the 1,3-dipolar cycloaddition of methyl malonate cyclopropanes 22 with $(E)$ - $N$-protected aryl aldimines 25, yielding under comparable reaction conditions the corresponding 2,5-cis-disubstituted pyrrolidines 26 in good yields (66-86\%) and diastereoselectivities (74->84\% de) along with high enantioselectivities (86-96\% ee). ${ }^{25}$ Electron-rich and neutral aryl aldimines as well as heteroaryl aldimines were compatible while aliphatic and electron-poor aryl aldimines did not react (Scheme 8).

1,3-Dipolar cycloadditions of nitrile imines with alkenes represent an attractive strategy to generate pyrazolines which constitute motifs in a number of bioactive compounds. In 2013, Stanley et al. reported a rare example of enantioselective 1,3-dipolar cycloadditions of nitrile imines 27 with a variety of $\mathrm{N}$-benzoyl methyleneoxindoles 28. ${ }^{26}$ As shown in Scheme 9, the reaction was performed at $-78{ }^{\circ} \mathrm{C}$ in dichloromethane in the presence of a combination of $\mathrm{Mg}\left(\mathrm{NTf}_{2}\right)_{2}$ and chiral bis(oxazoline) ligand 29 to afford a range of chiral spiro[pyrazolin$3,3^{\prime}$-oxindoles] 30 in moderate to high yields (43-91\%), good to high diastereoselectivities ( $80->90 \%$ de) and moderate to excellent enantioselectivities (61-99\% ee). The best enantioselectivities (92-99\% ee) were generally achieved with methyleneoxindoles substituted by halogenated aromatic groups $(\mathrm{R}=$ $p$ - $\left.\mathrm{ClC}_{6} \mathrm{H}_{4}, \quad p-\mathrm{BrC}_{6} \mathrm{H}_{4}, \quad o-\mathrm{BrC}_{6} \mathrm{H}_{4}\right)$ while an electron-deficient dipolarophile $\left(\mathrm{R}=p-\mathrm{F}_{3} \mathrm{CC}_{6} \mathrm{H}_{4}\right)$ furnished the corresponding cycloadduct in $80 \%$ ee and $81 \%$ yield. On the other hand, the reaction of a highly electron-rich substrate $(\mathrm{R}=3,4,5-$

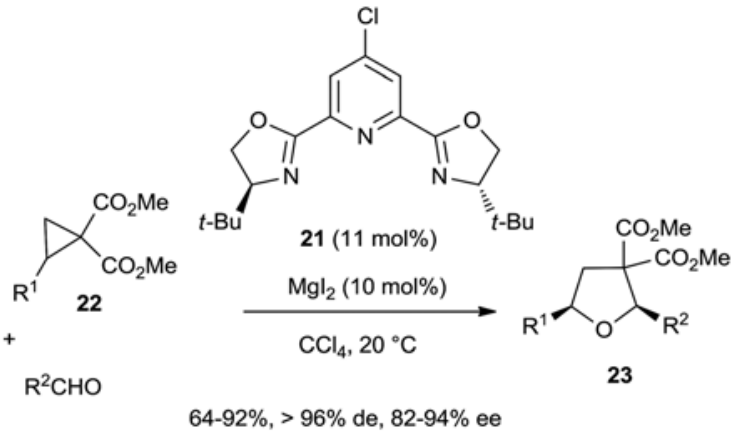

$\mathrm{R}^{1}=p-\mathrm{MeOC}_{6} \mathrm{H}_{4}, 2$-thienyl, $(E)-\mathrm{PhCH}=\mathrm{CH}$

$\mathrm{R}^{2}=p-\mathrm{MeOC}_{6} \mathrm{H}_{4}, p-\mathrm{ClC}_{6} \mathrm{H}_{4}, o-\mathrm{Tol}, \mathrm{Ph}, 2$-thienyl,

(E) $-\mathrm{PhCH}=\mathrm{CH}, n$-Pent, $i-\mathrm{Pr}$

Scheme 7 1,3-Dipolar cycloaddition of methyl malonate cyclopropanes with aldehydes through dynamic kinetic resolution.
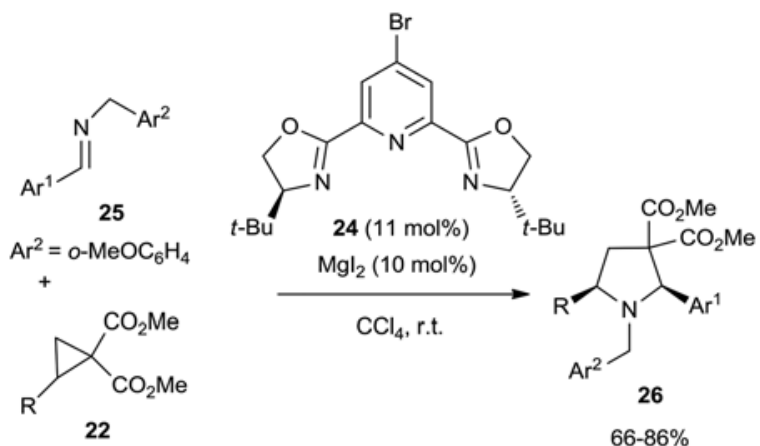

$66-86 \%$

$74->84 \%$ de

$86-96 \%$ ee
$\mathrm{Ar}^{1}=\mathrm{Ph}, p-\mathrm{MeOC}_{6} \mathrm{H}_{4}, o-\mathrm{Tol}, m-\mathrm{BrC}_{6} \mathrm{H}_{4}, p-\mathrm{FC}_{6} \mathrm{H}_{4}, 2$-thienyl

2-thienyl, (E)-PhCH=CH

Scheme 8 1,3-Dipolar cycloaddition of methyl malonate cyclopropanes with aryl aldimines through dynamic kinetic resolution.

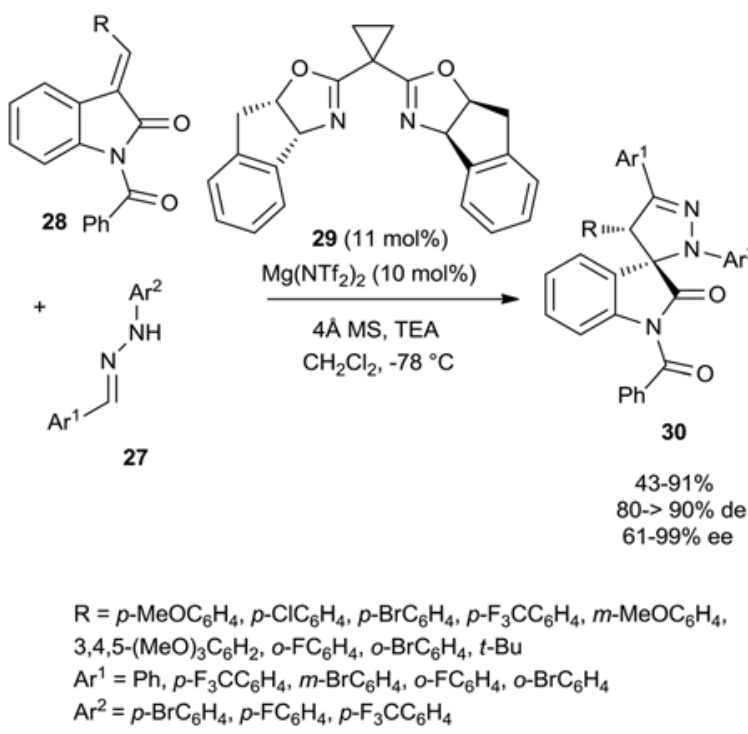

Scheme 9 1,3-Dipolar cycloaddition of $(E)$-methyleneoxindoles with nitrile imines.

$(\mathrm{MeO})_{3} \mathrm{C}_{6} \mathrm{H}_{2}$ ) occurred with only $61 \%$ ee in the presence of the same conditions. Notably, a methyleneoxindole bearing a bulky tert-butyl substituent ( $\mathrm{R}=t$-Bu) was tolerated, leading to the corresponding product in $99 \%$ ee and $70 \%$ yield. The enantioselectivity of the cycloaddition was found to be sensitive to the geometry of the alkene unit since the reaction of a (Z)-methyleneoxindole $(\mathrm{R}=t$ - $\mathrm{Bu})$ led to the diastereomeric cycloadduct with only $66 \%$ ee. Concerning the scope of the nitrile imines, the best enantioselectivities were generally achieved with those derived from benzaldehyde $\left(\mathrm{Ar}^{1}=\mathrm{Ph}\right)$ while the presence of substituents on both the aryl rings $\left(\mathrm{Ar}^{1}\right.$, $\mathrm{Ar}^{2}$ ) was compatible.

Besides bis(oxazoline) ligands, cinchona alkaloids have also been applied to enantioselective magnesium-catalyzed 1,3dipolar cycloadditions. As a recent example, Wang et al. have 
employed a chiral magnesium catalyst in situ generated from $\mathrm{MgBu}_{2}$ and quinine to promote $p$-xylene at $60{ }^{\circ} \mathrm{C}$ in the presence of the achiral $\mathrm{N}, \mathrm{O}$-bidentate ligand $\mathbf{3 1}$ as an additive, the formal $[3+2]$ cycloaddition between C3-alkylindoles 32 and meso-aziridine $33 \mathrm{a}^{27}$ As shown in Scheme 10, the process afforded the corresponding chiral pyrroloindolines 34 in moderate to good yields (19-81\%), good to high diastereoselectivities $(78->90 \%$ de) and high enantioselectivities (86-94\% ee). The presence of substituents with different electronic nature located at the C4-, C5-, or C6-position of the C3methylindole was tolerated, while a C7-substituted indole proved to be much less efficient (19\% yield). Notably, some functional groups, such as silyl ether and azide, at the C3-aliphatic chain were compatible $\left(\mathrm{R}^{2}=\left(\mathrm{CH}_{2}\right)_{2} \mathrm{OTBS},\left(\mathrm{CH}_{2}\right)_{2} \mathrm{~N}_{3}\right)$. Furthermore, the authors demonstrated that using quinidine instead of quinine as ligand under the same reaction conditions allowed the relative enantiomers of the cycloadducts to be achieved. As shown in Scheme 10, the quinidine-promoted

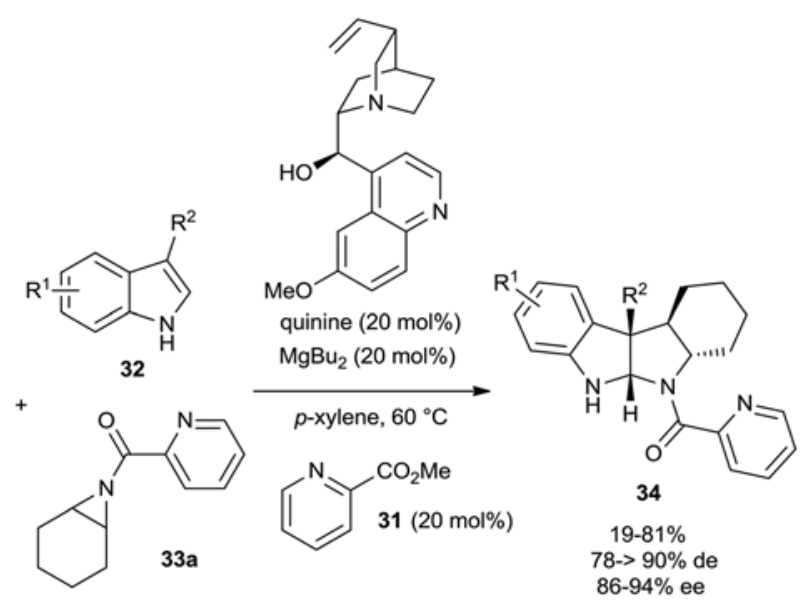

$\mathrm{R}^{1}=\mathrm{H}, 4-\mathrm{Me}, 5-\mathrm{Br}, 5-\mathrm{Me}, 5-\mathrm{MeO}, 6-\mathrm{F}, 6-\mathrm{Cl}, 7-\mathrm{Me}$

$\mathrm{R}^{2}=\mathrm{Me}, \mathrm{Et}, c$-Pent, $\left(\mathrm{CH}_{2}\right)_{2} \mathrm{OTBS},\left(\mathrm{CH}_{2}\right)_{2} \mathrm{~N}_{3}$
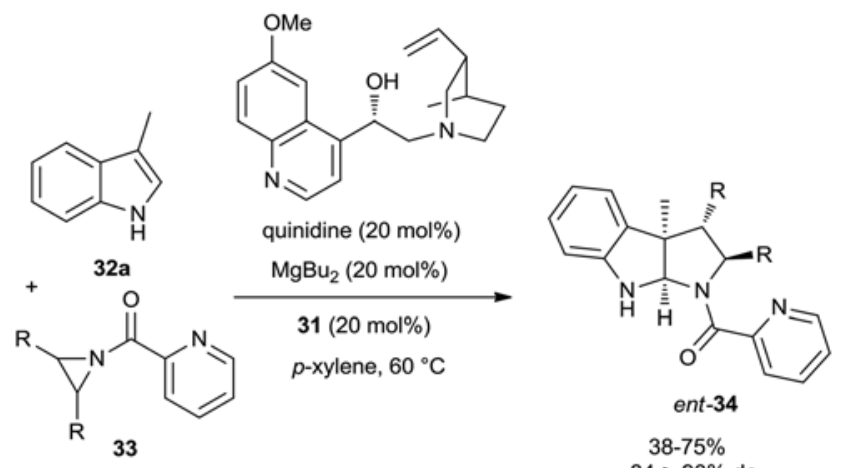

ent-34

$38-75 \%$ $84->90 \%$ de $81-94 \%$ ee

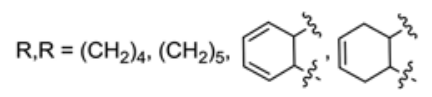

Scheme 10 1,3-Dipolar cycloadditions of C3-alkylindoles with mesoaziridines. reaction of various meso-aziridines 33 with $\mathrm{C} 3$-methylindole 32a led to the corresponding cycloadducts ent-34 in moderate to good yields (38-75\%), good to high diastereoselectivities (84->90\% de) and enantioselectivities (81-94\% ee).

In 2015 , the same authors reported the first enantioselective 1,3-dipolar cycloaddition between 3-isothiocyanato oxindoles 35 and alkynyl ketones $36 .^{28}$ The process was catalyzed by a combination of $\mathrm{MgBu}_{2}$ and chiral oxazoline ligand 37 in toluene at $0{ }^{\circ} \mathrm{C}$, providing the corresponding chiral spirooxindoles 38 in high yields (83-99\%) and good to high enantioselectivities (72-94\% ee), as shown in Scheme 11. The scope of the reaction was wide since a range of variously substituted aromatic; heteroaromatic as well as aliphatic ketones were compatible with the catalyst system, providing comparable excellent results in reactions with differently alkyl-substituted 3-isothiocyanato oxindoles. It must be noted that chiral spirooxindole structures containing a nitrogen atom at the C-3 position represent potentially bioactive compounds.

\subsection{Carbonyl ene reactions}

The catalytic asymmetric carbonyl ene reaction provides a powerful tool to construct versatile and useful building blocks through atom-economical carbon-carbon bond formation. ${ }^{29}$ In 2010, Feng et al. described highly efficient chiral magnesium complexes as catalysts for the asymmetric ketone ene reaction of trifluoropyruvate 39 by employing $C_{2}$-symmetric $N, N^{\prime}$-dioxide ligands for the first time. ${ }^{30}$ The reactions were performed in dichloromethane at $30{ }^{\circ} \mathrm{C}$ in the presence of only 0.5-2.5 mol\% of a combination of $\mathrm{Mg}(\mathrm{OTf})_{2}$ and chiral $N, N^{\prime}-$ dioxide ligand 40. A range of alkenes 41 were tolerated, including variously substituted aromatic ones, heteroaromatic as well as aliphatic alkenes, which led to the corresponding chiral fluoromethylated $\alpha$-hydroxy esters $\mathbf{4 2}$ in uniformly excellent enantioselectivities (95->99\% ee) along with good to excellent yields (75-97\%), as shown in Scheme 12. The scope was also

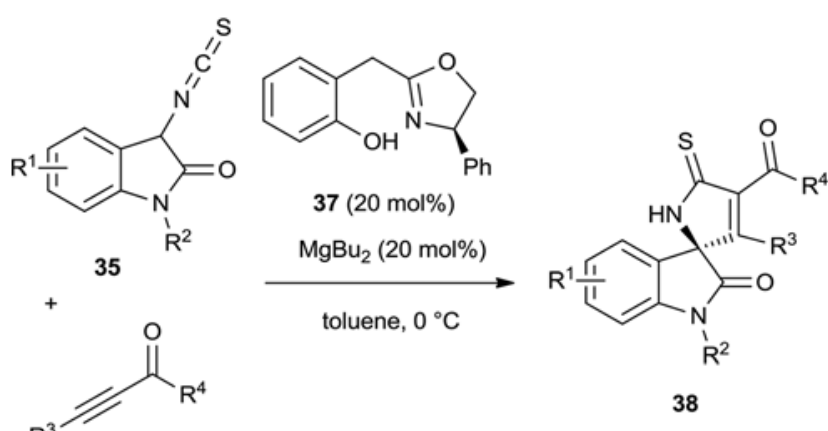

$83-99 \%, 72-94 \%$ ee
$\mathrm{R}^{1}=\mathrm{H}, 6-\mathrm{Me}$

$\mathrm{R}^{2}=\mathrm{Me}, n-\mathrm{Pr}, \mathrm{Bn}$

$\mathrm{R}^{3}=\mathrm{Ph}, p$-Tol, $n$-Pent

$\mathrm{R}^{4}=\mathrm{Ph}, p$-Tol, $p$ - $\mathrm{ClC}_{6} \mathrm{H}_{4}, p-\mathrm{BrC}_{6} \mathrm{H}_{4}, m-\mathrm{ClC}_{6} \mathrm{H}_{4}, p-\mathrm{MeOC}_{6} \mathrm{H}_{4}, m$-Tol,

o- $\mathrm{FC}_{6} \mathrm{H}_{4}$, 2-thienyl, 1-thienyl, Et, $c$ - $\mathrm{Pr}$

Scheme 11 1,3-Dipolar cycloaddition of 3-isothiocyanato oxindoles with alkynyl ketones. 


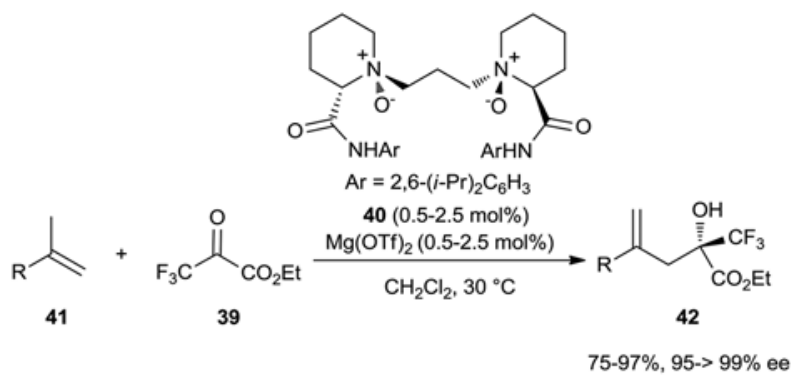

$\mathrm{R}=\mathrm{Ph}, o-\mathrm{Tol}, p-\mathrm{Tol}, o-\mathrm{MeOC}_{6} \mathrm{H}_{4}, m-\mathrm{MeOC}_{6} \mathrm{H}_{4}, p-\mathrm{MeOC}_{6} \mathrm{H}_{4}, m-\mathrm{ClC}_{6} \mathrm{H}_{4}, p-\mathrm{ClC}_{6} \mathrm{H}_{4}$ $3,4-\mathrm{Cl}_{2} \mathrm{C}_{6} \mathrm{H}_{3}, o-\mathrm{FC}_{6} \mathrm{H}_{4}, p-\mathrm{FC}_{6} \mathrm{H}_{4}, p-\mathrm{BrC}_{6} \mathrm{H}_{4}, 2-\mathrm{Naph}$, 2-furyl, 2-thienyl, Cy, $t-\mathrm{BuCH}_{2}, i-\mathrm{Pr}$

$$
\text { same conditions same conditions }
$$

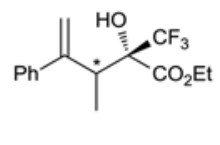

Scheme 12 Carbonyl ene reactions of trifluoropyruvate with alkenes.

extended to benzocyclic alkenes 41a and $\alpha$-substituted alkene 43 which led to the corresponding products $42 \mathrm{a}$ and 44 with 96-98\% ee. To further increase the synthetic utility of this novel process, the authors demonstrated that comparable enantioselectivities of 95-98\% ee could be also achieved under solvent-free conditions, to meet the requirements of green chemistry.

Later in 2013, the same authors reported the first carbonyl ene reaction of 1,2-dicarbonyl compounds, such as isatins, with alkyl enol ethers. ${ }^{31}$ In this case, catalyst loadings of 2-10 mol\% of $\mathrm{Mg}(\mathrm{OTf})_{2}$ and chiral $N, N^{\prime}$-dioxide ligand 45 were used to perform the reaction of various isatins 15 with alkyl enol ethers 46 to give the corresponding chiral 3-substituted 3-hydroxyindoles $\mathbf{4 7}$ in moderate to quantitative yields (52-98\%) and uniformly excellent enantioselectivities (94$>99 \%$ ee). As shown in Scheme 13, both $N$-protected isatins and $N$-unprotected isatins reacted with high enantioselectivities. While the former gave enantioselectivities up to $>99 \%$ ee, the latter proceeded with slightly decreased yields (52-92\% vs.

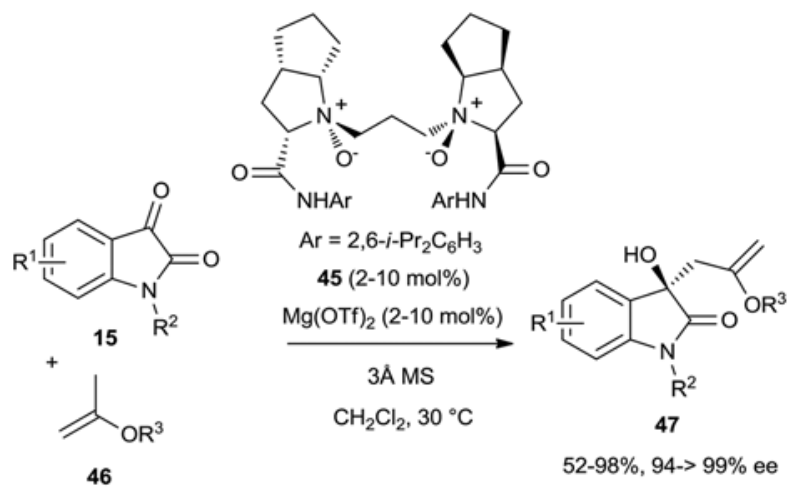

$$
\begin{aligned}
& \mathrm{R}^{1}=\mathrm{H}, 5-\mathrm{F}, 7-\mathrm{F}, 5-\mathrm{Cl}, 4-\mathrm{Br}, 5-\mathrm{Br}, 6-\mathrm{Br}, 5-\mathrm{Me}, 5,7-\mathrm{Me}_{2}, 5-\mathrm{MeO}, 5-\mathrm{O}_{2} \mathrm{~N} \\
& \mathrm{R}^{2}=\mathrm{Me}, \mathrm{H}, \mathrm{Bn}, 2-\text { methylallyl } \\
& \mathrm{R}^{3}=\mathrm{Me}, \mathrm{Bn}
\end{aligned}
$$

synthesis of $(R)$-convolutamydine $\mathrm{A}$ :

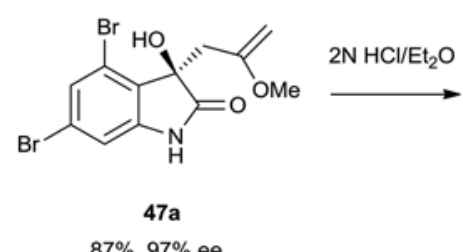

$87 \%, 97 \%$ ee

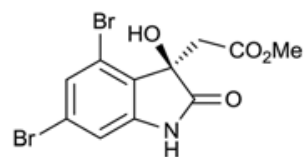

(R)-convolutamydine A: $98 \%, 97 \%$ ee
Scheme 13 Carbonyl ene reaction of isatins with alkyl enol ethers and synthesis of $(R)$-convolutamydine $\mathrm{A}$.

82-98\%) and enantioselectivities (94->99\% ee $v s .>99 \%$ ee) as a result of their poor solubility in dichloromethane. To illustrate the synthetic utility of this novel methodology, the authors converted one of the products $(\mathbf{4 7 a})$ into $(R)$-convolutamydine $\mathrm{A}$, which is a potent anti-leukaemia agent.

In 2015, these authors also described the first enantioselective carbonyl ene reaction of $\beta, \gamma$-unsaturated $\alpha$-ketoesters with 5 -methyleneoxazolines catalyzed by a chiral $N, N^{\prime}$-dioxide magnesium(II) complex. ${ }^{32}$ As shown in Scheme 14, a catalyst system composed of $\mathrm{Mg}(\mathrm{OTf})_{2}$ chiral $N, N^{\prime}$-dioxide ligand $\mathbf{4 0}$ was successfully applied at $10 \mathrm{~mol} \%$ catalyst loading to promote the formation of almost optically pure highly functionalized products (98->99\% ee) in all cases. Indeed, the reaction of 5-methyleneoxazolines $\mathbf{4 8}$ with a range of variously substituted (E)-2-oxo-3-enoates 49 led to the corresponding products 50 in good to quantitative yields (64-98\%) combined with exceptional enantioselectivities (98->99\% ee) regardless of the nature of the substituents of each substrate. Even better results were achieved by using 2-oxo-3-ynoates $\mathbf{5 1}$ as substrates since the corresponding products $\mathbf{5 2}$ were obtained in higher yields (91-99\%) with comparable excellent enantioselectivities (98->99\% ee). The catalyst system could also be applied to the ene reaction of 5-methyleneoxazoline 48a with a simple $\alpha$-ketoester 53a $(\mathrm{X}=\mathrm{OMe})$ or a $\beta, \gamma$-unsaturated $\alpha$-ketoamide 53b $(\mathrm{X}=\mathrm{NH} t-\mathrm{Bu})$, which provided the corresponding enantiopure products $\mathbf{5 4 a - b}(>99 \%$ ee) in low to high yields (95\% and $18 \%$, respectively). 


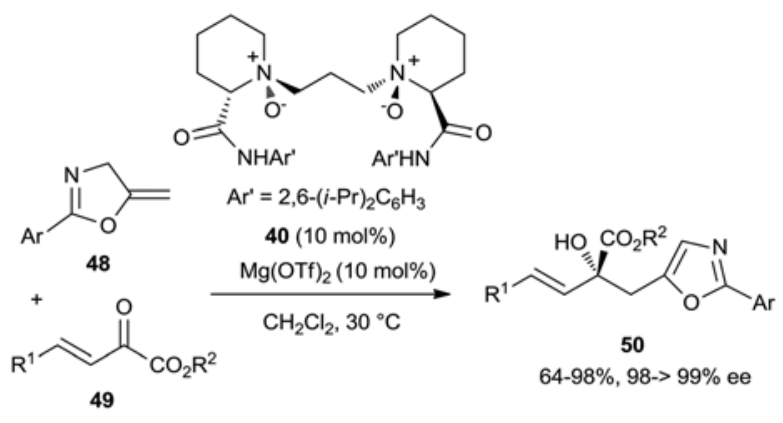

$\mathrm{Ar}=\mathrm{Ph}, m-\mathrm{MeOC}_{6} \mathrm{H}_{4}, p-\mathrm{Tol}$

$\mathrm{R}^{1}=\mathrm{Ph}, m-\mathrm{ClC}_{6} \mathrm{H}_{4}, m-\mathrm{MeOC}_{6} \mathrm{H}_{4}, p-\mathrm{FC}_{6} \mathrm{H}_{4}, p-\mathrm{ClC}_{6} \mathrm{H}_{4}, p-\mathrm{BrC}_{6} \mathrm{H}_{4}, p-\mathrm{Tol}$, $p$ - $\mathrm{MeOC}_{6} \mathrm{H}_{4}, p-\mathrm{PhC}_{6} \mathrm{H}_{4}, 2,6-\mathrm{F}_{2} \mathrm{C}_{6} \mathrm{H}_{3}, 2,6-\mathrm{Me}_{2} \mathrm{C}_{6} \mathrm{H}_{3}$, 2-Naph, 2-furyl, 2-thienyl, Cy $\mathrm{R}^{2}=\mathrm{Me}, \mathrm{Et}, i-\mathrm{Pr}$
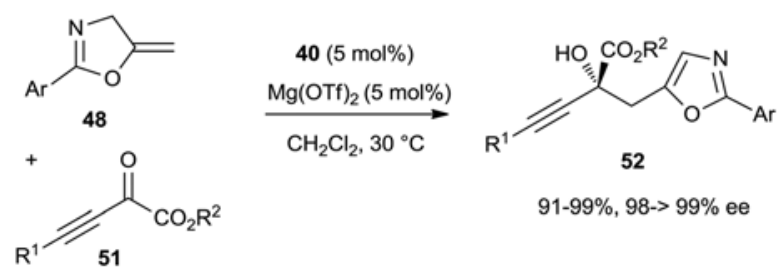

$91-99 \%, 98->99 \%$ ee

$\mathrm{Ar}=\mathrm{Ph}, m-\mathrm{MeOC}_{6} \mathrm{H}_{4}, p-\mathrm{Tol}$

$\mathrm{R}^{1}=\mathrm{Ph}, m-\mathrm{Tol}, p-\mathrm{FC}_{6} \mathrm{H}_{4}, p-\mathrm{BrC}_{6} \mathrm{H}_{4}, p-\mathrm{MeOC}_{6} \mathrm{H}_{4}, p-\mathrm{Tol}, p-\mathrm{MeOC}_{6} \mathrm{H}_{4}, p-\mathrm{PhC}_{6} \mathrm{H}_{4}$, 2,6- $\mathrm{F}_{2} \mathrm{C}_{6} \mathrm{H}_{3}, 2,6-\mathrm{Me}_{2} \mathrm{C}_{6} \mathrm{H}_{3}$, 2-Naph, 2-furyl, 2-thienyl, Cy, TMS $\mathrm{R}^{2}=\mathrm{Me}, \mathrm{Et}$

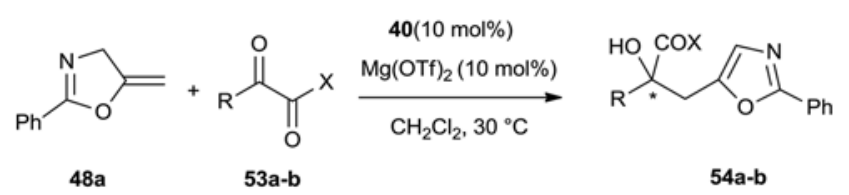

54a: $R=P h, X=O M e: ~ 95 \%,>99 \%$ ee

54b: $\mathrm{R}=(E)-\mathrm{PhCH}=\mathrm{CH}, \mathrm{X}=\mathrm{NH} t-\mathrm{Bu}: 18 \%,>99 \%$ ee

Scheme 14 Carbonyl ene reactions of $\beta, \gamma$-unsaturated $\alpha$-ketoesters (amide) with 5-methyleneoxazolines.

\section{Magnesium-catalyzed domino and tandem reactions}

\subsection{Michael-initiated domino reactions}

Domino reactions are processes in which two or more bondforming transformations occur based on functionalities formed in the previous step in which no additional reagents, catalysts or additives can be added to the reaction vessel, nor can the reaction conditions be changed. ${ }^{33}$ These fascinating reactions ${ }^{34}$ allow the synthesis of a wide variety of complex molecules including natural products and biologically active compounds to be economically achieved on the basis of onepot processes avoiding the use of costly and time-consuming protection-deprotection processes, as well as purification procedures of intermediates. ${ }^{32,35}$ It was only recently that the first enantioselective magnesium-catalyzed domino reactions have been developed. For example in 2015, Liu and Feng reported an asymmetric dearomatization of indoles evolving through a domino Michael/Friedel-Crafts-type/Mannich reaction, which occurred between 2-isocyanoethylindole 55 and alkylidene malonates 56. ${ }^{36}$ This process was catalyzed with a combination of $\mathrm{Mg}(\mathrm{OTf})_{2}$ and chiral $N, N^{\prime}$-dioxide ligand 57 in the presence of $\mathrm{NaBArF}_{4}$ as an additive. It provided a range of fused functionalized polycyclic chiral indolines $\mathbf{5 8}$ as single diastereomers ( $>99 \%$ de) exhibiting three stereocenters in moderate to good yields (45-98\%) and high enantioselectivities (81-95\% ee), as shown in Scheme 15. The best enantioselectivities (90-95\% ee) were achieved in the reaction of (hetero)aryl-substituted $\left(\mathrm{R}^{1}=\right.$ (hetero)aryl) alkylidene malonates while alkyl-substituted substrates $\left(\mathrm{R}^{1}=\mathrm{Cy}\right.$, i-Pr) provided a lower enantioselectivity (81\% ee).

The same authors also applied these conditions to the domino reaction of 2-isocyanoethylindoles 59 bearing a substituent at the $\mathrm{C} 2$-position of the indole $\left(\mathrm{R}^{3} \neq \mathrm{H}\right)$ with alkylidene malonates 56. ${ }^{35}$ Interestingly, a simple domino Michael/ Friedel-Crafts-type reaction proceeded in this case of substrates, leading to the corresponding chiral spiroindolines 60 in good to quantitative yields (70-99\%), high enantioselectivities $(85-96 \%$ ee) and moderate to high diastereoselectivities $(48->90 \%$ de), as depicted in Scheme 16. Actually, in the presence of this C2-substituent, the final sequential Mannich reaction of the malonate to the imine intermediate could not occur because of steric hindrance and low electrophilicity of the C2-position of the spiroindoline. As shown in Scheme 16, regardless of the aryl substituent and heteroaromatic substitu-
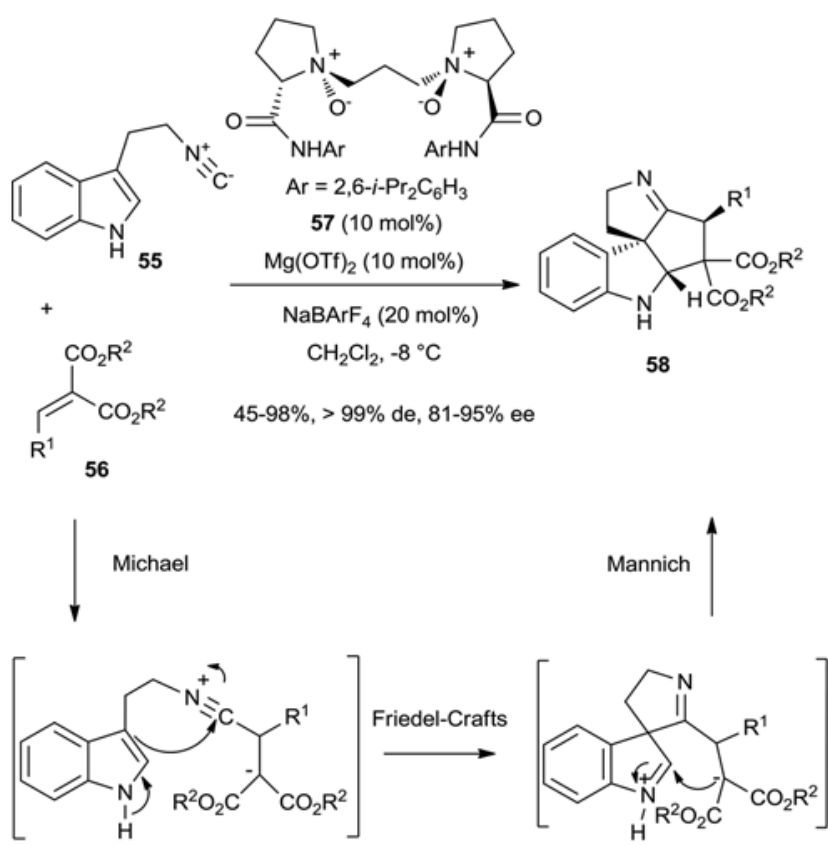

$\mathrm{R}^{1}=\mathrm{Ph}, p-\mathrm{FC}_{6} \mathrm{H}_{4}, m-\mathrm{ClC}_{6} \mathrm{H}_{4}, p-\mathrm{ClC}_{6} \mathrm{H}_{4}, p-\mathrm{BrC}_{6} \mathrm{H}_{4}, m-\mathrm{Tol}, p-\mathrm{Tol}, m-\mathrm{MeOC}_{6} \mathrm{H}_{4}$, $m-\mathrm{PhOC}_{6} \mathrm{H}_{4}, p-\mathrm{PhC}_{6} \mathrm{H}_{4}, 2-\mathrm{Naph}$, 3-thienyl, $\mathrm{Me}, \mathrm{Cy}, i-\mathrm{Pr}$ $\mathrm{R}^{2}=\mathrm{Me}, \mathrm{Et}, \mathrm{Bn}$

Scheme 15 Domino Michael/Friedel-Crafts/Mannich reaction of 2-isocyanoethylindole with alkylidene malonates. 


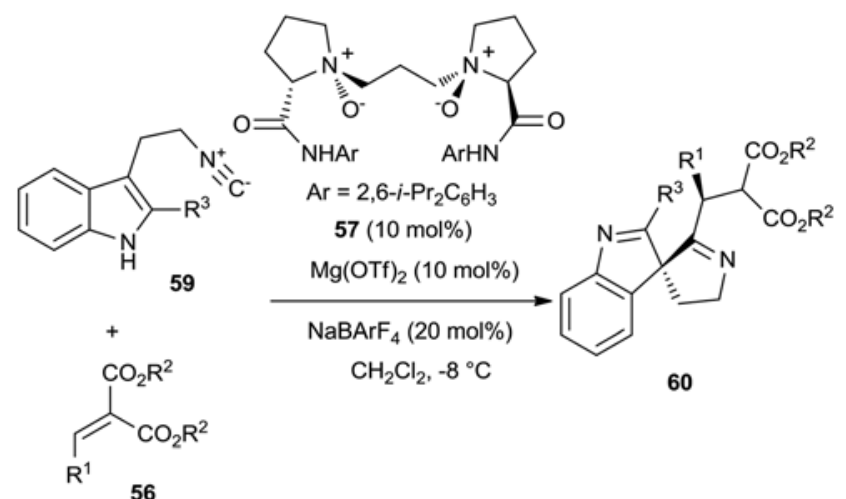

60a: $R^{1}=P h, R^{2}=R^{3}=M e: 86 \%,>90 \%$ de, $92 \%$ ee
60b: $R^{1}=P h, R^{2}=E t, R^{3}=M e: 82 \%,>90 \%$ de, $90 \%$ ee
60c: $R^{1}=p-B_{6} H_{6} H_{4}, R^{2}=R^{3}=M e: 72 \%,>90 \%$ de, $92 \%$ ee
60d: $R^{1}=p-F_{3} C_{6} H_{4}, R^{2}=R^{3}=M e: 80 \%,>90 \%$ de, $92 \%$ ee
60e: $R^{1}=p-P_{6} H_{6} H_{4}, R^{2}=R^{3}=M e: 75 \%,>90 \%$ de, $94 \%$ ee
60f: $R^{1}=3-t h i e n y l, R^{2}=E t, R^{3}=M e: 70 \%,>90 \%$ de, $93 \%$ ee
60g: $R^{1}=C y, R^{2}=E t, R^{3}=M e: 99 \%,>90 \%$ de, $85 \%$ ee
60h: $R^{1}=p-B_{6}{ }_{6} H_{4}, R^{2}=M e, R^{3}=P h: 98 \%, 56 \%$ de, $90 \%$ ee
60i: $R^{1}=p-B_{0}{ }_{6} H_{4}, R^{2}=M e, R^{3}=P h: 96 \%, 48 \%$ de, $96 \%$ ee

Scheme 16 Domino Michael/Friedel-Crafts reaction of C2-substituted 2-isocyanoethylindoles with alkylidene malonates.

ent at the $\beta$-position $\left(\mathrm{R}^{1}\right)$ or the ester group $\left(\mathrm{R}^{2}\right)$ of the alkylidene malonates, the reaction with 2-methyl-substituted 2-isocyanoethylindole $\left(\mathrm{R}^{3}=\mathrm{Me}\right)$ proceeded with high yields (70-99\%), excellent diastereoselectivity (>90\% de) and high enantioselectivities (85-94\% ee) to give products 60a-g. An aliphatic alkylidene malonate $\left(\mathrm{R}^{1}=\mathrm{Cy}\right)$ also proved to be compatible with the reaction, yielding the corresponding product $60 \mathrm{~g}$ in $99 \%$ yield, $>90 \%$ de and $85 \%$ ee. Furthermore, 2-phenylsubstituted 2-isocyanoethylindole $\left(\mathrm{R}^{3}=\mathrm{Ph}\right)$ also led to the corresponding products $\mathbf{6 0 h - i}$ in excellent yields (96-98\%) and enantioselectivities $(90-96 \%$ ee), although with moderate diastereoselectivities (48-56\% de).

The same catalyst system was also employed to promote the asymmetric domino Michael/Friedel-Crafts/Mannich reaction of variously substituted 2-isocyanoethylindoles $\mathbf{6 1}$ with a 3-alkenyl-oxindole such as (E)-1-Boc-3-tert-butylideneindolinone $62 .{ }^{37}$ In this case, the reaction was performed in DCE at $0{ }^{\circ} \mathrm{C}$ to provide a straightforward route to a series of chiral polycyclic 3 -spirooxindoles 63 bearing cyclopenta[$[b]$ indole units with four contiguous stereocenters in high yields (75-96\%) and enantioselectivities of $73-93 \%$ ee, combined with moderate to high diastereoselectivities of $38->90 \%$ de (Scheme 17). It was noteworthy that the electronic nature and position of the substituents on the indole unit of the 2-isocyanoethylindole derivative had a slight influence on the enantioselectivity of the process, while the electron-donating substituent had an obvious effect on the diastereoselectivity. Indeed in most cases, a higher diastereoselectivity was observed for the electron-withdrawing substituted compounds $\left(\mathrm{R}^{1}\right.$ or $\left.\mathrm{R}^{2}=\mathrm{F}, \mathrm{Cl}, \mathrm{Br}\right)$ compared to the electron-donating ones $\left(\mathrm{R}^{1}\right.$ or $\left.\mathrm{R}^{2}=\mathrm{Me}, \mathrm{OMe}, \mathrm{OBn}\right)$. Surprisingly, in contrast with the

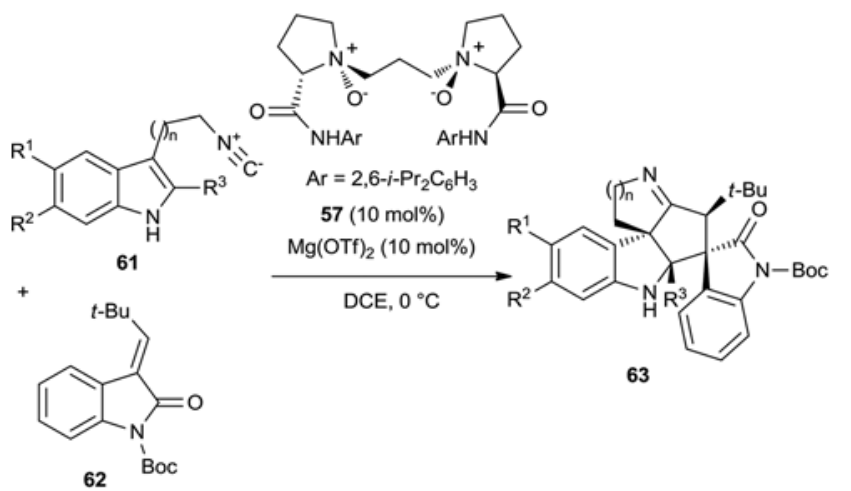

63a: $R^{1}=F, R^{2}=R^{3}=H, n=1: 95 \%, 80 \%$ de, $92 \%$ ee 63b: $R^{1}=R^{3}=H, R^{2}=F, n=1: 96 \%,>90 \%$ de, $92 \%$ ee 63c: $R^{1}=\mathrm{Cl}, \mathrm{R}^{2}=\mathrm{R}^{3}=\mathrm{H}, \mathrm{n}=1: 95 \%, 87 \%$ de, $93 \%$ ee 63d: $R^{1}=R^{3}=H, R^{2}=C l, n=1: 96 \%,>90 \%$ de, $93 \%$ ee 63e: $R^{1}=B r, R^{2}=R^{3}=H, n=1: 94 \%,>90 \%$ de, $93 \%$ ee 63f: $R^{1}=M e, R^{2}=R^{3}=H, n=1: 94 \%, 76 \%$ de, $90 \%$ ee 63g: $R^{1}=R^{3}=H, R^{2}=M e, n=1: 95 \%,>90 \%$ de, $90 \%$ ee 63h: $R^{1}=O M e, R^{2}=R^{3}=H, n=1: 93 \%, 53 \%$ de, $91 \%$ ee 63i: $R^{1}=O B n, R^{2}=R^{3}=H, n=1: 93 \%, 38 \%$ de, $91 \%$ ee 63j: $R^{1}=R^{2}=R^{3}=H, n=2: 75 \%, 71 \%$ de, $85 \%$ ee 63k: $R^{1}=R^{2}=H, R^{3}=M e, n=1: 95 \%,>90 \%$ de, $73 \%$ ee

Scheme 17 Domino Michael/Friedel-Crafts/Mannich reaction of 2-isocyanoethylindoles with (E)-1-Boc-3-tert-butylideneindolinone.

previous reaction (Scheme 16) of C2-substituted 2-isocyanoethylindoles with alkylidene malonates, a substrate bearing a methyl at the $\mathrm{C} 2$ position of the indole $\left(\mathrm{R}^{3}=\mathrm{Me}\right)$ led to the corresponding domino Michael/Friedel-Crafts/Mannich product $63 \mathbf{k}$ in $95 \%$ yield, $>90 \%$ de and $73 \%$ ee.

In 2016, the same group applied a related catalyst system composed of $\mathrm{Mg}(\mathrm{OTf})_{2}$ and chiral $N, N^{\prime}$-dioxide ligand 45 to promote other enantioselective domino Michael/FriedelCrafts-type reactions of alkylidene malonates 56 involving another type of isocyanide, such as $\alpha$-isocyanoacetamides $64^{38}$ As illustrated in Scheme 18, the domino reaction allowed a range of chiral 2-alkyl-5-aminooxazoles 65 to be obtained in moderate to quantitative yields (28-99\%) and good to excellent enantioselectivities $(72-96 \%$ ee $)$. Generally, the highest enantioselectivities (80-96\% ee) were achieved with variously substituted (hetero)aromatic alkylidene malonates while aliphatic substrates gave moderate enantioselectivities (72-86\% ee). Concerning the $\alpha$-isocyanoacetamide partners, comparable high enantioselectivities were obtained regardless of the aliphatic or aromatic nature of substituent $\mathrm{R}^{3}$. To illustrate the synthetic utility of this novel methodology, the authors converted some products into a chiral imide and a dipeptide through ring-opening of their oxazole ring, both of which are important structural motifs for many biologically active compounds.

\subsection{Other domino reactions}

In 2007, Willis et al. reported the enantioselective magnesiumcatalyzed domino Mannich/cyclization reaction of imide $\mathbf{6 6}$ with $N$-tosylimines 67 , providing the corresponding cyclized Mannich adducts 68 in good to excellent yields (63-99\%) and 


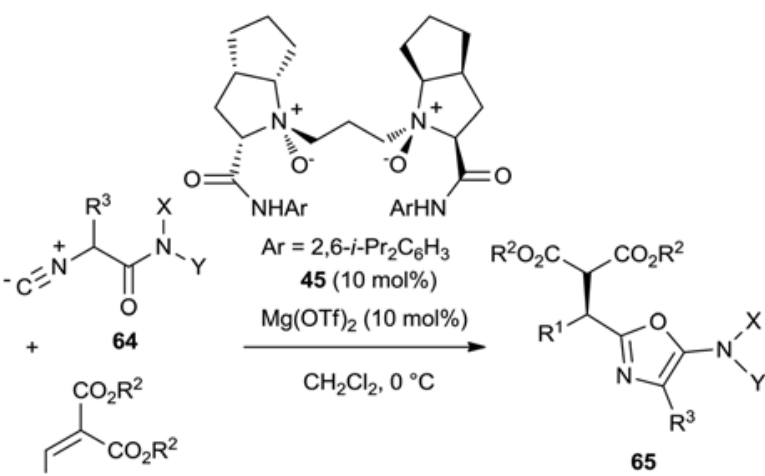

$28-99 \%, 72-96 \%$ ee

$\mathrm{R}^{1}=\mathrm{Ph}, o-\mathrm{FC}_{6} \mathrm{H}_{4}, m-\mathrm{FC}_{6} \mathrm{H}_{4}, m-\mathrm{ClC}_{6} \mathrm{H}_{4}, m-\mathrm{BrC}_{6} \mathrm{H}_{4}, m-\mathrm{Tol}, m-\mathrm{MeOC}_{6} \mathrm{H}_{4}$, $m-\mathrm{PhOC}_{6} \mathrm{H}_{4}, p-\mathrm{FC}_{6} \mathrm{H}_{4}, p-\mathrm{ClC}_{6} \mathrm{H}_{4}, p-\mathrm{BrC}_{6} \mathrm{H}_{4}, p-\mathrm{F}_{3} \mathrm{CC}_{6} \mathrm{H}_{4}, p-\mathrm{NCC}_{6} \mathrm{H}_{4}$, $p-\mathrm{O}_{2} \mathrm{NC}_{6} \mathrm{H}_{4}, p-\mathrm{Tol}, p-\mathrm{PhC}_{6} \mathrm{H}_{4}, p-\mathrm{MeOC}_{6} \mathrm{H}_{4}, p-\mathrm{PhOC}_{6} \mathrm{H}_{4}, p-\mathrm{BnOC}_{6} \mathrm{H}_{4}$, 3,4- $\mathrm{Cl}_{2} \mathrm{C}_{6} \mathrm{H}_{3}$, 2-Naph, 2-thienyl, 3-furyl, $\mathrm{Cy}, \mathrm{Me}$

$\mathrm{R}^{2}=\mathrm{Me}, \mathrm{Et}, i-\mathrm{Pr}$

$\mathrm{R}^{3}=t-\mathrm{Bu}, \mathrm{Bn}, \mathrm{Ph}, \mathrm{Me}, i-\mathrm{Pr}, \mathrm{H}$

$X, Y=\left(\mathrm{CH}_{2}\right)_{2} \mathrm{O}\left(\mathrm{CH}_{2}\right)_{2},\left(\mathrm{CH}_{2}\right)_{5},\left(\mathrm{CH}_{2}\right)_{4}$

Scheme 18 Domino Michael/Friedel-Crafts reaction of isocyanides with alkylidene malonates.
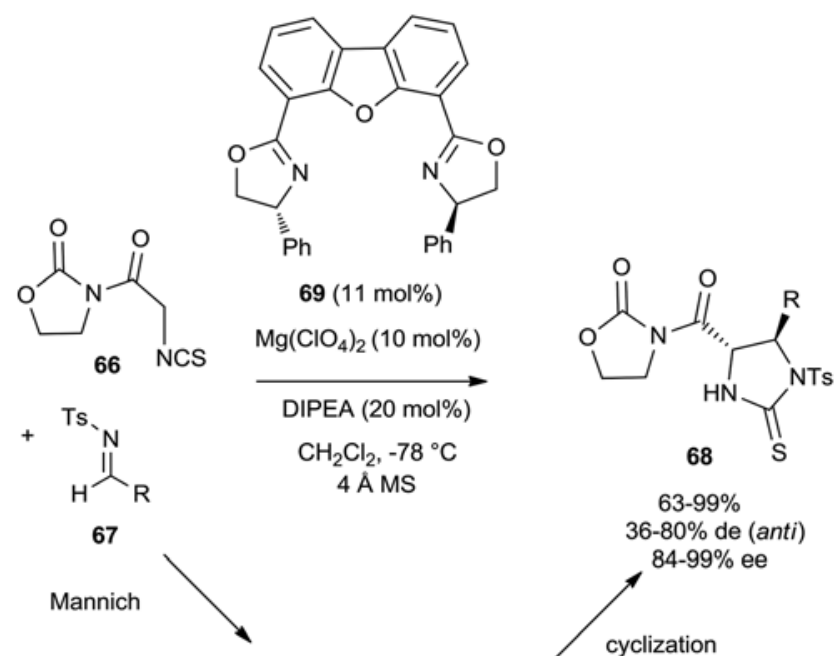

$63-99 \%$ $36-80 \%$ de (anti) $84-99 \%$ ee

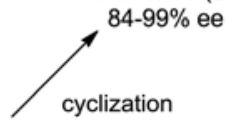<smiles>[R]C1C(C(=O)N2CCOC2=O)N=C(C)C[N+]1(C)C</smiles>

$\mathrm{R}=\mathrm{Ph}, p$-Tol, $m$-Tol, $o-\mathrm{Tol}, p-(t-\mathrm{Bu}) \mathrm{C}_{6} \mathrm{H}_{4}, p-\mathrm{MeOC}_{6} \mathrm{H}_{4}, p-\mathrm{BrC}_{6} \mathrm{H}_{4}$, $p$ - $\mathrm{ClC}_{6} \mathrm{H}_{4}, p-\mathrm{FC}_{6} \mathrm{H}_{4}, p-\mathrm{NCC}_{6} \mathrm{H}_{4}, 2-\mathrm{Naph}$, 2-thiophenyl, 3-furyl,

2- $\mathrm{N}$-Ts-indolyl, $(E)-\mathrm{PhCH}=\mathrm{CH}, \mathrm{Cy}, c-\mathrm{Pr}, n$-Pent

Scheme 19 Domino Mannich/cyclization reaction of an imide with $\mathrm{N}$-tosylaldimines.

enantioselectivities (84-99\% ee) albeit with moderate to good anti-diastereoselectivities $(36-80 \%$ de $)$, as shown in Scheme $19 .^{39}$ The reaction was catalyzed by a chiral magnesium complex in situ generated from $\mathrm{Mg}\left(\mathrm{ClO}_{4}\right)_{2}$ and chiral bis(oxazoline) ligand 69, which was selected as optimal among a series of chiral ligands tested, including other bis(oxazoline) ligands such as pybox ligands. As shown in Scheme 19, a variety of aryl-, alkenyl- and alkyl-derived imines could be employed, allowing a novel enantioselective route to anti-configured protected $\alpha, \beta$-diamino acids to be achieved on the basis of a direct enantioselective Mannich reaction.

Later in 2011, Shibasaki et al. employed much less reactive ketimines in related enantioselective magnesium-catalyzed domino Mannich/cyclization reactions for the first time. ${ }^{40}$ As shown in Scheme 20, the reaction of a range of $\mathrm{N}$-diphenylphosphinoyl (DPP) aryl and heteroaryl methyl ketimines 70 with $\alpha$-methyl- $\alpha$-isothiocyanato methyl ester 71a performed in the presence of $\mathrm{MgBu}_{2}$ and the Schiff base ligand 72 yielded the corresponding chiral densely functionalized $\alpha, \beta$-diamino esters 73 bearing two vicinal tetrasubstituted carbon stereocenters. These products were obtained in good to quantitative yields (70-99\%), good syn-diastereoselectivities $(80-86 \%$ de) and good to very high enantioselectivities (80-95\% ee).

The direct catalytic asymmetric aldol reaction is a powerful and atom-economical method for synthesizing chiral

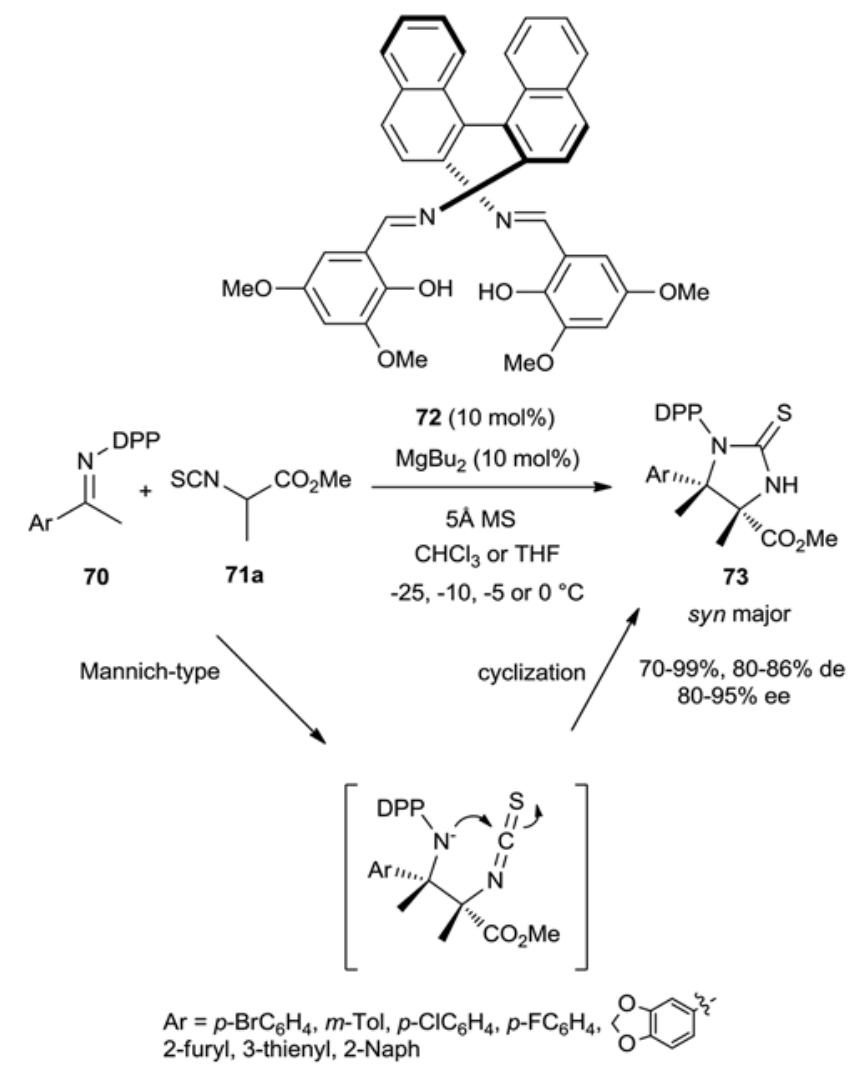

Scheme 20 Domino Mannich/cyclization reaction of ketimines with $\alpha$-methyl- $\alpha$-isothiocyanato methyl ester. 
$\beta$-hydroxy carbonyl compounds. Many metals and organocatalysts for reactions of aldehyde electrophiles have been developed in the past decade. ${ }^{41}$ The use of ketone electrophiles in direct aldol reactions for the construction of a tetrasubstituted carbon stereocenter, however, is limited to either activated ketones or intramolecular reactions. In order to address this issue, Shibasaki et al. have employed a chiral magnesium catalyst to promote the domino aldol/cyclization reaction of $\alpha$-substituted $\alpha$-isothiocyanato esters $\mathbf{7 1}$ with aryl, heteroaryl, alkyl and alkenyl methyl ketones in addition to a cyclic ketone. ${ }^{42}$ The process was catalyzed by a combination of $\mathrm{MgBu}_{2}$ with chiral Schiff bases $72(\mathrm{X}=\mathrm{OMe})$ or $74(\mathrm{X}=\mathrm{H})$, affording at room temperature the corresponding protected $\alpha$-amino- $\beta$-hydroxy esters 75 bearing two contiguous tetrasubstituted carbon stereocenters in good to quantitative yields (68-99\%), moderate to high diastereoselectivities (48-94\% de) and high enantioselectivities $(82-98 \%$ ee), as shown in Scheme 21.

In 2007, Lautens and Taillier developed the first enantioselective catalytic expansion of monoactivated methylenecyclopropanes by using a chiral magnesium catalyst, allowing direct access to chiral methylenepyrrolidines. ${ }^{43}$ The reaction occurred between $N$-phenyl- $N$ '-aryl methylenecyclopropane amides 76 and $N$-tosylaldimines 77 in the

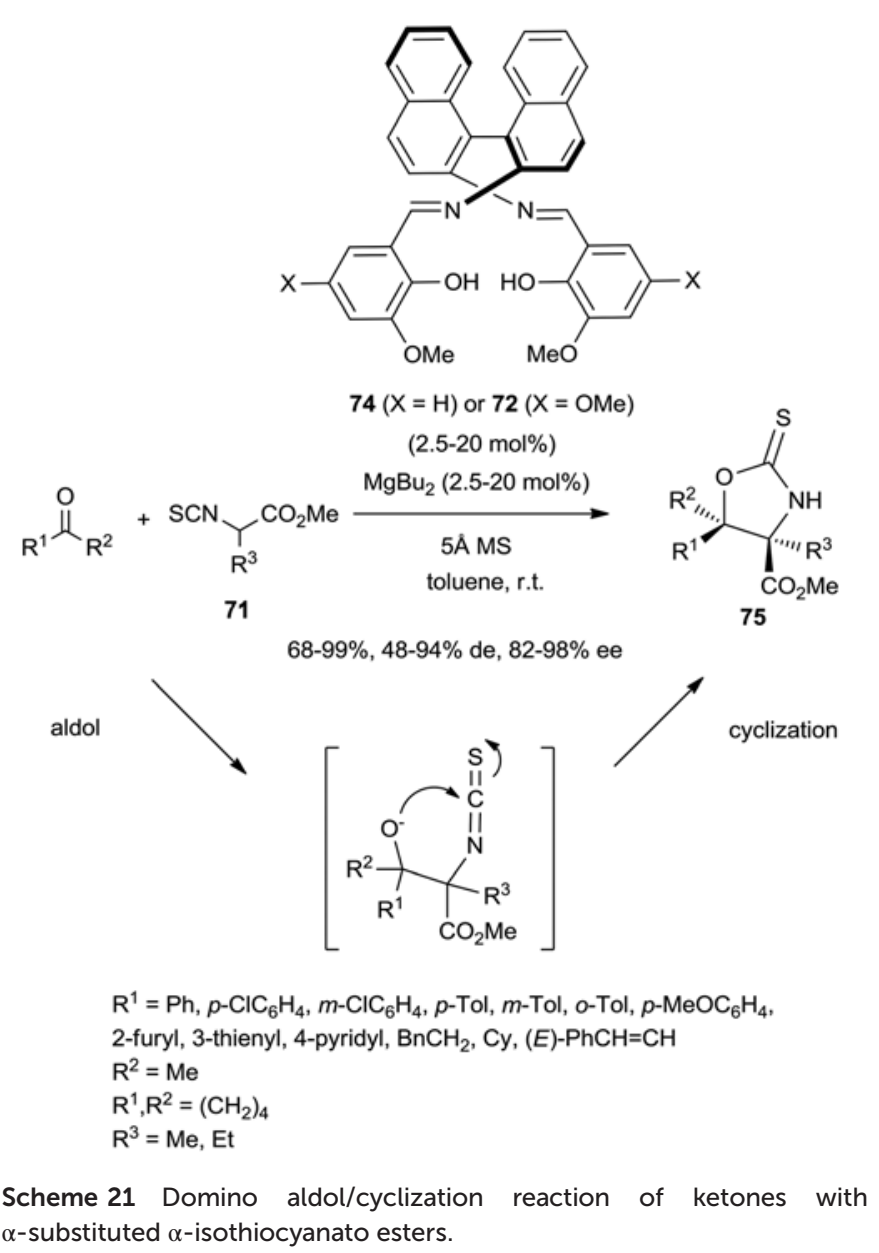

presence of a combination of $\mathrm{MgI}_{2}$ and the chiral bis(oxazoline) ligand ent-29 as the catalyst system in THF at $60^{\circ} \mathrm{C}$. As shown in Scheme 22, it afforded through a domino ringopening/ $\alpha$-alkylation/cyclization reaction the corresponding chiral ring-expanded products $\mathbf{7 8}$ in moderate to high yields (52-92\%) and enantioselectivities (47-86\% ee) as single transdiastereomers. The electronic nature and position of substituents on the aryl ring $\left(\mathrm{Ar}^{2}\right)$ of the $N$-tosylaldimines seemed to have little or no influence on the yields and diastereoselectivities of the reaction while the highest enantioselectivities were obtained for aldimines bearing electron-withdrawing groups on their aromatic ring.

In another context, Seidel et al. described the first example of a catalytic enantioselective domino hydride shift/ring closure reaction by using a chiral magnesium catalyst. ${ }^{44}$ Indeed, performed in dichloromethane at reflux in the presence of a catalyst in situ generated from $\mathrm{Mg}(\mathrm{OTf})_{2}$ and chiral bis(oxazoline) ligand ent-69, various $N$-acyl oxazolidinones 79 underwent a 1,5-hydride shift to give intermediates 80 which subsequently cyclized to afford the corresponding ring-fused chiral tetrahydroquinolines $\mathbf{8 1}$ (Scheme 23) in good to excellent yields (80-91\%), low to moderate diastereoselectivities (up to $68 \%$ de) and moderate to high enantioselectivities (60-90\% ee). The scope was extended to $N$-acyl oxazolidinones $79 a-d$ which afforded the corresponding products 82 and 83 in moderate to high yields ( $72-80 \%$ and $83-97 \%$, respectively) with the lowest stereoselectivities obtained for substrates $79 \mathbf{c}-\mathbf{d}$ incorporating seven- and eight-membered azacycles (Scheme 23).

Another type of enantioselective magnesium-catalyzed domino 1,5-hydride shift/cyclization reaction was reported by

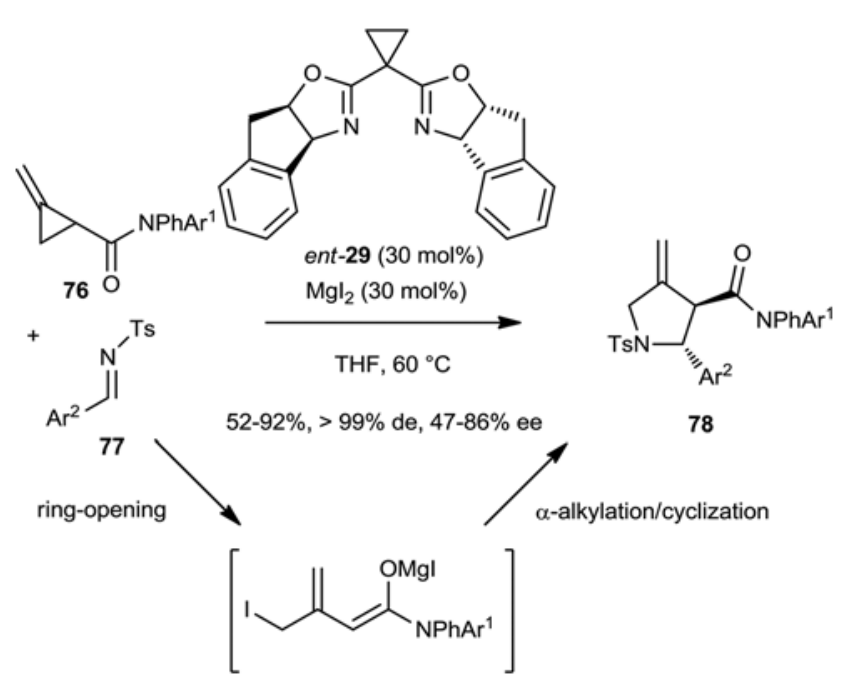

$\mathrm{Ar}^{1}=\mathrm{Ph}, 2$-pyridyl

$\mathrm{Ar}^{2}=o-\mathrm{F}_{3} \mathrm{CC}_{6} \mathrm{H}_{4}, p-\mathrm{F}_{3} \mathrm{CC}_{6} \mathrm{H}_{4}, o-\mathrm{BrC}_{6} \mathrm{H}_{4}, m-\mathrm{BrC}_{6} \mathrm{H}_{4}, p-\mathrm{BrC}_{6} \mathrm{H}_{4}, 2,4-\mathrm{Cl}_{2} \mathrm{C}_{6} \mathrm{H}_{3}$, 2,4- $\mathrm{Me}_{2} \mathrm{C}_{6} \mathrm{H}_{3}, 0-\mathrm{MeOC}_{6} \mathrm{H}_{4}, p-\mathrm{MeOC}_{6} \mathrm{H}_{4}, 0-\mathrm{AcOC}_{6} \mathrm{H}_{4}, 3,4-\left(\mathrm{OCH}_{2} \mathrm{O}\right) \mathrm{C}_{6} \mathrm{H}_{3}$, 2-furyl, $\mathrm{Ph}, 2-(\mathrm{N}-\mathrm{Me}-\mathrm{pyrrole})$

Scheme 22 Domino ring-opening/ $\alpha$-alkylation/cyclization reaction of $N$-phenyl- $N^{\prime}$-aryl $N$-tosylaldimines. methylenecyclopropane amides with 

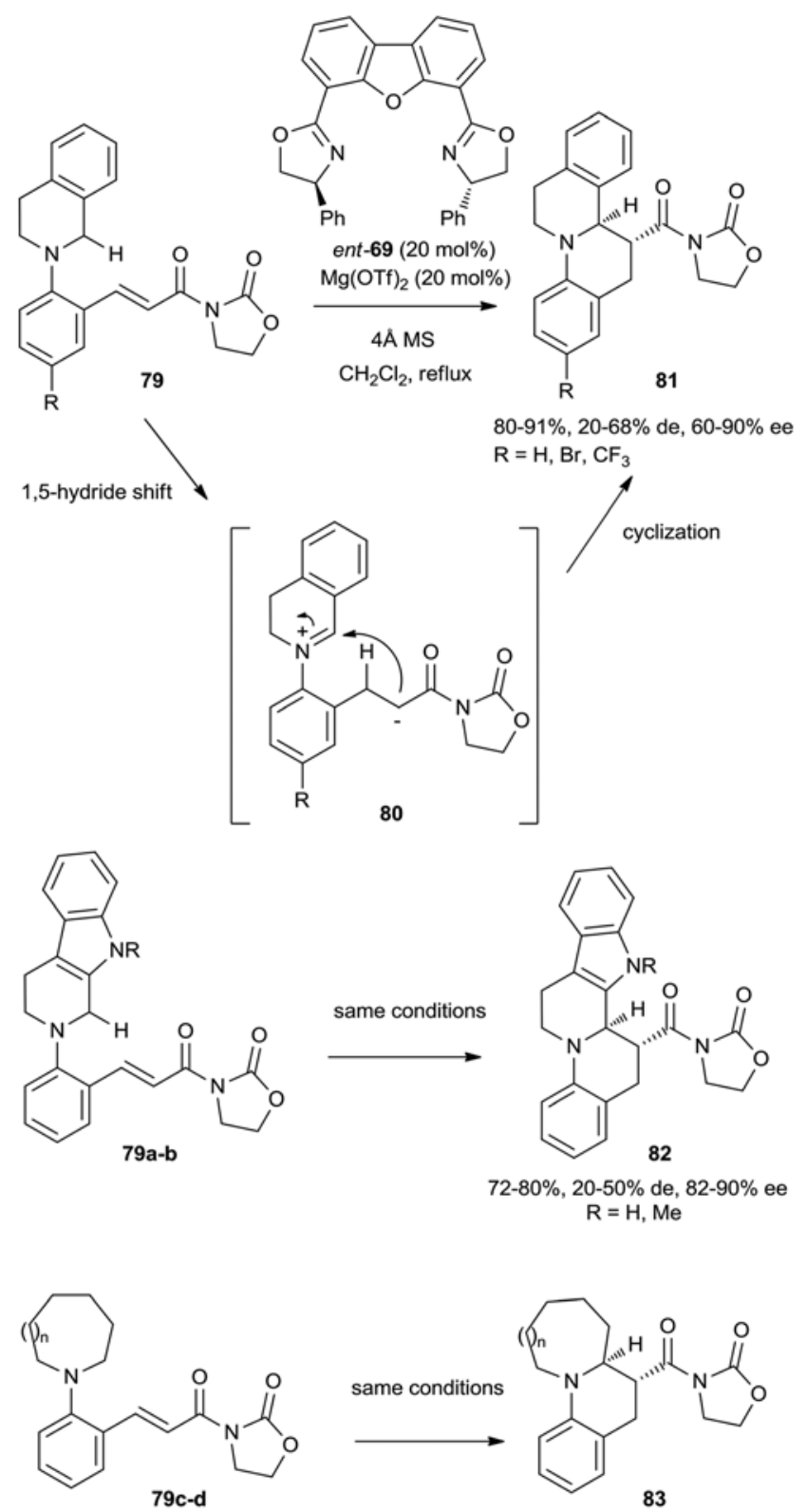

$83-97 \%, 0-40 \%$ de, $60-75 \%$ ee $n=1,2$

Scheme 23 Domino 1,5-hydride shift/cyclization reactions of $\mathrm{N}$-acyl oxazolidinones.

Luo et al. in $2012 .{ }^{45}$ In this case, the substrates were cyclic tertiary amines $\mathbf{8 4}$ and the catalyst system a combination of $\mathrm{MgCl}_{2}$ with chiral phosphoric acid 85 employed in dichloromethane at room temperature or $30-60{ }^{\circ} \mathrm{C}$. As shown in Scheme 24, under these conditions a series of cyclic tertiary amines $\mathbf{8 4}$ underwent a 1,5-hydride shift to give intermediate $\mathbf{8 6}$ which then cyclized into the corresponding tetrahydroquinolines 87 in low to quantitative yields (28->99\%) and moderate to high enantioselectivities (66-94\% ee). While uniformly high enantioselectivities (92-94\% ee) were obtained with substrates bearing electron-withdrawing substituents $\left(\mathrm{R}^{3}, \mathrm{R}^{4}\right)$, the
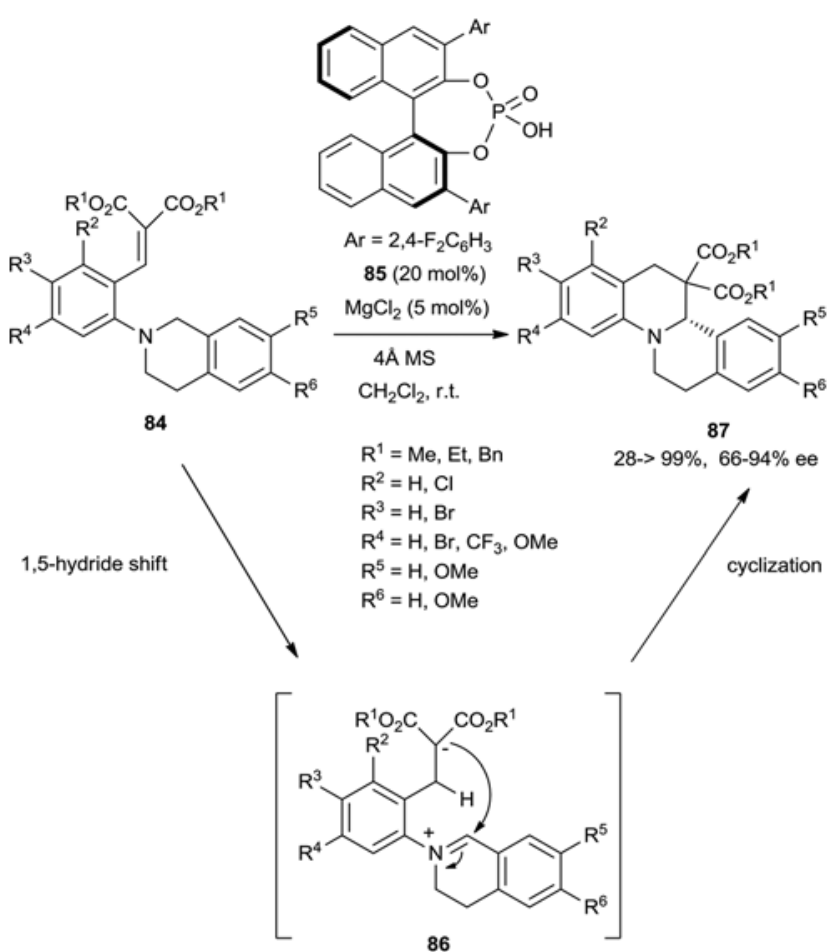<smiles>[R]CN(C[R])c1ccccc1C=C(C(=O)O[R6])C(=O)O[R2]</smiles>
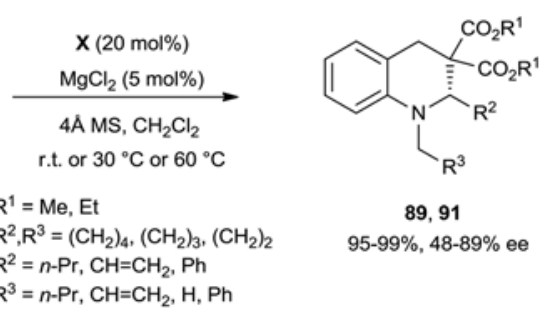

89,91

$95-99 \%, 48-89 \%$ ee $\mathrm{R}^{2}=n-\mathrm{Pr}, \mathrm{CH}=\mathrm{CH}_{2}, \mathrm{Ph}$

Scheme 24 Domino 1,5-hydride shift/cyclization reactions of tertiary amines.

substrate with an electron-donating group (MeO) at the meta position $\left(\mathrm{R}^{4}\right)$ of the nitrogen atom provided the lowest activity $(28 \%$ yield) and enantioselectivity ( $66 \%$ ee). The catalytic system was compatible with other cyclic tertiary amines $\mathbf{8 8}$ with five-, six-, or seven-membered rings $\left(\mathrm{R}^{2}, \mathrm{R}^{3}=\left(\mathrm{CH}_{2}\right)_{2}\right.$, $\left(\mathrm{CH}_{2}\right)_{3}$ or $\left.\left(\mathrm{CH}_{2}\right)_{4}\right)$, giving the corresponding products 89 in $48-89 \%$ ee, and also to acyclic tertiary amines $90\left(\mathrm{R}^{2}=n-\mathrm{Pr}\right.$, $\mathrm{CH}=\mathrm{CH}_{2}$ or $\mathrm{Ph}, \mathrm{R}^{3}=n-\mathrm{Pr}, \mathrm{CH}=\mathrm{CH}_{2}, \mathrm{H}$ or $\mathrm{Ph}$ ) which afforded products 91 with $69-70 \%$ ee.

In 2013, Wang et al. reported the first examples of $\gamma$-sitespecific functionalization of linear $\alpha, \beta$-unsaturated ketones which usually act as electrophiles in Michael additions or prefer to selectively direct the reaction toward $\alpha$-alkylation. ${ }^{46}$ Indeed, in the presence of a combination of $\mathrm{MgBu}_{2}$ and the chiral salen ligand 92 in $p$-xylene at $60{ }^{\circ} \mathrm{C}$, linear $\alpha, \beta$-unsaturated ketones 93 were subjected to $\gamma$-deprotonation, followed by a Michael addition of the thus-formed dienol intermediate $\mathbf{9 4}$ to nitroalkenes $\mathbf{9 5}$ to give novel intermediates 96 which then cyclized into the final densely functionalized chiral cyclohexenes $\mathbf{9 7}$ bearing four contiguous stereocenters 
in moderate to good yields (42-82\%) and diastereoselectivities (50-84\% de) along with high enantioselectivities (86-99\% ee), as shown in Scheme 25. Nitroalkenes bearing a variety of aryl groups with either electron-donating or electron-withdrawing substituents or heteroaryl groups were well tolerated whereas aliphatic nitroalkenes did not undergo the reaction. Furthermore, $\alpha, \beta$-unsaturated ketones bearing different aryl groups at either the $\beta$ - or the $\alpha^{\prime}$-positions were also compatible.

\subsection{Multicatalyzed domino reactions}

In the last few years, an explosive number of multiple-catalyst systems for various organic transformations have been developed. ${ }^{47}$ This novel methodology is particularly adapted for enantioselective domino and tandem reactions. ${ }^{48}$ In 2010, Scheidt et al. reported the first enantioselective cooperative catalytic system consisting of $\mathrm{Mg}(\mathrm{O} t-\mathrm{Bu})_{2}$ and a chiral $\mathrm{N}$-heterocyclic carbene such as 98, which was applied in the presence of a base, such as 1,5,7-triazabicyclo[4.4.0]dec-5-ene (TBD), to a diastereo- and enantioselective synthesis of chiral $\gamma$-lactams from the reaction of $N$-acyl hydrazones 99 with $\alpha, \beta$-unsaturated aldehydes 100 (Scheme 26). ${ }^{49}$ The key behind the success was the reversible magnesium-N-heterocyclic carbene interaction, allowing the corresponding chiral $\gamma$-lactams 101 to be achieved with high levels of diastereo- and
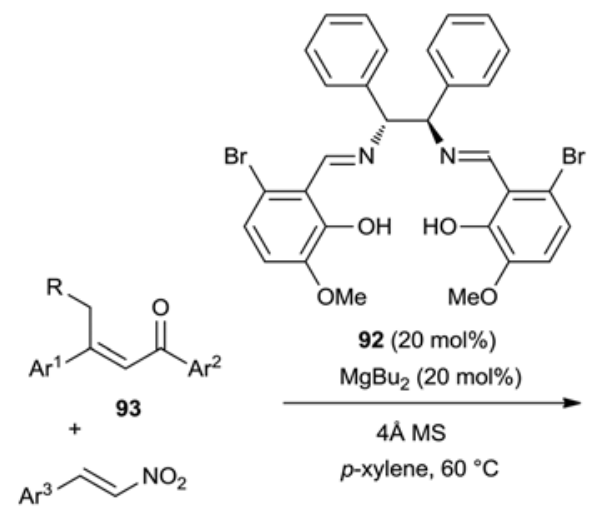

$4 \AA \mathrm{MS}$ p-xylene, $60^{\circ} \mathrm{C}$

95

MgL*$_{2} \downarrow \gamma$-deprotonation

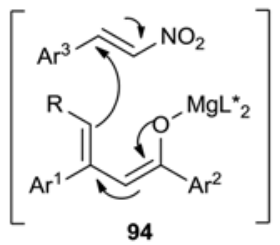

Michael addition

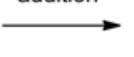

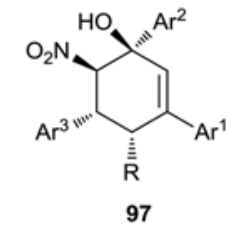

$42-82 \%, 50-84 \%$ de $86-99 \%$ ee cyclization

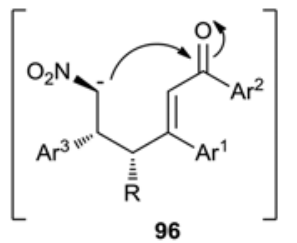

$\mathrm{Ar}^{1}=\mathrm{Ph}, p-\mathrm{ClC}_{6} \mathrm{H}_{4}, o-\mathrm{FC}_{6} \mathrm{H}_{4}, m-\mathrm{Tol}, p-\mathrm{MeOC}_{6} \mathrm{H}_{4}, p-\mathrm{FC}_{6} \mathrm{H}_{4}, m-\mathrm{MeOC}_{6} \mathrm{H}_{4}$ $\mathrm{Ar}^{2}=\mathrm{Ph}, p-\mathrm{FC}_{6} \mathrm{H}_{4}, m-\mathrm{MeOC}_{6} \mathrm{H}_{4}, 2$-thienyl

$\mathrm{Ar}^{3}=\mathrm{Ph}, p-\mathrm{Tol}, p-\mathrm{FC}_{6} \mathrm{H}_{4}, p-\mathrm{ClC}_{6} \mathrm{H}_{4}, p-\mathrm{BrC}_{6} \mathrm{H}_{4}, p-\mathrm{MeOC}_{6} \mathrm{H}_{4}, m-\mathrm{Tol}$, $m-\mathrm{ClC}_{6} \mathrm{H}_{4}, o-\mathrm{FC}_{6} \mathrm{H}_{4}, 2-\mathrm{Naph}, 1-\mathrm{Naph}$, 2-thienyl

$\mathrm{R}=\mathrm{Me}, \mathrm{H}, \mathrm{Et}, \mathrm{Ph}$

Scheme 25 Domino $\gamma$-deprotonation/Michael/cyclization reaction of linear $\alpha, \beta$-unsaturated ketones with nitroalkenes.

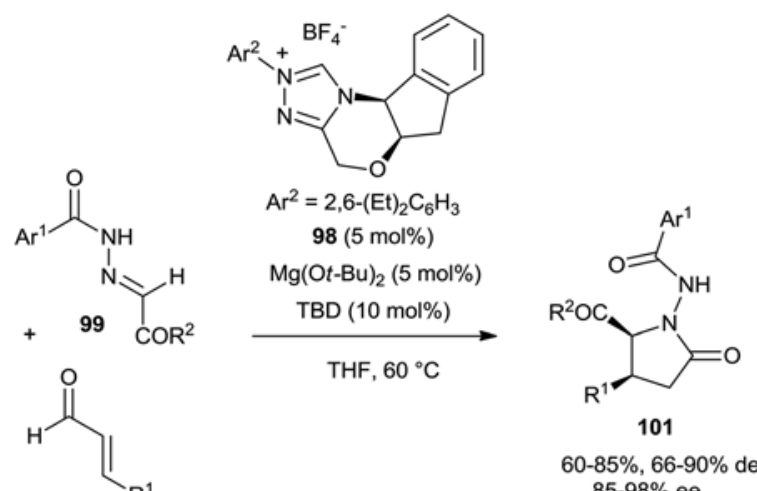

100

$\mathrm{R}^{1}=\mathrm{Ph}, p$-Tol, 2-Naph, $p-\mathrm{BrC}_{6} \mathrm{H}_{4}, p-\mathrm{ClC}_{6} \mathrm{H}_{4}, o-\mathrm{ClC}_{6} \mathrm{H}_{4}, m-\mathrm{ClC}_{6} \mathrm{H}_{4}$, 2-furyl, $p-\mathrm{MeOC}_{6} \mathrm{H}_{4}, n-\mathrm{Pr}, p-\left(\mathrm{MeO}_{2} \mathrm{C}\right) \mathrm{C}_{6} \mathrm{H}_{4}, p-\mathrm{BrC}_{6} \mathrm{H}_{4}, \mathrm{Cy}, \operatorname{TBDPSO}\left(\mathrm{CH}_{2}\right)_{3}$<smiles></smiles>

$\mathrm{Ar}^{1}=p$-Tol, 2-furyl, $\mathrm{Ph}, p-\mathrm{BrC}_{6} \mathrm{H}_{4}, p-\mathrm{ClC}_{6} \mathrm{H}_{4}, p-\mathrm{FC}_{6} \mathrm{H}_{4}, p-\mathrm{MeOC}_{6} \mathrm{H}_{4}$<smiles>[R]C=CC(=O)C=C[R]</smiles>

100

98

102

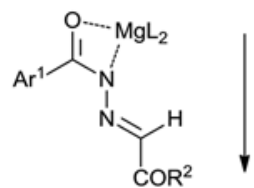

101

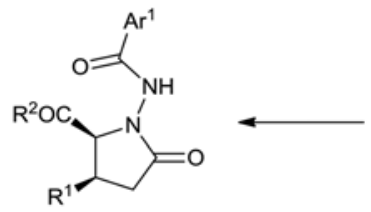

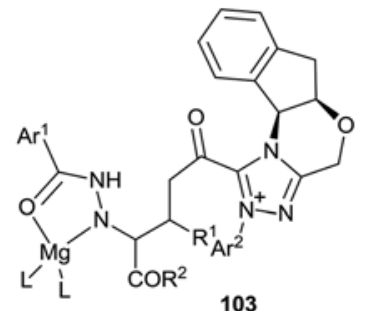

103
Scheme 26 Formal [3 + 2] cycloaddition through cooperative magnesium and $\mathrm{N}$-heterocyclic carbene catalysis.

enantioselectivities (up to $90 \%$ de and $98 \%$ ee, respectively), as shown in Scheme 26. The process began with the addition of the NHC catalyst previously deprotonated by the base to the $\alpha, \beta$-unsaturated aldehyde to give the corresponding dienol intermediate $\mathbf{1 0 2}$ which further added to the $N$-acyl hydrazone activated by $\mathrm{Mg}$ (II) complex to give intermediate 103. The latter then underwent an intramolecular acylation to afford the final formal [3+2] cycloadduct 101 .

In 2012, Gong et al. reported an enantioselective threecomponent reaction based on an asymmetric relay catalytic 
domino Friedländer condensation/transfer hydrogenation reaction of 2-aminophenyl ketones 104, methyl Hantzsch ester 105 and ethyl acetoacetate 106, providing the corresponding chiral tetrahydroquinolines 107 in moderate to high yields (64-97\%), diastereoselectivities of $>90 \%$ de in all cases of substrates studied, combined with high to excellent enantioselectivities (85-98\% ee).$^{50}$ As shown in Scheme 27 , the catalyst system was constituted by a combination of $\mathrm{Mg}(\mathrm{OTf})_{2}$ and chiral phosphoric acid 108. The authors assumed that the process could evolve through a Friedländer condensation catalyzed by either the chiral phosphoric acid or the Lewis acid, while the following asymmetric transfer hydrogenation was promoted solely by chiral Brønsted acid 108 (Scheme 27).

In order to extend to electrophiles other than nitroalkenes the work depicted in Scheme 25, dealing with domino $\gamma$-deprotonation/Michael/cyclization reactions of linear $\alpha, \beta$-unsaturated ketones with nitroalkenes, the same authors later developed a more complex catalyst system composed of chiral phosphoric acid 109, quinidine, and $\mathrm{MgBu}_{2}$ in $p$-xylene at $35{ }^{\circ} \mathrm{C} .{ }^{51}$ The domino $\gamma$-deprotonation/Michael/cyclization cross reaction of linear $\alpha, \beta$-unsaturated ketones 110 and 111 led to the corresponding highly functionalized chiral cyclohexenes 112 in moderate to good yields (27-83\%), high diastereoselectivities $(84->90 \%$ ee) and good to excellent

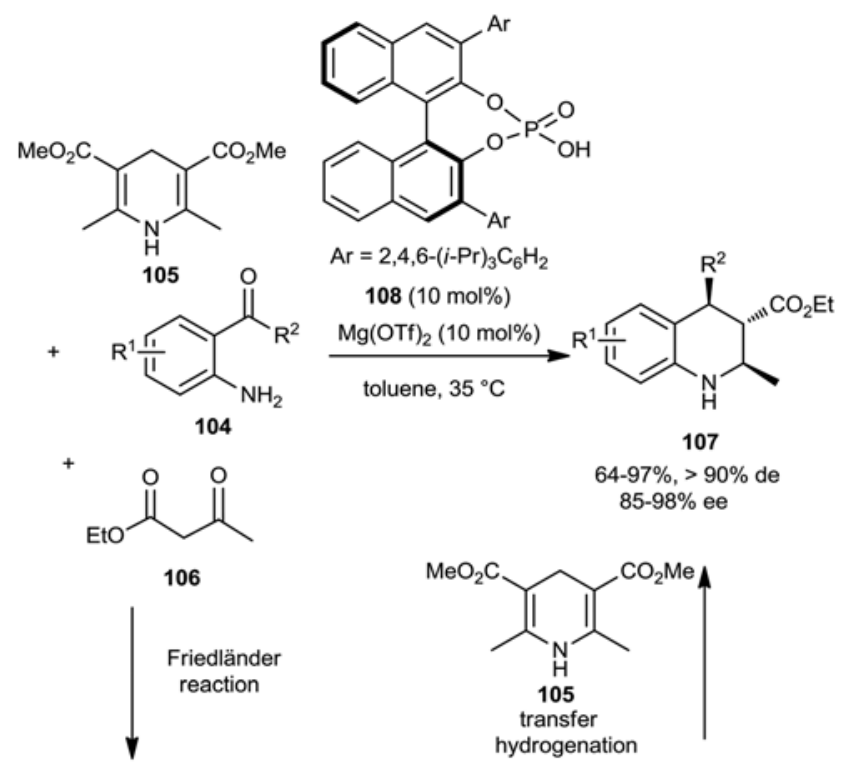<smiles>[R]c1c2c(nc(C)c1C(=O)OCC)C=C[R1](C)C=C2</smiles>

$\mathrm{R}^{1}=\mathrm{H}, 5-\mathrm{Me}, 5-\mathrm{Cl}, 5-\mathrm{F}, 5-\mathrm{BnO}, 5-\mathrm{AcO}, 5-\mathrm{MeO}, 5-\mathrm{Br}, 4-\mathrm{Cl}$ $\mathrm{R}^{2}=\mathrm{H}, \mathrm{Me}, \mathrm{Ph}, p-\mathrm{Tol}$

Scheme 27 Three-component domino Friedländer/transfer hydrogenation reaction through relay magnesium and phosphoric acid catalysis.

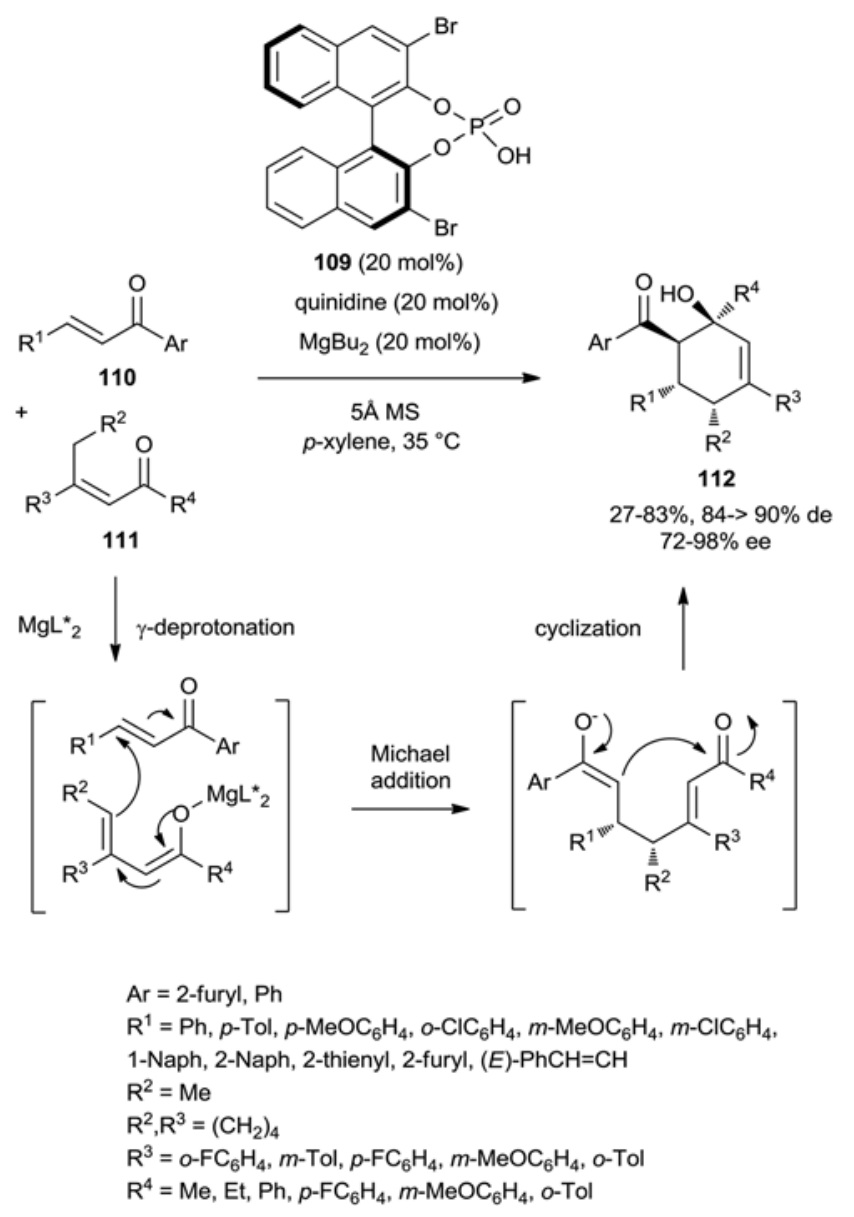

Scheme 28 Domino $\gamma$-deprotonation/Michael/cyclization reaction of linear $\alpha, \beta$-unsaturated ketones through magnesium, cinchona alkaloid and phosphoric acid catalysis.

enantioselectivities ( $72-98 \%$ ee), as shown in Scheme 28. Even if the authors did not specify the exact role of each member of the catalyst system, they demonstrated that the presence of the three members was indispensable to achieve these excellent results. For example, in the absence of the acid cinchona alkaloid almost no product was generated while the absence of the chiral phosphoric acid led to the product albeit with very low stereoselectivities $(\leq 3 \%$ ee). This work represented the first stereocontrolled cross reaction of linear $\alpha, \beta$-unsaturated ketones.

In 2016, Lin et al. reported the use of a combination of $\mathrm{MgCl}_{2}$ with chiral phosphoric acid 113 to promote enantioselective domino 1,5-hydride transfer/cyclization reactions of oxindole derivatives 114 performed in toluene at $80{ }^{\circ} \mathrm{C} .{ }^{52}$ As shown in Scheme 29, the reaction led to a series of structurally diverse spirooxindole tetrahydroquinolines $\mathbf{1 1 5}$ in high yields (80-95\%) and diastereoselectivities ( $80->90 \%$ de) along with moderate to excellent enantioselectivities (50-97\% ee). The lowest enantioselectivity of $50 \%$ ee was obtained with a substrate bearing an electron-rich substituent $\left(\mathrm{R}^{1}=\mathrm{Me}\right)$ on the oxindole aromatic ring whereas the highest enantioselectivities 


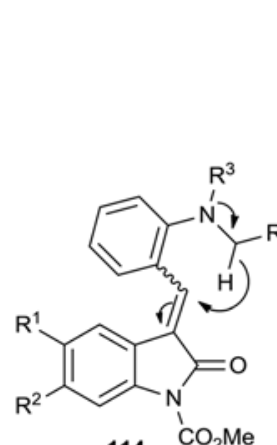

114

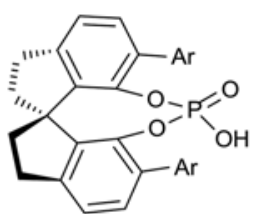

$\mathrm{R}^{4} \quad \mathrm{Ar}=9$-phenanthryl 113 (10 mol\%) $\mathrm{MgCl}_{2}$ (2.5 mol\%)

$4 \mathrm{~A}$ MS toluene, $80^{\circ} \mathrm{C}$ $\mathrm{R}^{1}=\mathrm{H}, \mathrm{NO}_{2}, \mathrm{~F}, \mathrm{Br}, \mathrm{Me}$ $\mathrm{R}^{2}=\mathrm{H}, \mathrm{Cl}$ $\mathrm{R}^{3}, \mathrm{R}^{4}=\left(\mathrm{CH}_{2}\right)_{3},\left(\mathrm{CH}_{2}\right)_{4}$ $\mathrm{R}^{3}=\mathrm{Bn}, \mathrm{R}^{4}=\mathrm{Ph}$ 1,5-hydride transfe

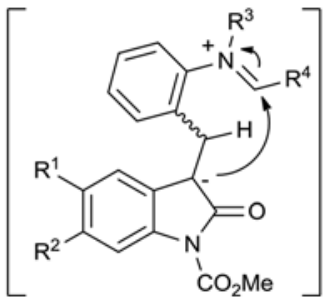

Scheme 29 Domino 1,5-hydride transfer/cyclization reaction of oxindole derivatives through magnesium and phosphoric acid catalysis.

(93-97\% ee) were reached with substrates bearing a strong electron-withdrawing group such as $\mathrm{NO}_{2}$ on this ring $\left(\mathrm{R}^{1}=\mathrm{NO}_{2}\right)$.

\subsection{Tandem reactions}

Tandem catalyzed reactions refer to the synthetic strategies of modular combination of catalytic reactions into one synthetic operation, occurring one after the other and working in conjunction with each other with minimum workup or change in conditions $^{53}$ in comparison with domino reactions defined by Tietze as strictly one-pot reactions. ${ }^{33} \mathrm{~A}$ recent example of enantioselective magnesium-catalyzed tandem reactions was described by Antilla et al., applied to the synthesis of chiral 1,3-oxazolidines and 1,3-oxazinanes under mild reaction conditions (Scheme 30). ${ }^{54}$ The reaction began with the formation of hemiaminal intermediates $\mathbf{1 1 6}$ through enantioselective addition of the respective alcohols 117 to $N$-benzyl imines 118 catalyzed by the preformed chiral magnesium BINOL-derived phosphate catalyst $\mathbf{1 1 9}$, followed by intramolecular cyclization to give the final products $\mathbf{1 2 0}$ in good to excellent yields (77-99\%) and enantioselectivities (80-97\% ee). Generally, better yields (92-99\% vs. 77-96\%) and slightly higher enantioselectivities $(83-97 \%$ ee vs. $80-95 \%$ ee) were achieved in the formation of 1,3-oxazinanes $(n=2)$ in comparison with 1,3oxazolidines $(n=1)$.

Another type of enantioselective magnesium-catalyzed tandem reaction was developed by Wang et al., involving 3-iso-

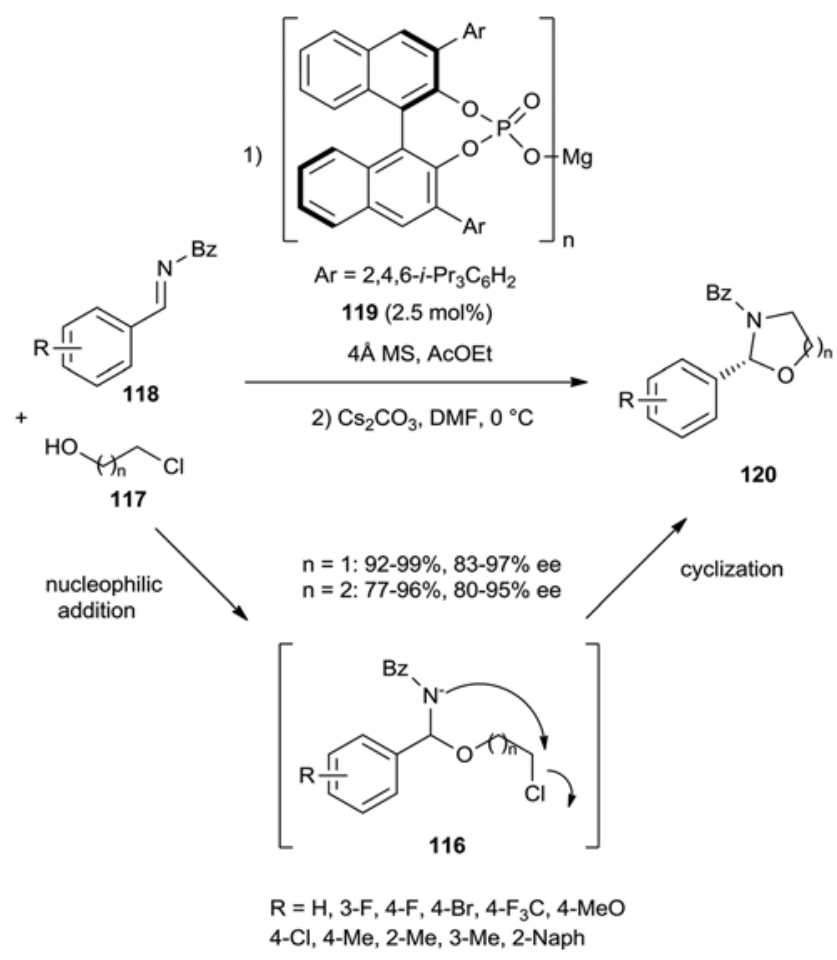

Scheme 30 Tandem nucleophilic addition/cyclization reaction of $N$-benzyl imines with alcohols.

thiocyanato oxindoles 35 and $N$-(2-picolinoyl)aziridines 33 as substrates. ${ }^{55}$ It constituted the first asymmetric formal $[3+3]$ cycloaddition with aziridines. This tandem reaction was mediated by a magnesium catalyst in situ generated from $\mathrm{MgBu}_{2}$ and chiral BINOL-derived fluorinated ligand 121 in toluene at $0{ }^{\circ} \mathrm{C}$ to room temperature. It began with the ringopening of aziridines with 3-isothiocyanato oxindoles to give intermediates $\mathbf{1 2 2}$ which subsequently cyclized into final products 123 by treatment with $t$-BuOK/MeI (Scheme 31). This novel tandem ring-opening/ring-closing reaction allowed a range of densely functionalized chiral pyrimidine derivatives 123 to be synthesized in moderate to high yields (37-92\%) with uniformly high diastereo- and enantioselectivities (88$>90 \%$ de and $89->99 \%$ ee, respectively).

\section{Magnesium-catalyzed ring- opening reactions}

The nucleophilic ring-opening of three-membered compounds, such as epoxides, represents an important strategy in organic synthesis because of its powerful capability of forming bonds. ${ }^{56}$ This process leads to the possible formation of two adjacent stereocenters at the $\alpha, \alpha^{\prime}$-positions of the mesoepoxide, allowing chiral 1,2-difunctional compounds, including 1,2-diol monoethers, 1,2-amino alcohols, or 1,2-thioalcohols, to be easily synthesized. In the past decade, magnesium complexes derived from various chiral ligands have been 


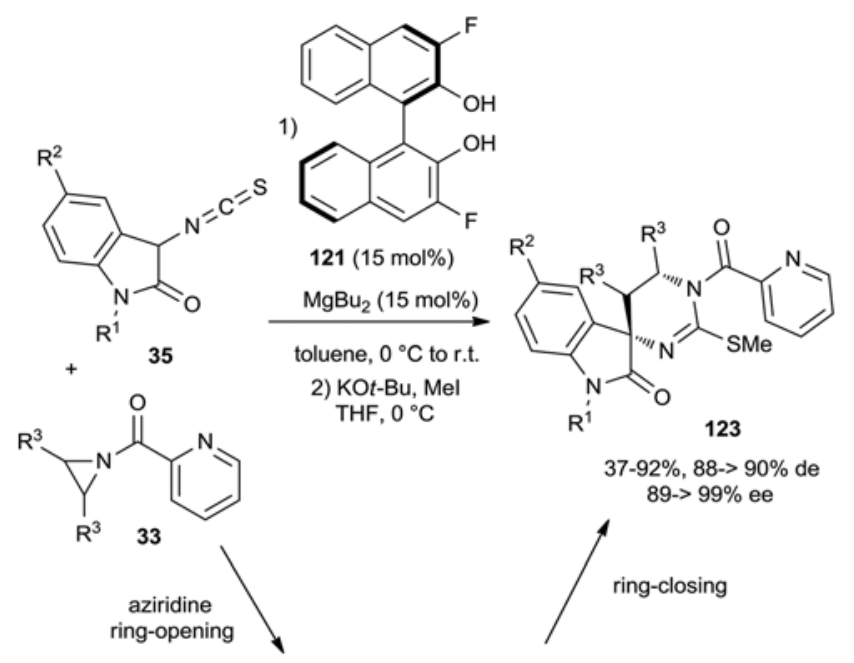

$$
\begin{aligned}
& \mathrm{R}^{1}=\mathrm{Me}, n-\mathrm{Pr}, \mathrm{Bn} \\
& \mathrm{R}^{2}=\mathrm{H}, \mathrm{Me} \\
& \mathrm{R}^{3}, \mathrm{R}^{3}=\left(\mathrm{CH}_{2}\right)_{4},\left(\mathrm{CH}_{2}\right)_{5},\left(\mathrm{CH}_{2}\right)_{3}, \mathrm{R}_{\mathrm{s}}
\end{aligned}
$$

Scheme 31 Tandem ring-opening/ring-closing reaction of 3-isothiocyanato oxindoles with $N$-(2-picolinoyl)aziridines.

successfully applied to the ring-opening reactions of mesoepoxides with a variety of nucleophiles such as amines. For example, Ding et al. have developed enantioselective ringopening of meso-cyclohexene epoxide 124a with aromatic amines catalyzed by a low quantity (1-1.3 mol\%) of a chiral magnesium complex in situ generated from $\mathrm{MgBu}_{2}$ and $(R)$ BINOL as ligand in toluene at room temperature. ${ }^{57}$ As shown in Scheme 32, the corresponding chiral $\beta$-amino alcohols 125 were obtained in moderate to high yields (55-92\%) and enantioselectivities $(65-82 \%$ ee). The substrate scope of the procedure was applied to more challenging aliphatic amines but in the case of substrates better yields and enantioselectivities were achieved by using the partially reduced $(R)$-BINOL derivative, $(R)-\mathrm{H}_{4}$-BINOL, instead of BINOL itself as ligand. As shown in Scheme 32, the reaction of different meso-epoxides 124a-d with aliphatic amines including sterically bulky isopropyl or tert-butylamines led to the corresponding ring-opened products 126 in moderate to high yields (46-92\%) and enantioselectivities (56-94\% ee).

Later, these authors reinvestigated the ring-opening reaction of meso-epoxides 12a-b,e-f with aniline derivatives 127 by using another type of chiral magnesium catalyst such as that in situ generated from $\mathrm{MgBu}_{2}$ and the chiral multidentate semi-azacrown ether ligand $\mathbf{1 2 8} .{ }^{58}$ As shown in Scheme 33, the process performed in pentane at room temperature afforded a

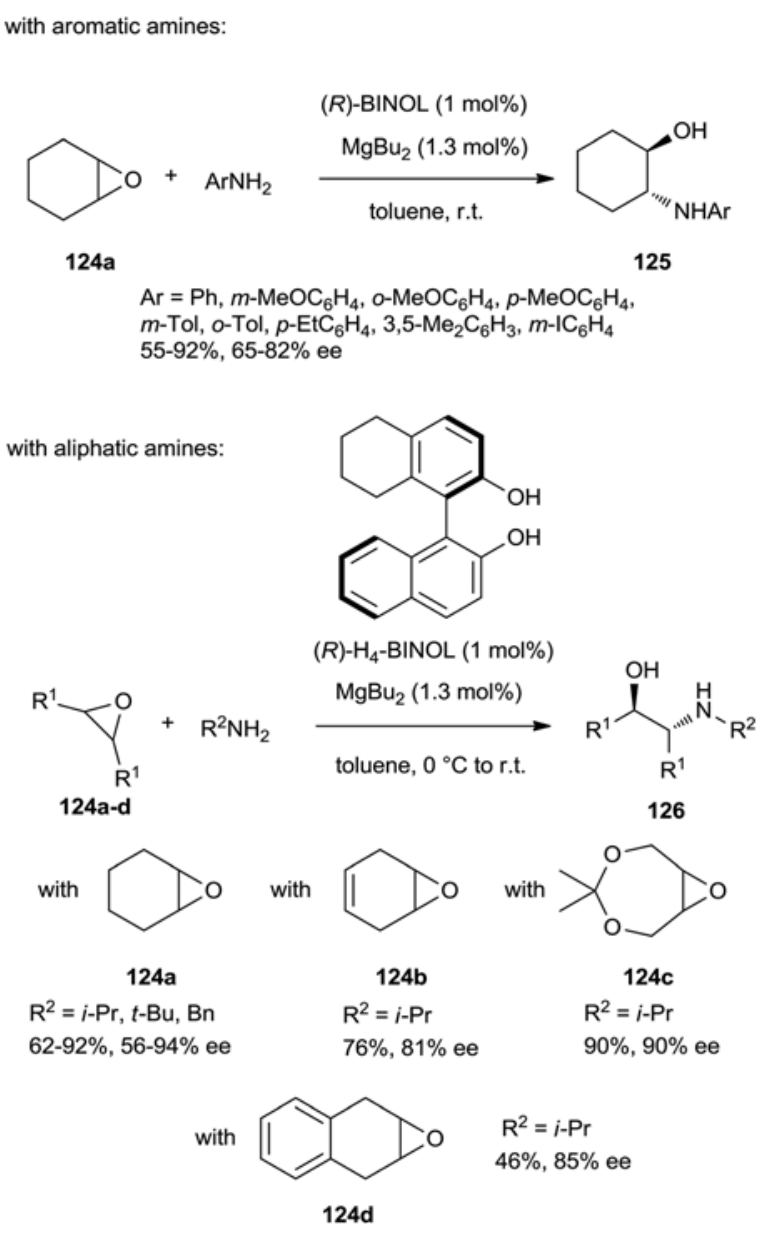

Scheme 32 Ring-opening reactions of meso-epoxides with aromatic and aliphatic amines.

series of chiral $\beta$-amino alcohols 129 in moderate to high yields (24-90\%) and enantioselectivities (63-90\% ee). The best results were obtained in the reaction of cyclohexene epoxide 124a (61-90\% yield and $76-90 \%$ ee). The authors have proposed a binuclear complex as the active catalyst in the process, acting as a Brønsted base-Lewis acid bifunctional catalyst for dual activation of both the amine and the epoxide, so that an oriented intramolecular delivery of the nucleophilic amine could occur with good stereochemical control at the two proximal metal centers within the chiral cavity of the complex (see the transition state in Scheme 33).

The enantioselective nucleophilic ring-opening of mesoaziridines has also received a large amount of attention, since it furnishes valuable nitrogen-containing products. ${ }^{59}$ In the last decade, a range of chiral magnesium catalysts derived from different types of ligands, including $N, N^{\prime}$-dioxides, cinchona alkaloids, amino alcohols, phosphates, and BINOL derivatives, have been successfully applied to ring-opening reactions of meso-aziridines with a variety of nucleophiles. For example, $N, N^{\prime}$-dioxide ligand $\mathbf{4 5}$ was employed by Feng et al. in combination with $\mathrm{Mg}(\mathrm{OTf})_{2}$ in $p$-xylene at $35{ }^{\circ} \mathrm{C}$ to promote the first enantioselective ring-opening reaction of a variety of cyclic and 


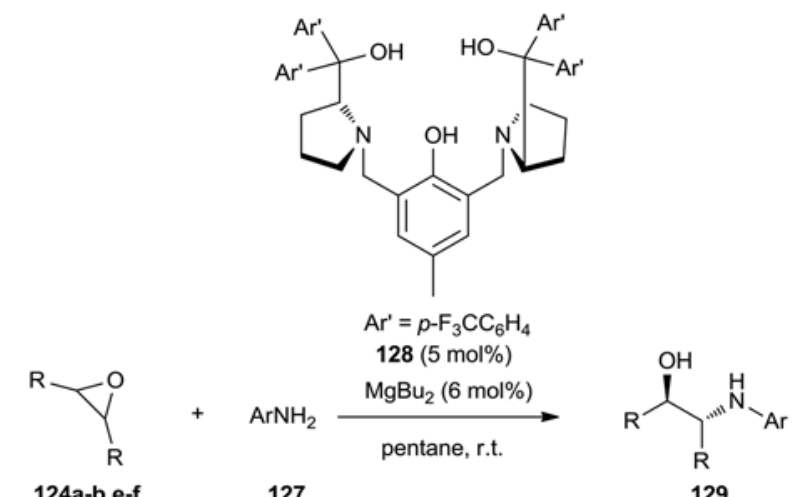

with 124f: $\mathrm{R}=\mathrm{Ar}=\mathrm{Ph}: 83 \%, 88 \%$ ee

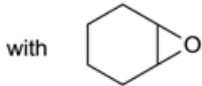

$\mathrm{Ar}=\mathrm{Ph}, m-\mathrm{MeOC}_{6} \mathrm{H}_{4}, o-\mathrm{MeOC}_{6} \mathrm{H}_{4}, p-\mathrm{MeOC}_{6} \mathrm{H}_{4}$ $m$-Tol, o-Tol, $p$ - $\mathrm{EtC}_{6} \mathrm{H}_{4}, 3,5-\mathrm{Me}_{2} \mathrm{C}_{6} \mathrm{H}_{3}, m-\mathrm{IC}_{6} \mathrm{H}_{4}$ : $61-90 \%, 76-90 \%$ ee

$124 a$

with

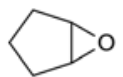

$\mathrm{Ar}=\mathrm{Ph}: 24 \%, 65 \%$ ee

with<smiles></smiles>

$\mathrm{Ar}=\mathrm{Ph}: 67 \%, 63 \%$ ee

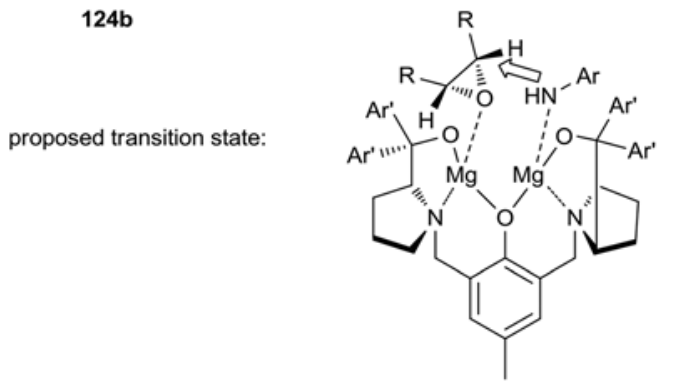

Scheme 33 Ring-opening reaction of meso-epoxides with anilines.

acyclic meso-aziridines 33 with primary alcohols to give the corresponding chiral $\beta$-amino ethers 130 in moderate to high yields (62-96\%) and enantioselectivities (57-92\% ee), as shown in Scheme $34 .^{60}$

In 2014, Wang et al. reported the first example of an asymmetric ring-opening reaction of meso-aziridines 33 with C3unsubstituted indoles 131 catalyzed by a chiral magnesium complex. ${ }^{61}$ While C3-alkylindoles 32 reacted with meso-aziridines 33 through 1,3-dipolar cycloadditions (Scheme 10), the reaction of meso-aziridines 33 with indoles 131 , promoted by a combination of $\mathrm{MgBu}_{2}$ and quinine in $p$-xylene at $30{ }^{\circ} \mathrm{C}$, afforded the corresponding Friedel-Crafts products 132 in moderate to high yields (31-94\%) and good to high enantioselectivities $(70-95 \%$ ee). In addition to various cyclic aziridines, acyclic aryl- and aliphatic aziridines were also tolerated in the reaction, providing the corresponding products in good yields $(71-83 \%)$ and high enantioselectivities ( $84-93 \%$ ee). To illustrate the synthetic utility of this novel methodology, some of the formed products were converted into various types of

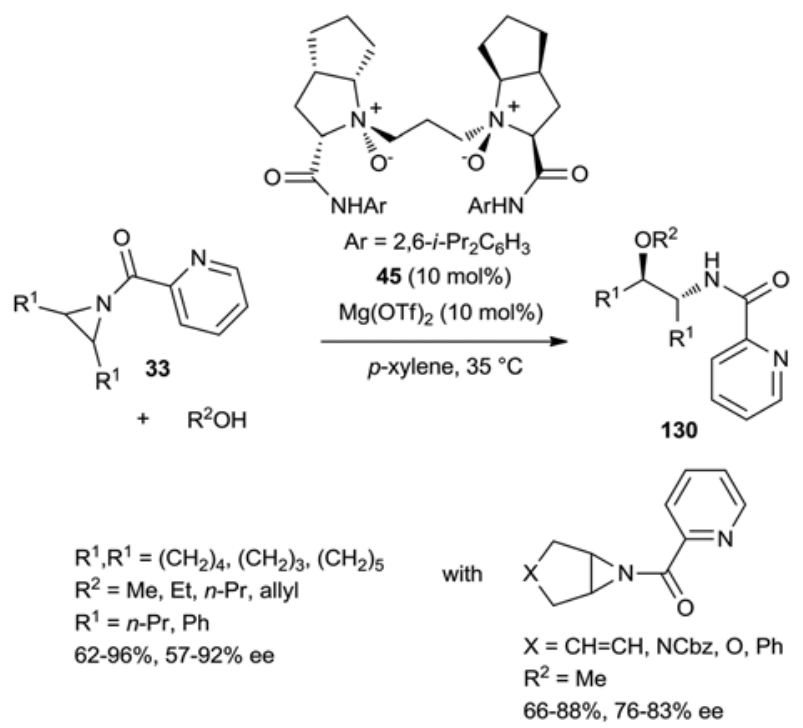

Scheme 34 Ring-opening reaction of meso-aziridines with primary alcohols.

chiral C3-halogenated pyrroloindolines playing an important role in medicinal chemistry (Scheme 35 ).

In 2015, the same authors employed the novel chiral bis (oxazoline) ligand $(S)-\mathbf{1 3 3}$ to promote the first enantioselective<smiles>[R]C1C([R])N1C(=O)c1ccccn1</smiles><smiles>[R]c1cc2[nH]ccc2c([R])c1[R]</smiles>

131<smiles>C=CC1CC2CCC1N2C(O)c1ccnc2ccc(OC)cc12</smiles>

p-xylene, $30^{\circ} \mathrm{C}$<smiles>[R]c1cc2[nH]cc(C([R])[C@@H]([R])NC(=O)c3ccc[R]([H])c3)c2c([R])c1[R]</smiles>

132

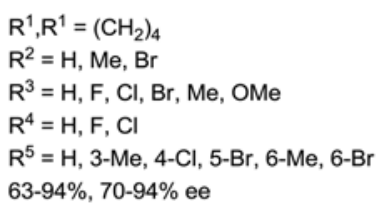

$\mathrm{R}^{1}, \mathrm{R}^{1}=\left(\mathrm{CH}_{2}\right)_{4}$ $\mathrm{R}^{2}=\mathrm{H}, \mathrm{Me}, \mathrm{Br}$ $\mathrm{R}^{3}=\mathrm{H}, \mathrm{F}, \mathrm{Cl}, \mathrm{Br}, \mathrm{Me}, \mathrm{OMe}$ $\mathrm{R}^{4}=\mathrm{H}, \mathrm{F}, \mathrm{Cl}$ $\mathrm{R}^{5}=\mathrm{H}, 3-\mathrm{Me}, 4-\mathrm{Cl}, 5-\mathrm{Br}, 6-\mathrm{Me}, 6-\mathrm{Br}$ $63-94 \%, 70-94 \%$ ee

$R^{1}, R^{1}=\left(C_{2}\right)_{2}, R^{2}=R^{3}=R^{4}=R^{5}=H: 80 \%, 95 \%$ ee $R^{1}, R^{1}=\left(C_{2}\right)_{5}, R^{2}=R^{3}=R^{4}=R^{5}=H: 31 \%, 85 \%$ ee $R^{1}, R^{1}=\left(C_{2} C H\right)_{2}, R^{2}=R^{3}=R^{4}=R^{5}=H: 79 \%, 93 \%$ ee $R^{1}=P h, R^{2}=R^{3}=R^{4}=R^{5}=H: 71 \%, 86 \%$ ee $R^{1}=M e, R^{2}=R^{3}=R^{4}=R^{5}=H: 81 \%, 84 \%$ ee $R^{1}=E t, R^{2}=R^{3}=R^{4}=R^{5}=H: 83 \%, 93 \%$ ee

Scheme 35 Ring-opening reaction of meso-aziridines with indoles. 
magnesium-catalyzed ring-opening reactions of meso-aziridines 33 with $\beta$-naphthols 134 . $^{62}$ Performed in toluene at $40{ }^{\circ} \mathrm{C}$, the process afforded the corresponding products 135 in moderate to quantitative yields (48-99\%), moderate to high diastereoselectivities (64->90\% de) and high enantioselectivities (91->99\% ee), as shown in Scheme 36. The reaction constituted the first direct, facile, and highly stereoselective dearomatization of $\beta$-naphthol derivatives. Furthermore, the enantiomeric ring-opening products ent-135 could be obtained with excellent yields (94-96\%), a diastereoselectivity of $>90 \%$ de, and remarkable enantioselectivities (98->99\% ee) when using (R)-133 as ligand (Scheme 36).<smiles>[R]C1C([R])N1C(=O)c1ccccn1</smiles>

33<smiles>[R]c1cc2ccccc2c([R])c1O</smiles>

134

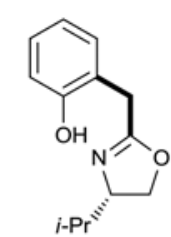

(S)-133 (5 mol\%) $\mathrm{MgBu}_{2}(5 \mathrm{~mol} \%)$

toluene, $40^{\circ} \mathrm{C}$

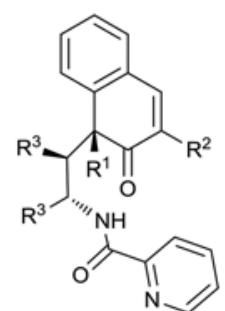

135
$\mathrm{R}^{1}=\mathrm{H}, \mathrm{Me}, \mathrm{Et}, n-\mathrm{Pr}, n-\mathrm{Hept}$

$\mathrm{R}^{2}=\mathrm{H}, \mathrm{Et}, \mathrm{TMS}, \mathrm{Cl}, \mathrm{Br}, \mathrm{I}, \mathrm{Me}, \mathrm{Ph}, \mathrm{PhC} \equiv \mathrm{C}$ $\mathrm{R}^{3}, \mathrm{R}^{3}=\left(\mathrm{CH}_{2}\right)_{4}$

$59-99 \%, 64->90 \%$ de, $91->99 \%$ ee

$R^{1}=R^{2}=H, R^{3}, R^{3}=\left(C_{2}\right)_{5}: 48 \%,>90 \%$ de, $>99 \%$ ee

$R^{1}=R^{2}=H, R^{3}, R^{3}=\left(C_{2}\right)_{3}: 98 \%,>90 \%$ de, > $99 \%$ ee

$R^{1}=R^{2}=H, R^{3}, R^{3}=\left(C_{2} C H\right)_{2}: 93 \%,>90 \%$ de, $>99 \%$ ee

$R^{1}=R^{2}=H, R^{3}=$ Me: $99 \%,>90 \%$ de, $>99 \%$ ee

$R^{1}=R^{2}=H, R^{3}=$ Et: $99 \%,>90 \%$ de, $>99 \%$ ee

$R^{1}=R^{2}=H, R^{3}=P h: 99 \%,>90 \%$ de, $>99 \%$ ee<smiles>[R]C1C([R])N1C(=O)c1ccccn1</smiles>

33<smiles>[R]c1cc2ccccc2c([R])c1O</smiles>

134

$R^{1}=R^{2}=H, R^{3}, R^{3}=\left(\mathrm{CH}_{2}\right)_{3}: 96 \%,>90 \%$ de, $>99 \%$ ee $R^{1}=R^{2}=H, R^{3}=P h: 94 \%,>90 \%$ de, $98 \%$ ee

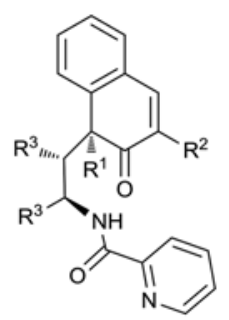

ent-135
Scheme 36 Ring-opening reactions of meso-aziridines with $\beta$-naphthols.
In 2015 , the same authors also described the first enantioselective magnesium-catalyzed ring-opening reaction of mesoaziridines 33 with benzofuran-2(3H)-ones $136 .{ }^{63}$ In this case, $(R)$-BINOL was selected as the optimal ligand of $\mathrm{MgBu}_{2}$, leading to the corresponding products 137 (Scheme 37). These chiral 3,3-disubstituted benzofuran-2(3H)-ones bearing three contiguous stereocenters were obtained in moderate to good yields (46-92\%), moderate to high diastereoselectivities (66$>90 \%$ de) and enantioselectivities (56-99\% ee). The simple catalytic system was compatible with cyclic as well as acyclic meso-aziridines and with the presence of different substituents at the C-5 and C-7 positions of the aromatic ring of the benzofuran-2(3H)-ones.

In addition, the first enantioselective magnesium-catalyzed ring-opening reaction of meso-aziridines with 3-aryl-oxindoles was described by the same authors. ${ }^{64}$ In this case, the BINOL fluorinated derivative $\mathbf{1 2 1}$ was selected as the optimal ligand to promote, in combination with $\mathrm{MgBu}_{2}$ in toluene at room temperature, the reaction of a variety of cyclic and acyclic meso-aziridines 33 with 3-phenyl-oxindoles 138. As shown in Scheme 38, a range of chiral 3-alkyl-3-phenyl oxindoles 139 exhibiting three contiguous stereocenters were achieved in moderate to high yields (44-94\%), a uniformly high diastereoselectivity of $>90 \%$ de, and good to excellent enantioselectivities (72->99\% ee). Oxindoles with different substituents at the C5-, C6-, and C7positions were all tolerated under the catalytic system, providing comparable excellent enantioselectivities (87->99\% ee).

Finally, these authors disclosed the first enantioselective magnesium-catalyzed ring-opening reaction of meso-aziridines

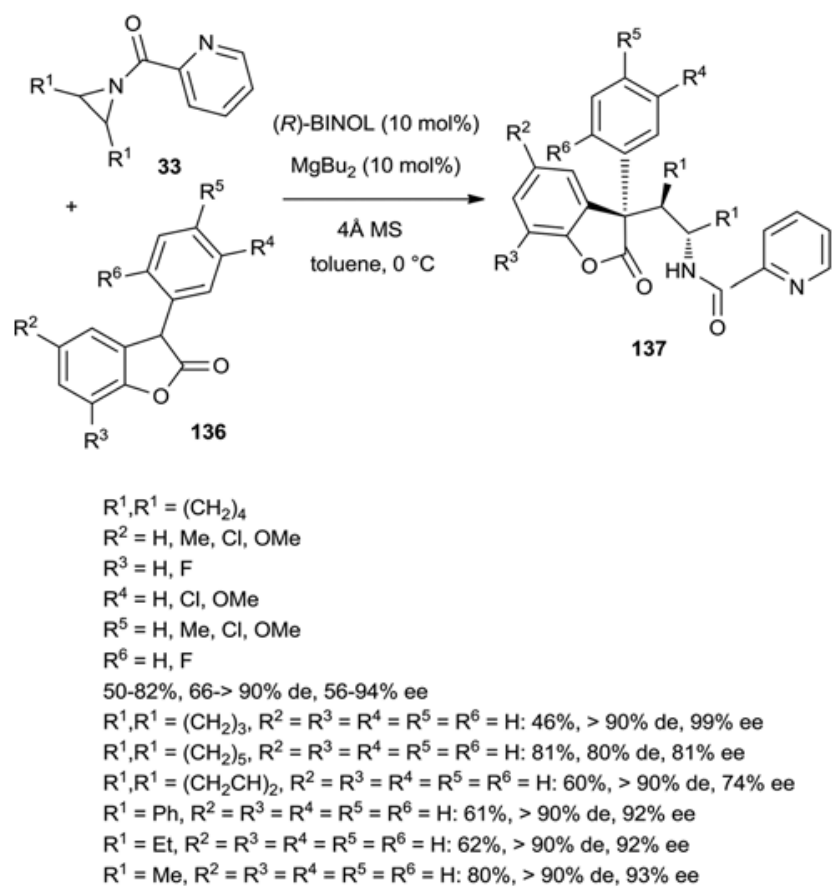

Scheme 37 Ring-opening reaction of meso-aziridines with benzofuran-2(3H)-ones. 

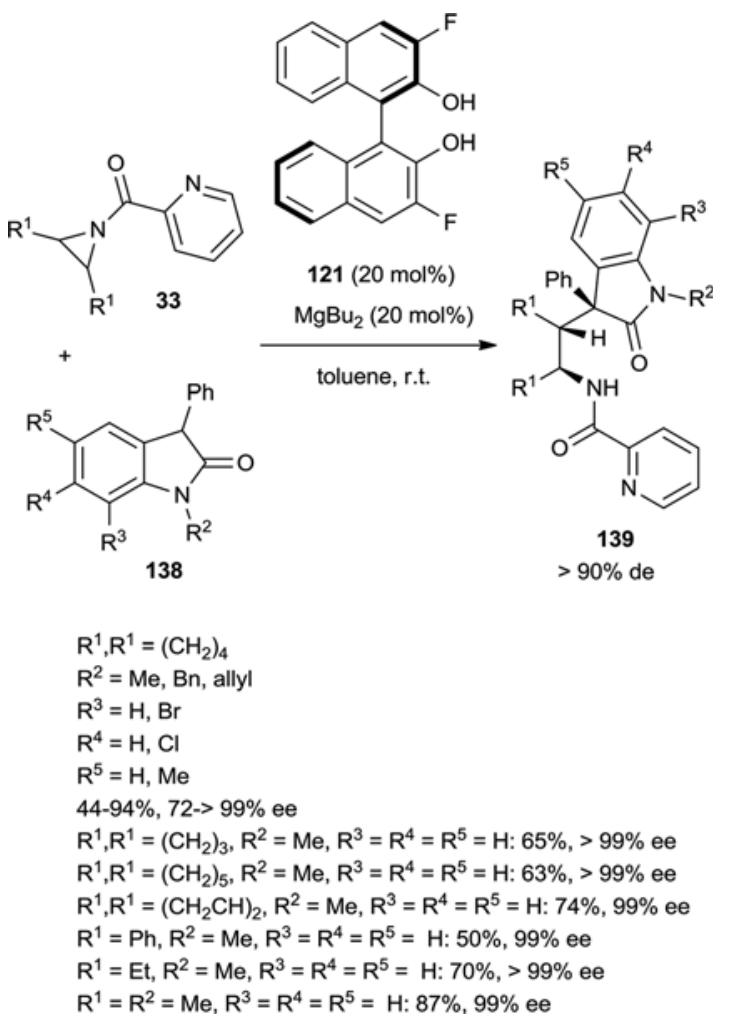

Scheme 38 Ring-opening reaction of meso-aziridines with 3-phenyloxindoles.

33 with $\alpha, \beta$-unsaturated $\gamma$-butyrolactam $140 .{ }^{65}$ Among a variety of ligands derived from $(S)$-BINOL and $(S)-\mathrm{H}_{8}$-BINOL, the chiral ligand $(S)$-141 was selected as the most efficient to promote, in combination with $\mathrm{MgBu}_{2}$ in toluene, the first $\alpha$-sp ${ }^{2}$-carbon attacked catalytic asymmetric ring-opening of aziridines. As shown in Scheme 39, the process led to the formation of a series of chiral amines $\mathbf{1 4 2}$ containing aryl or alkyl groups in moderate to good yields (30-75\%) with high enantioselectivities $(80-97 \%$ ee). Studying different ligands, the authors demonstrated that the bromine atom of the ligand played a key role in introducing a high level of enantioselectivity and a high reaction efficiency. Moreover, the enantiomeric products could be prepared with up to $93 \%$ ee by using $(R)$-141 as ligand.

In another context, Sala has developed enantioselective ring-opening reactions of cyclic meso-aziridines 143 with various silylated nucleophiles $144 .{ }^{66}$ The process was promoted by a $1: 1$ mixture of magnesium and calcium VAPOLderived phosphate catalysts 145 and 146 employed at $50 \mathrm{~mol} \%$ catalyst loading. As shown in Scheme 40, silylated sulfur nucleophiles yielded the corresponding ring-opened products 147 in moderate to quantitative yields (53-98\%) with high enantioselectivities $(82-92 \%$ ee) while the reaction of a thiocyanate nucleophile $(\mathrm{X}=\mathrm{NCS})$ provided only $42 \%$ ee. The best enantioselectivity of $96 \%$ ee was achieved in the reaction of a silylated selenium nucleophile $(\mathrm{X}=\mathrm{SePh})$. Moreover, a silylated azide nucleophile $\left(\mathrm{X}=\mathrm{N}_{3}\right)$ led to the corresponding product in

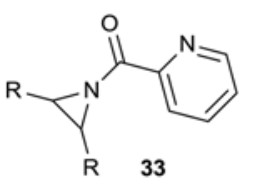<smiles>CC(=O)OC(=O)N1CC=CC1=O</smiles>

140<smiles>OC1=C(c2c(O)c(Br)cc3c2CCCC3)C2CCCCC2C=C1Br</smiles>

(S)-141 (10 or $20 \mathrm{~mol} \%$ ) $\mathrm{MgBu}_{2}$ (10 or $20 \mathrm{~mol} \%$ )

toluene, 30 or $60^{\circ} \mathrm{C}$ $5 \AA$ MS

$\mathrm{R}, \mathrm{R}=\left(\mathrm{CH}_{2}\right)_{4}: 75 \%, 97 \%$ ee $R, R=\left(\mathrm{CH}_{2}\right)_{3}: 52 \%, 93 \%$ ee $\mathrm{R}, \mathrm{R}=\left(\mathrm{CH}_{2}\right)_{5}: 30 \%, 83 \%$ ee $\mathrm{R}, \mathrm{R}=\left(\mathrm{CH}_{2} \mathrm{CH}\right)_{2}: 83 \%, 86 \%$ ee $\mathrm{R}=\mathrm{Me}: 70 \%, 93 \%$ ee

$\mathrm{R}=\mathrm{Et}: 56 \%, 80 \%$ ee

$\mathrm{R}=\mathrm{Ph}: 56 \%, 82 \%$ ee
Scheme 39 Ring-opening reaction of meso-aziridines with a $\gamma$-butyrolactam.

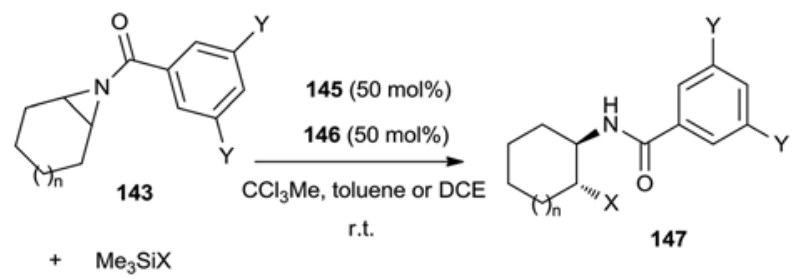

$144 \quad X=S P h, Y=N_{2}, n=1: 94 \%, 90 \%$ ee $\mathrm{X}=\mathrm{SPh}, \mathrm{Y}=\mathrm{NO}_{2}, \mathrm{n}=0: 98 \%, 92 \%$ ee $X=S P h, Y=N_{2}, n=0: 98 \%, 92 \%$ ee
$X=S B n, Y=N_{2}, n=1: 53 \%, 85 \%$ ee $\mathrm{X}=\mathrm{SMe}, \mathrm{Y}=\mathrm{NO}_{2}, \mathrm{n}=1: 67 \%, 82 \%$ ee $X=N S C, Y=N_{2}, n=1:>99 \%, 42 \%$ ee $\mathrm{X}=\mathrm{SePh}, \mathrm{Y}=\mathrm{NO}_{2}, \mathrm{n}=1: 90 \%, 96 \%$ ee $X=N_{3}, Y=C F_{3}, n=1: 94 \%, 91 \%$ ee

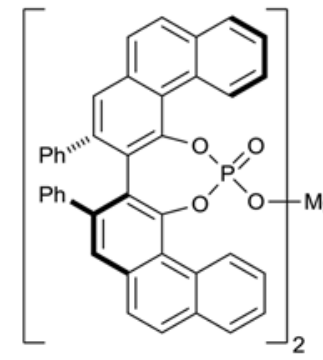

145

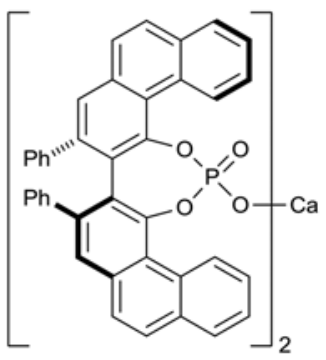

Scheme $40 \mathrm{Mg}$ - and Ca-catalyzed ring-opening reaction of mesoaziridines with silylated nucleophiles.

91\% ee. With the aim of determining the active catalyst of the process, the authors have demonstrated that the phosphoric acid alone was not able to promote efficiently the reaction and proposed that the two metals played a key role in the catalytic cycle, whether as part of a bimetallic species or as distinct monometallic molecules. One metal center could act as a Lewis acid, activating the aziridine, while the ligand attached to the other metal center generated the reactive nucleophile. 


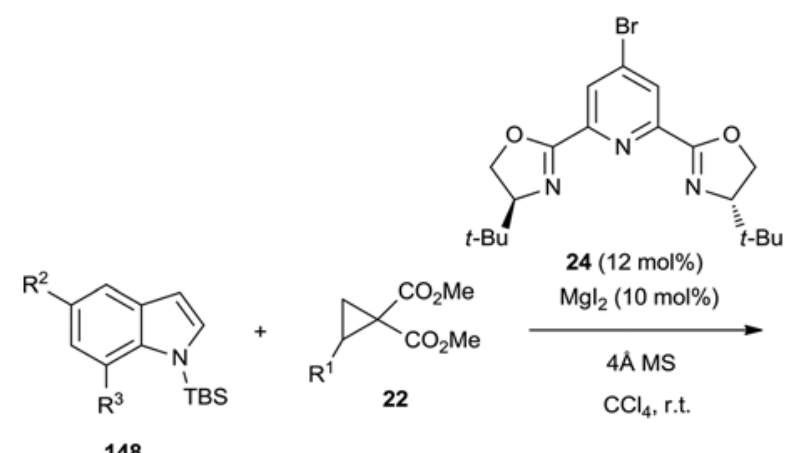

148<smiles>[R]c1cc([R])c2c(c1)c(C([R])CC(C(C)=O)C(C)=O)cn2[13CH3]</smiles>

149

$38-96 \%, 70-94 \%$ ee

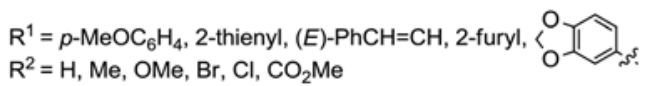
$\mathrm{R}^{2}=\mathrm{H}, \mathrm{Me}, \mathrm{OMe}, \mathrm{Br}, \mathrm{Cl}, \mathrm{CO}_{2} \mathrm{Me}$

$\mathrm{R}^{3}=\mathrm{H}, \mathrm{Me}$

Scheme 41 Ring-opening reaction of donor-acceptor cyclopropanes with $N$-TBS indoles.

In another context, donor-acceptor cyclopropanes, especially those derived from 1,1-dicarboxylate esters, can act as homo-Michael acceptors in ring-opening reactions under Lewis acid catalysis. ${ }^{67}$ In 2013 , Johnson et al. investigated the asymmetric magnesium-catalyzed ring-opening of this type of cyclopropane with $\mathrm{N}$-protected indoles. ${ }^{68}$ In the presence of $\mathrm{MgI}_{2}$ and chiral pybox ligand 24 as a catalyst system in $\mathrm{CCl}_{4}$ at room temperature, $N$-TBS indoles 148 underwent a FriedelCrafts reaction with donor-acceptor cyclopropanes 22 to give the corresponding chiral homo-Michael products 149 in moderate to high yields (38-96\%) and good to high enantioselectivities (70-94\% ee), as shown in Scheme 41. A range of indoles with electronically diverse substituents $\left(\mathrm{R}^{2}, \mathrm{R}^{3}\right)$ underwent the reaction with generally high yields with the exception of electron-deficient indoles bearing halo or ester substituents (38-52\% yield $v$ s. $80-96 \%$ yield). The cyclopropane partner tolerated aromatic, heteroaromatic and ethylenic substituents $\left(\mathrm{R}^{1}\right)$ which all provided high enantioselectivities with the exception of the para-methoxyphenyl substituent giving a lower enantioselectivity of $70 \%$ ee while the best enantioselectivity of $94 \%$ ee was achieved by using the cyclopropane bearing a thienyl group.

\section{Magnesium-catalyzed Michael reactions}

Michael-type reactions ${ }^{69}$ can be considered as one of the most powerful tools for the stereocontrolled formation of carbon- carbon as well as carbon-heteroatom bonds. ${ }^{70} \mathrm{~A}$ range of chiral metals and chiral organocatalysts have already been applied to promote these reactions. It is only in 1997 that Sibi and Ji reported the first example of a highly enantioselective magnesium-catalyzed Michael radical addition performed in the presence of chiral bis(oxazoline) ligands, providing enantioselectivities of up to $97 \%$ ee. ${ }^{71}$ Later in 1998 , a comparable catalytic system was applied by these authors to develop the first examples of highly enantioselective magnesium-catalyzed Michael additions of amines with the same enantioselectivity. ${ }^{72}$ In 1999, comparable excellent enantioselectivities were achieved by Ji et al. in asymmetric magnesium-catalyzed conjugate additions of 1,3-dicarbonyl compounds to nitroalkenes by using the same ligand in combination with $\mathrm{Mg}(\mathrm{OTf})_{2} \cdot{ }^{73}$ Later in 2007 , Kantam et al. reported asymmetric Michael additions of malonates 150 to $\alpha, \beta$-unsaturated ketones catalyzed by heterogeneous nanocrystalline $\mathrm{MgO}$ (NAP-MgO).$^{74}$ As shown in Scheme 42, these reactions were performed in THF at $-20{ }^{\circ} \mathrm{C}$ in the presence of the chiral diamine ligand 151. When cyclic $\alpha, \beta$-unsaturated ketones 152 were employed as substrates as electrophilic partners, the corresponding Michael products 153 were obtained in uniformly high yields (90-96\%) with good to excellent enantioselectivities (84-96\% ee) while acyclic $\alpha, \beta$-unsaturated ketone $\mathbf{1 5 4 a}$ provided the corresponding products 155 with slightly lower enantioselectivities $(76-85 \%$ ee) with comparable high yields (92-95\%).

Asymmetric conjugate additions of vinyl nucleophiles performed on $\alpha, \beta$-unsaturated ketones appended at the $\beta$-position of an unprotected indole are still very rare. To address the lack of such methods, May et al. have employed a chiral magnesium catalyst in situ generated from $\mathrm{Mg}(\mathrm{O} t-\mathrm{Bu})_{2}$ and $(R)-$

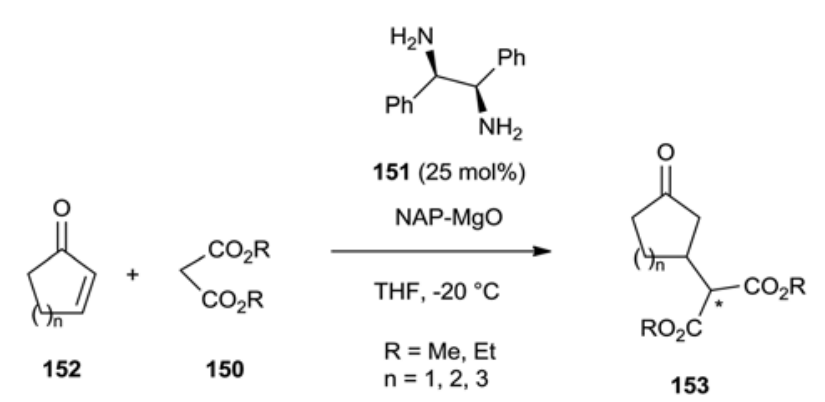

$90-96 \%, 84-96 \%$ ee

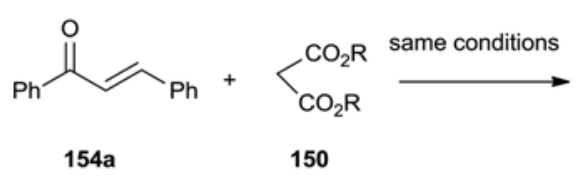<smiles>[R]OC(=O)C(C(=O)O[R2])C(CC(=O)c1ccccc1)c1ccccc1</smiles>

155

$\mathrm{R}=\mathrm{Me}: 93 \%, 82 \%$ ee R = Et: $95 \%, 76 \%$ ee $\mathrm{R}=\mathrm{Bn}: 92 \%, 85 \%$ ee

Scheme 42 Heterogeneous Michael additions of malonates to $\alpha, \beta$-unsaturated ketones. 
BINOL-derived fluorinated ligand 156 to promote the Michael addition of vinyl nucleophiles, such as $(E)$-alkenylboronic acids $\mathbf{1 5 7}$, to indole-appended $\alpha, \beta$-unsaturated ketones 158 . $^{75}$ As shown in Scheme 43, the reaction led to the corresponding chiral $\alpha$-branched indole derivatives 159 in good to high yields (70-91\%) and uniformly high enantioselectivities (87-99\% ee). An unprotected indole was not necessary for the reaction, as both Boc- and methyl-protected indoles $(\mathrm{X}=\mathrm{Boc}, \mathrm{Me})$ reacted smoothly with high yields (85-86\%) and excellent enantioselectivities (97-98\% ee). Concerning the scope of the $(E)$-alkenylboronic acids, both alkylvinylboronic acids and arylvinylboronic acids bearing electron-withdrawing or electron-donating substituents on the phenyl ring were tolerated, providing the corresponding products in comparable high enantioselectivities. Even alkynylboronic acid $\mathbf{1 6 0}$ led to the corresponding product 161 by reaction with indole 158a in $71 \%$ yield and $98 \%$ ee.

In 2011, Wang et al. reported enantioselective magnesiumcatalyzed vinylogous Michael additions of $\alpha, \beta$-unsaturated $\gamma$-butyrolactam 140 to $\alpha, \beta$-unsaturated aryl ketones $154{ }^{76}$ The reaction employed a combination of $\mathrm{MgBu}_{2}$ and the chiral BINOL derivative 162 as ligand in dichloromethane at $0{ }^{\circ} \mathrm{C}$ and afforded the corresponding Michael adducts 163 in good to high yields (72-94\%) and diastereoselectivities (75->90\% de) along with excellent enantioselectivities (91-98\% ee), as shown in Scheme 44. The process was compatible with a<smiles>[R]C(=O)/C=C/c1cn(C)c2ccc([R])cc12</smiles>

$158 \mathrm{X}$<smiles>[R]C([R3])=C([R])[R]O</smiles>

157
$156(15 \mathrm{~mol} \%)$ $\mathrm{Mg}(\mathrm{Ot}-\mathrm{Bu})_{2}(10 \mathrm{~mol} \%)$

$4 \AA ̊ M S$

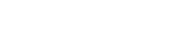

$\mathrm{R}^{1}=\mathrm{H}, \mathrm{Br}, \mathrm{OMe}$

$\mathrm{R}^{2}=\mathrm{Me}, i-\mathrm{Pr}, \mathrm{Ph}, t-\mathrm{Bu}, \mathrm{Cy}$

$\mathrm{R}^{3}=\mathrm{Ph}, \mathrm{Me}$

$\mathrm{R}^{4}=\mathrm{H}, \mathrm{Me}, p-\mathrm{FC}_{6} \mathrm{H}_{4}$

$\mathrm{R}^{5}=\mathrm{H}, \mathrm{Me}$

$X=H, B o c, M e$

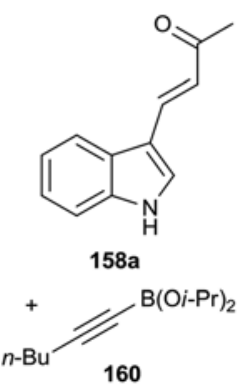<smiles>Oc1c(C(F)(F)F)cc2ccccc2c1-c1c(O)c(C(F)(F)F)cc2ccccc12</smiles>
$\left(\mathrm{CICH}_{2}\right)_{2}, 70^{\circ} \mathrm{C}$

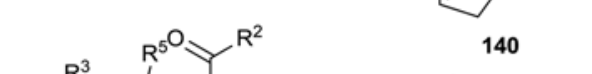

$+$<smiles></smiles>

154

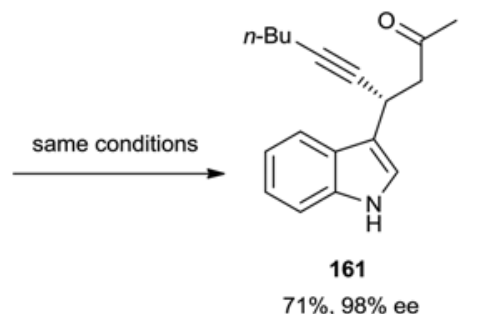

$71 \%, 98 \%$ ee

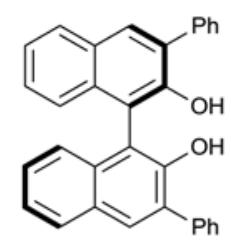

162 (10 mol\%)

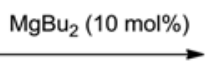

$4 \AA \AA M S$

$\mathrm{CH}_{2} \mathrm{Cl}_{2}, 0^{\circ} \mathrm{C}$

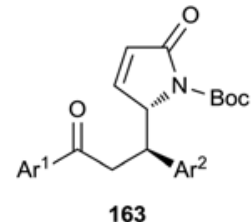

$72-94 \%, 75->90 \%$ de

$91-98 \%$ ee
$\mathrm{Ar}^{1}=\mathrm{Ph}, p-\mathrm{BrC}_{6} \mathrm{H}_{4}, p$-Tol, 2-furyl

$\mathrm{Ar}^{2}=\mathrm{Ph}, o-\mathrm{MeOC}_{6} \mathrm{H}_{4}, m-\mathrm{MeOC}_{6} \mathrm{H}_{4}, p-\mathrm{MeOC}_{6} \mathrm{H}_{4}, o-\mathrm{FC}_{6} \mathrm{H}_{4}, p-\mathrm{FC}_{6} \mathrm{H}_{4}$ $o-\mathrm{ClC}_{6} \mathrm{H}_{4}, p-\mathrm{ClC}_{6} \mathrm{H}_{4}, m-\mathrm{Tol}, p-\mathrm{BrC}_{6} \mathrm{H}_{4}, p-\mathrm{NCC}_{6} \mathrm{H}_{4}, 1-\mathrm{Naph}, 2-\mathrm{Naph}$<smiles>O=C1C=CCN1C(=O)c1ccccc1</smiles>

same conditions

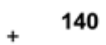<smiles>[R]C=CC([R1])=O</smiles>

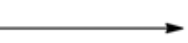

variety of aryl enones with the enantioselectivity minimally by either the (hetero)aryl substituent of the carbonyl $\beta$-unsaturated aliphatic ketone 164a which afforded the corresponding product 165a with a high enantioselectivity of $92 \%$ ee albeit combined with a moderate yield of $62 \%$ (Scheme 44). ther hand, replacing the $\gamma$-aryl moiety $\left(\mathrm{Ar}^{2}\right)$ in enone the reaction decreasing dramatically (54\% ee, Scheme 44 ). Finally, the catalyst system was successfully applied to $\alpha, \beta$-unsaturated $\gamma$-butyrolactams $\quad$ to $\alpha, \beta$-unsaturated

Chiral organophosphorus compounds exhibit many biological activities and constitute important chiral ligands. ${ }^{77}$ The of the most powerful synthetic methodologies for the construction of these compounds. ${ }^{78}$ In this context, Ishihara et al. have

$$
\begin{aligned}
& \text { 165a: } R^{1}=M e, R^{2}=P h: 62 \%, 92 \% \text { de, } 92 \% \text { ee } \\
& \text { 165b: } R^{1}=P h, R^{2}=M e: 70 \%,>88 \% \text { de, } 54 \% \text { ee } \\
& \text { 165c: } R^{1}=-\xi-N, R^{2}=2 \text {-thienyl: } 60 \%, 82 \% \text { de, } 92 \% \text { ee }
\end{aligned}
$$

Scheme 44 Vinylogous Michael additions of an $\alpha, \beta$-unsaturated $\gamma$-butyrolactam to $\alpha, \beta$-unsaturated ketones and $\alpha, \beta$-unsaturated $N$-acylpyrrole.

Scheme 43 Michael additions of alkenyl- and alkynylboronic acids to indole-appended $\alpha, \beta$-unsaturated ketones. 
developed the first highly enantioselective Michael addition of diaryl phosphine oxides 166 to $\alpha, \beta$-unsaturated esters 167 by using a combination of $\mathrm{MgBu}_{2}$ and $(R)-\mathrm{H}_{8}$-BINOL as chiral ligand in THF at $-40{ }^{\circ} \mathrm{C}$ (Scheme 45$) .{ }^{79}$ The process afforded the corresponding chiral Michael products 168 in both high yields (78-93\%) and enantioselectivities (85-96\% ee).

In 2014, another type of chiral magnesium complex was applied by Wang et al. to develop the first enantioselective magnesium-catalyzed conjugate cyanation of $\alpha, \beta$-unsaturated compounds. ${ }^{80}$ As shown in Scheme 46, the Michael addition of TMSCN ( $\mathrm{X}=$ TMS) to a range of $\alpha, \beta$-unsaturated ketones 169 performed in the presence of $\mathrm{MgBu}_{2}$ and chiral multidentate ligand $(S, S)$-170 afforded the corresponding chiral cyanide products 171 in good to high yields (75-95\%) and enantioselectivities (77-95\% ee). The enone substrates could bear aromatic substituents (R) with both electron-donating and electron-withdrawing groups, heteroaromatic substituents, and even aliphatic ones. Moreover, the cyanation also occurred by replacing TMSCN as a cyanide source with TBSCN or HCN, leading to products in $92-93 \%$ ee and $64-93 \%$ yields. The authors have proposed that the active catalyst was dinuclear with one metal coordinating the cyanide and the other metal coordinating the carbonyl group of the $\alpha, \beta$-unsaturated ketone. With the aim of extending the scope of this methodology to other electrophilic partners, the authors found that using $\alpha, \beta$-unsaturated amides, better results were obtained with a mononuclear magnesium catalyst derived from $\mathrm{MgBu}_{2}$ and $(S)$ BINOL. Indeed, under these catalytic conditions, the conjugate addition of TMSCN to $\alpha, \beta$-unsaturated $N$-acylimides 172 led to the corresponding chiral cyanides $\mathbf{1 7 3}$ in moderately good yields (58-79\%) and enantioselectivities $(37-82 \%$ ee), as shown in Scheme 46 . The best results (up to $82 \%$ ee) were generally achieved with $\alpha, \beta$-unsaturated $N$-acylimides bearing aromatic substituents (R) while alkyl-substituted ones provided lower enantioselectivities (37-50\% ee).

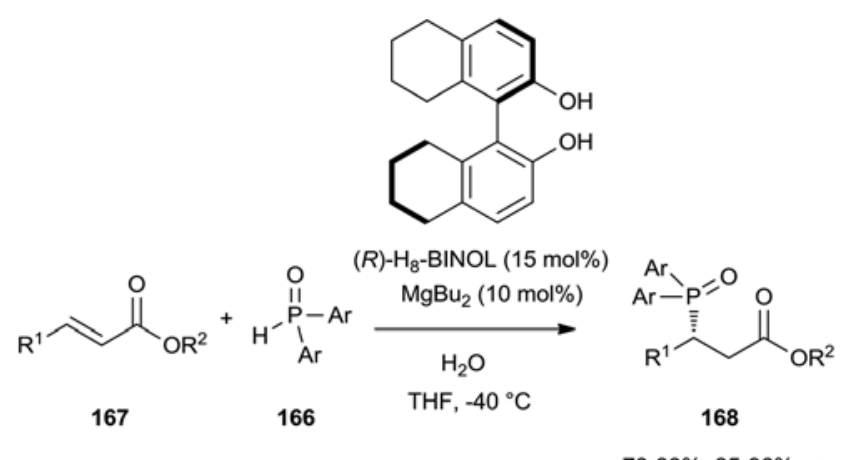

$78-93 \%, 85-96 \%$ ee

\footnotetext{
$\mathrm{R}^{1}=\mathrm{Ph}, p-\mathrm{ClC}_{6} \mathrm{H}_{4}, p$-Tol, $p$ - $\mathrm{MeOC}_{6} \mathrm{H}_{4}, 2$-furyl, 3-pyridyl, $\mathrm{Cy},(E)-\mathrm{PhCH}=\mathrm{CH}$

$\mathrm{R}^{2}=\mathrm{Me}, \mathrm{Et}$

$\mathrm{Ar}=\mathrm{Ph}, 2-\mathrm{Naph}, 3,5-\mathrm{Me}_{2} \mathrm{C}_{6} \mathrm{H}_{3}$
}

Scheme 45 Michael addition of diaryl phosphine oxides to $\alpha, \beta$-unsaturated esters.

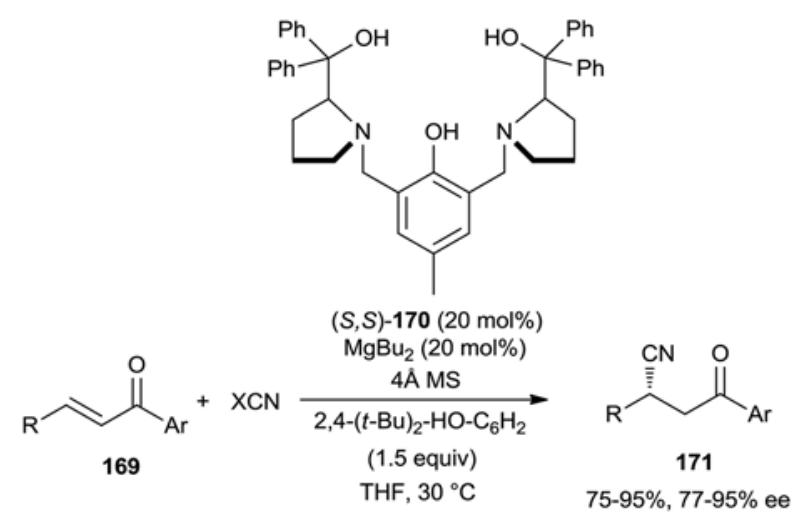
$\mathrm{R}=\mathrm{Ph}, p-\mathrm{Tol}, o-\mathrm{Tol}_{1} p-\mathrm{ClC}_{6} \mathrm{H}_{4}, o-\mathrm{BrC}_{6} \mathrm{H}_{4}, p-\mathrm{BrC}_{6} \mathrm{H}_{4}$,
$o-\mathrm{MeOC}_{6} \mathrm{H}_{4}, p-\mathrm{MeOC}_{6} \mathrm{H}_{4}, 2-\mathrm{Naph}_{2}$ 2-furyl, $n-\mathrm{Hex},(E)-\mathrm{PhCH}=\mathrm{CH},\langle$
$\mathrm{Ar}=\mathrm{Ph}, p-\mathrm{Tol}, o-\mathrm{ClC}_{6} \mathrm{H}_{4}, p-\mathrm{ClC}_{6} \mathrm{H}_{4}, m-\mathrm{ClC}_{6} \mathrm{H}_{4}, p-\mathrm{MeOC}_{6} \mathrm{H}_{4}$ $\mathrm{Ar}=\mathrm{Ph}, p-\mathrm{Tol}, o-\mathrm{ClC}_{6} \mathrm{H}_{4}, p-\mathrm{ClC}_{6} \mathrm{H}_{4}, m-\mathrm{ClC}_{6} \mathrm{H}_{4}, p-\mathrm{MeOC}_{6} \mathrm{H}_{4}$ $X=T M S, T B S, H$

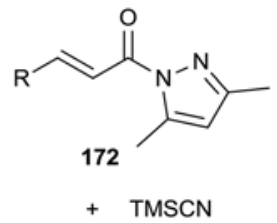

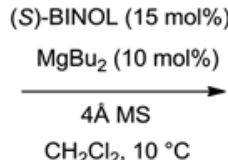

$\mathrm{CH}_{2} \mathrm{Cl}_{2}, 10^{\circ} \mathrm{C}$

+ TMSCN

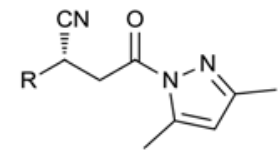

173
$\mathrm{R}=\mathrm{Ph}, o-\mathrm{Tol}, m-\mathrm{Tol}, p-\mathrm{Tol}, p-\mathrm{ClC}_{6} \mathrm{H}_{4}, p-\mathrm{BrC}_{6} \mathrm{H}_{4}, 2,4-\mathrm{Cl}_{2} \mathrm{C}_{6} \mathrm{H}_{3}, p-\mathrm{F}_{3} \mathrm{CC}_{6} \mathrm{H}_{4}$, p-MeOC ${ }_{6} \mathrm{H}_{4}, 2-\mathrm{Naph},(E)-\mathrm{PhCH}=\mathrm{CH}, \mathrm{Me}, 3-\mathrm{N}$-methylindol

Scheme 46 Conjugate cyanations of $\alpha, \beta$-unsaturated ketones and amides.

Later, related reactions with chalcones were developed by $\mathrm{Xu}$ et al. using Py-BINMOL as chiral magnesium ligand bearing both axial and $\mathrm{sp}^{3}$-central chirality. ${ }^{81}$ As shown in Scheme 47 , the conjugate addition of TMSCN to a range of chalcones $\mathbf{1 5 4}$ in the presence of this chiral ligand combined with $\mathrm{MgBu}_{2}$ in diethyl ether at $-5{ }^{\circ} \mathrm{C}$ afforded the corresponding chiral cyanides $\mathbf{1 7 4}$ in moderate to high yields (67-91\%) and enantioselectivities (45-92\% ee). It was found that the presence of para-nitrophenol as a stoichiometric additive was indispensable to achieve good yields and enantioselectivities. The reaction was compatible with the presence of methyl, halide, methoxy, trifluoromethyl, and phenyl groups in the chalcones while the introduction of a nitro group in chalcones led to no reaction probably because of the competing coordination to magnesium of the nitro and the carbonyl groups during the activation of the substrate with the magnesium catalyst.

In 2015, Wang et al. described a rare example of dearomatization of naphthols based on a catalytic asymmetric conjugate addition. ${ }^{82}$ Indeed, these authors developed enantioselective magnesium-catalyzed Michael additions of $\beta$-naphthols 134 to propargylic ketones $\mathbf{1 7 5}$ performed in cyclopentyl methyl ether (CPME) at $0{ }^{\circ} \mathrm{C}$ in the presence of $\mathrm{MgBu}_{2}$ and chiral oxazoline ligand 176 (Scheme 48). The process afforded the corres- 

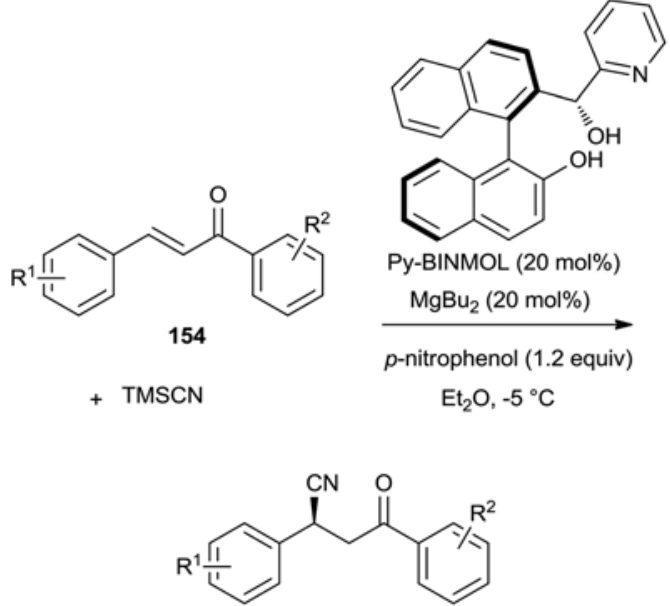

174

$67-91 \%, 45-92 \%$ ee

$\mathrm{R}^{1}=\mathrm{H}, 4-\mathrm{F}, 4-\mathrm{Cl}, 4-\mathrm{Br}, 4-\mathrm{Me}, 4-\mathrm{CF}_{3}$ 4-Ph, 2-MeO, 3-MeO, 4-MeO $\mathrm{R}^{2}=\mathrm{H}, 4-\mathrm{F}, 4-\mathrm{Cl}, 4-\mathrm{Br}, 4-\mathrm{Me}$, pyridyl

Scheme 47 Michael addition of TMSCN to chalcones.<smiles>[R]C(=O)C#C[13CH2]</smiles>
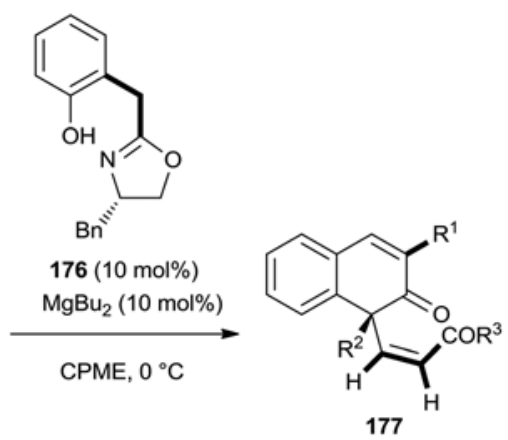

$32-84 \%$ $Z / E=89: 11$ to $94: 6$ $72-98 \%$ ee
$\mathrm{R}^{1}=\mathrm{Me}, \mathrm{Et}, \mathrm{Ph}, \mathrm{Cl}, \mathrm{Br}, \mathrm{I}, \mathrm{TMS}, \mathrm{C} \equiv \mathrm{CPh}$

$\mathrm{R}^{2}=\mathrm{Me}, \mathrm{Et}, n-\mathrm{Pr}$

$\mathrm{R}^{3}=\mathrm{Ph}, p-\mathrm{Tol}, p-\mathrm{ClC}_{6} \mathrm{H}_{4}, p-\mathrm{FC}_{6} \mathrm{H}_{4}, p-\mathrm{BrC}_{6} \mathrm{H}_{4}, m-\mathrm{MeOC}_{6} \mathrm{H}_{4}, o-\mathrm{MeOC}_{6} \mathrm{H}_{4}$, $o-\mathrm{FC}_{6} \mathrm{H}_{4}, 3,5-(\mathrm{MeO})_{2} \mathrm{C}_{6} \mathrm{H}_{3}$, 2-thienyl, 3-thienyl, 2-Naph, $n$-Hex

Scheme 48 Michael addition of $\beta$-naphthols to propargylic ketones.

ponding products 177 as major $Z$-diastereomers $(Z / E=89: 11$ to $94: 6)$ in moderate to high yields $(32-84 \%)$ and good to excellent enantioselectivities $(72-98 \%$ ee). Excellent enantioselectivities of $92-98 \%$ ee and high yields (73-85\%) were obtained in the reaction of a range of $\beta$-naphthols bearing alkyl, aryl, and halogen groups at the $\mathrm{C}-3$ position $\left(\mathrm{R}^{1}\right)$ of the $\beta$-naphthols while a lower yield (32\%) was observed in the reaction of a C-3-TMS-substituted $\beta$-naphthol albeit with still a high ee value ( $90 \%$ ee). Moreover, in addition to a methyl group, the substituent at the $\mathrm{C}-1$ position $\left(\mathrm{R}^{2}\right)$ of the $\beta$-naphthol could be a bulkier group such as ethyl and $n$-propyl ones, providing moderate to high enantioselectivities (96-97\% ee for $\mathrm{R}^{2}=\mathrm{Et}, 72 \%$ ee for $\mathrm{R}^{2}=n$-Pr). Even a phenylethynyl group $\left(\mathrm{R}^{1}=\mathrm{C} \equiv \mathrm{C}-\mathrm{Ph}\right)$ allowed the corresponding Michael product to be obtained with $84 \%$ ee. Concerning the propargylic ketone partner, (hetero)aryl-alkynyl ketones bearing various substituents all provided excellent enantioselectivities while a lower enantioselectivity (76\% ee) was obtained in the reaction of an alkyl-alkynyl ketone $\left(\mathrm{R}^{3}=n\right.$-Hex $)$.

Continuing their research in this area, these authors disclosed enantioselective magnesium-catalyzed Michael additions of $\beta$-naphthols $\mathbf{1 3 4}$ to dialkyl acetylenedicarboxylates $\mathbf{1 7 8}$ to give the corresponding chiral trisubstituted olefins 179 bearing an all carbon quaternary center. ${ }^{83}$ As shown in Scheme 49, in this case the oxazoline chiral ligand 180 gave the best results in combination with $\mathrm{MgBu}_{2}$ in toluene at room temperature. The $Z$-diastereomers were generated as major products $(Z / E=69: 31$ to $93: 7)$ in moderate to quantitative yields (66-98\%) and high enantioselectivities (84->99\% ee). A wide variety of substituents at the $\mathrm{C}-3$ position $\left(\mathrm{R}^{2}\right)$ of the $\beta$-naphthol was tolerated, including halogen, allyl, methyl, benzyl, phenyl, 2-naphthyl, and alkynyl groups. In addition to a methyl group at the $\mathrm{C}-1$ position $\left(\mathrm{R}^{1}\right)$ of the $\beta$-naphthol, bulkier alkyl groups, such as ethyl and $n$-heptyl groups, gave generally lower yields (36-77\%) albeit with high enantioselectivities (93-96\% ee). Concerning the dialkyl acetylenedicarboxylates, comparable high enantioselectivities were achieved regardless of the alkyl substituent group $\left(R^{3}\right)$.

Earlier, Luo et al. reported the use of a combination of $\mathrm{MgF}_{2}$ and (S)-BINOL-derived phosphoric acid 181 in enantioselective Friedel-Crafts reactions of phenols and indoles with $\beta, \gamma$-unsaturated $\alpha$-ketoesters. ${ }^{84}$ As shown in Scheme 50, in the presence of $20 \mathrm{~mol} \%$ of this ligand and $5 \mathrm{~mol} \%$ of $\mathrm{MgF}_{2}$ in dichloromethane at $-70{ }^{\circ} \mathrm{C}$, the reaction of phenols 182 with $\beta, \gamma$-unsaturated $\alpha$-ketoesters 49 led to the corresponding Friedel-Crafts products $\mathbf{1 8 3}$ in moderate to good yields (57-82\%) and good to excellent enantioselectivities (82->99\% ee). Notably, this constituted the first use of $\mathrm{MgF}_{2}$ as a homogeneous Lewis acid in asymmetric catalysis. This methodology

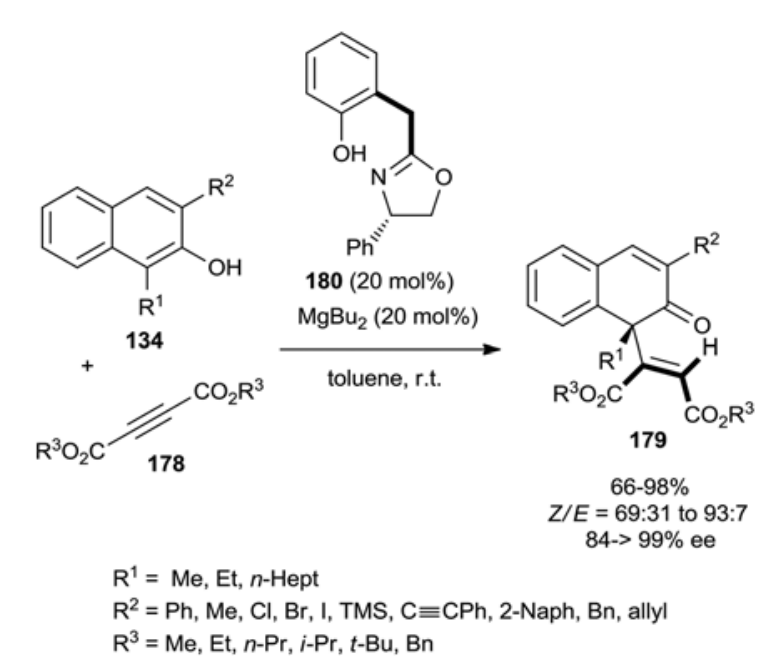

Scheme 49 Michael addition of $\beta$-naphthols to dialkyl acetylenedicarboxylates. 


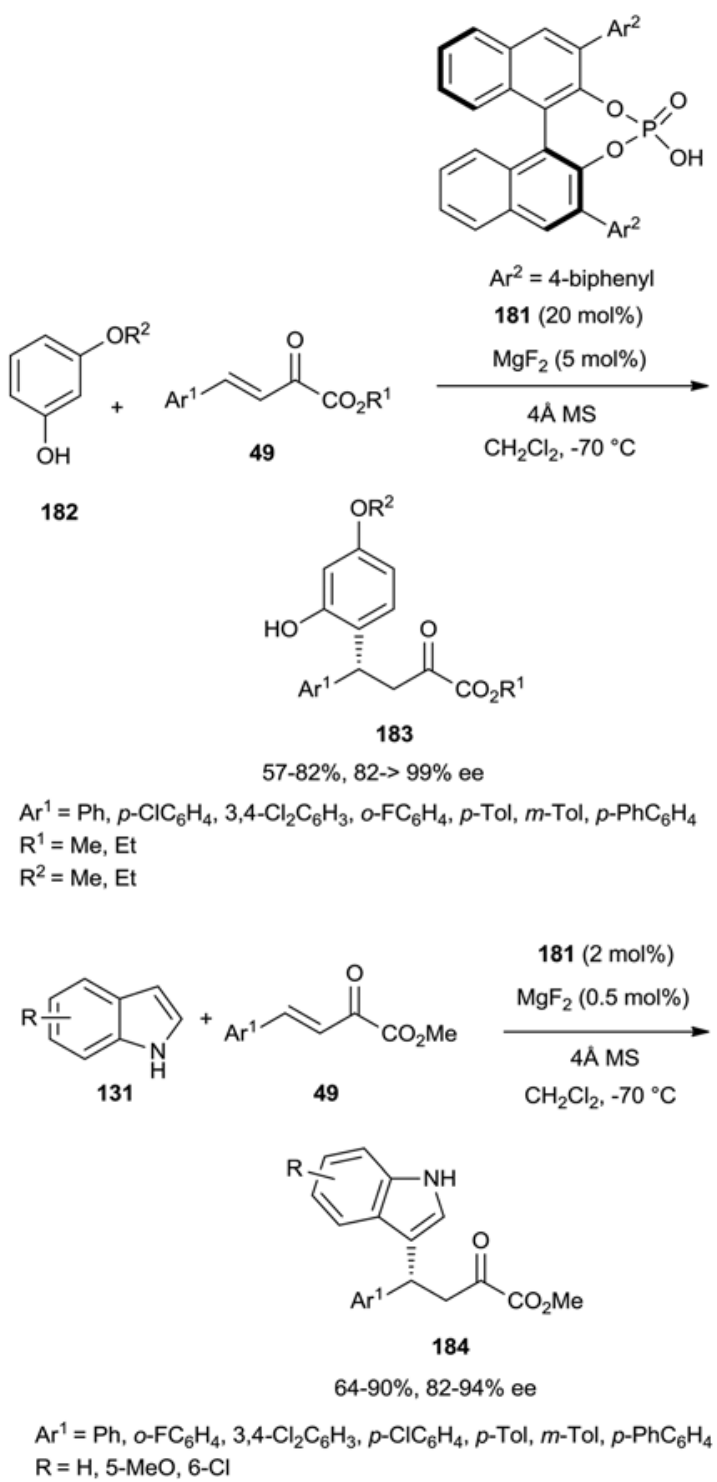

Scheme 50 Friedel-Crafts reactions of phenols and indoles with $\beta, \gamma$-unsaturated $\alpha$-ketoesters.

was extended to other nucleophiles, such as indoles 131, which led, through reaction with $\beta, \gamma$-unsaturated $\alpha$-ketoesters 49, to the corresponding chiral Friedel-Crafts products 184 in moderate to high yields (64-90\%) and high enantioselectivities $(82-94 \%$ ee). In this case, lower catalyst loadings were sufficient to reach these good results since $2 \mathrm{~mol} \%$ of phosphoric acid and only $0.5 \mathrm{~mol} \%$ of $\mathrm{MgF}_{2}$ were used.

\section{Magnesium-catalyzed 1,2- nucleophilic additions to carbonyl compounds and imines}

In 1993, Corey and Wang reported the first enantioselective magnesium-catalyzed addition of TMSCN to aldehydes, leading to the corresponding cyanohydrins in enantioselectivities of up to $95 \%$ ee by employing a chiral bis(oxazoline) ligand. ${ }^{85}$ Among other asymmetric 1,2-nucleophilic additions to carbonyl compounds, the catalytic asymmetric aldol reaction is a powerful method for synthesizing chiral $\beta$-hydroxy carbonyl derivatives. A wide range of chiral catalyst systems have been successfully developed to promote this type of reaction including metals as well as organocatalysts. ${ }^{40,86}$ Early in 2005, Willis et al. reported an enantioselective direct aldol reaction for the synthesis of chiral aryl $\beta$-hydroxy- $\alpha$-amino acids catalyzed by a chiral pybox $\mathrm{Mg}$ (II) complex, providing enantioselectivities of up to $95 \%$ ee ${ }^{87}$ Later in 2009 , Trost et al. developed enantioselective magnesium-catalyzed direct aldol reactions between commercially available ethyl diazoacetate (EDA) and aldehydes, providing the corresponding chiral highly synthetically useful $\alpha$-diazo- $\beta$-hydroxy esters $185 .{ }^{88}$ The process was promoted by a combination of $\mathrm{MgBu}_{2}$ and multidentate ligand $(S, S)-\mathbf{1 7 0}$ in THF at $-20{ }^{\circ} \mathrm{C}$ in the presence of cis-1,2cyclopentanediol 186 as an additive. A wide range of (hetero) aromatic aldehydes but also more challenging aliphatic ones were compatible, leading to products $(S)-\mathbf{1 8 5}$ in moderate to high yields (50-92\%) with uniformly high enantioselectivities (89-98\% ee), as shown in Scheme 51. Whereas comparable excellent enantioselectivities were obtained for these two classes of aldehydes, lower yields (50-76\% vs. 70-92\%) were observed in the case of aliphatic aldehydes in comparison with

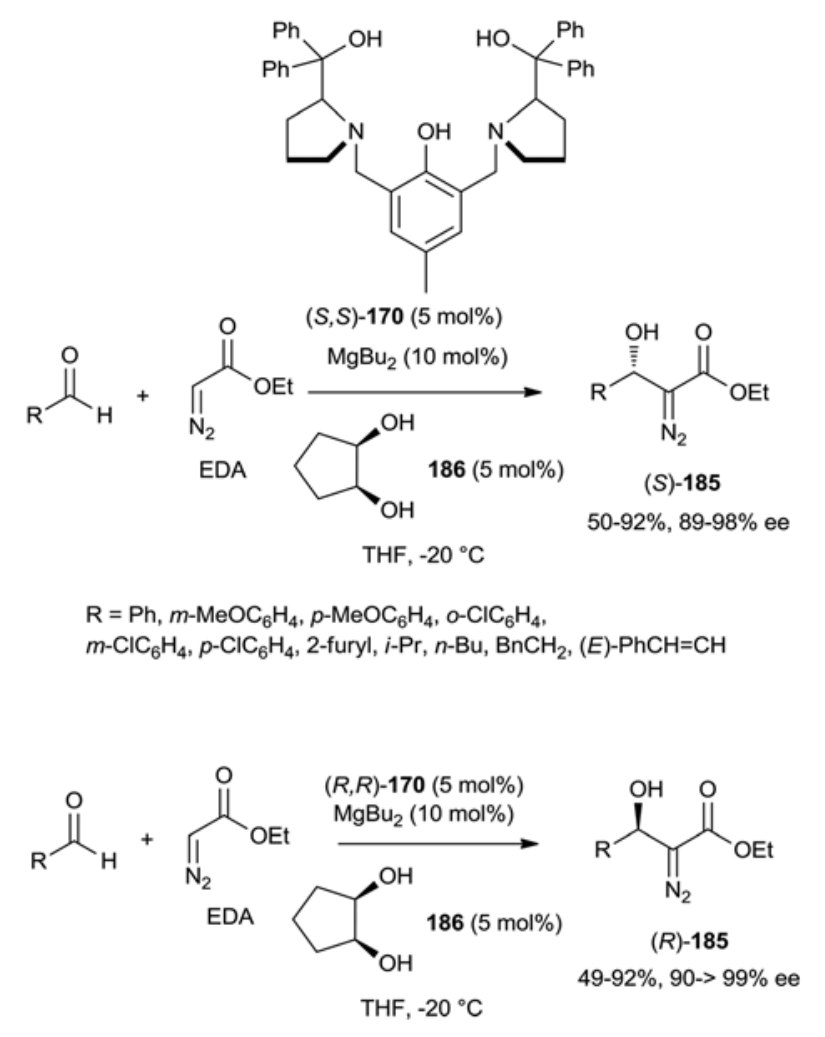

$\mathrm{R}=\mathrm{Ph}, m-\mathrm{MeOC}_{6} \mathrm{H}_{4}, p-\mathrm{MeOC}_{6} \mathrm{H}_{4}, o-\mathrm{ClC}_{6} \mathrm{H}_{4}, m-\mathrm{FC}_{6} \mathrm{H}_{4}, p-\mathrm{FC}_{6} \mathrm{H}_{4}, m-\mathrm{ClC}_{6} \mathrm{H}_{4}$, $p$ - $\mathrm{ClC}_{6} \mathrm{H}_{4}, 2$-furyl, $i$ - $\mathrm{Pr}, n-\mathrm{Bu}, \mathrm{Cy}, \mathrm{Et}, c-\mathrm{Pr}, \mathrm{BnCH}_{2},(E)-(\mathrm{TBS}) \mathrm{CH}=\mathrm{CH}$

Scheme 51 Aldol reactions of ethyl diazoacetate to aldehydes. 
aromatic ones. Using enantiomeric ligand $(R, R)-\mathbf{1 7 0}$ under the same conditions allowed the corresponding enantiomeric products $(R)-\mathbf{1 8 5}$ to be formed with comparable yields (49-92\%) and enantioselectivities (90->99\% ee), as shown in Scheme 51. The synthetic utility of this methodology was demonstrated through the conversion of the products into chiral 1,2-diols bearing a tertiary alcohol through the addition of carbon nucleophiles. $^{89}$

In 2013, Ishihara et al. reported the use of a very simple catalyst system composed of a combination of $\mathrm{MgBu}_{2}$ and $(R)$ BINOL in toluene at $-20{ }^{\circ} \mathrm{C}$ to promote a highly regio- and enantioselective 1,2-hydrophosphonylation of $\alpha, \beta$-unsaturated ketones with dialkyl phosphites. ${ }^{79}$ As shown in Scheme 52, the reaction of variously substituted benzalacetones 187 with dimethyl and diethyl phosphites $\mathbf{1 8 8}$ led to the corresponding chiral tertiary allylic alcohols $\mathbf{1 8 9}$ in moderate to quantitative yields (59-96\%) and good enantioselectivities (81-86\% ee). Both aromatic and heteroaromatic moieties (Ar) in benzalacetones were tolerated. The synthetic utility of this novel practical methodology was demonstrated in the conversion of some products into chiral five-membered oxaphospholanols which are analogues of bioactive materials with anticholinesterase properties.

In addition to enantioselective magnesium-catalyzed 1,2nucleophilic additions to carbonyl compounds, related reactions performed with imines as electrophilic partners have also been recently developed. For example, Antilla et al. have reported a novel methodology to add diphenylphosphine oxide 166a to imines with generally moderate to quantitative yields (65-98\%) and enantioselectivities of up to $99 \%$ ee. ${ }^{90}$ The process was catalyzed with only $5 \mathrm{~mol} \%$ of chiral phosphate magnesium complex 190 in acetonitrile at room temperature, as shown in Scheme 53. Two differently $N$-substituted imines were investigated under these conditions. Benzhydryl imines 191 provided the corresponding chiral $\alpha$-amino phosphine oxide products 192 in moderate to excellent yields (65-97\%) and enantioselectivities (48-96\% ee). The best results were achieved with (hetero)aromatic imines (93-97\% yield, 89-96\% ee) while aliphatic imines provided lower yields (65-92\%) and enantioselectivities (48-86\% ee). Another class of imines 193 derived from $5 H$-dibenzo[a,d]cyclohepten-5-amine was also investigated under the same catalytic conditions but in di-

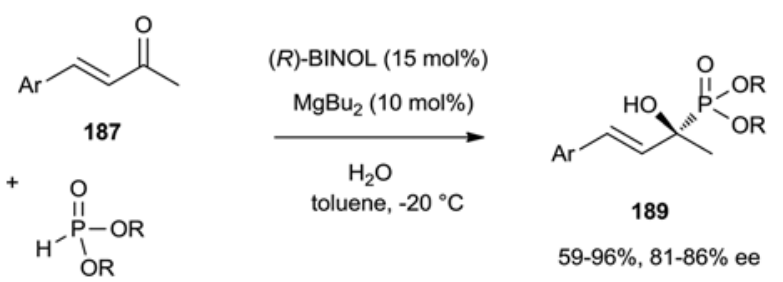

188

$\mathrm{Ar}=\mathrm{Ph}, m-\mathrm{Tol}, 3,5-\mathrm{Cl}_{2} \mathrm{C}_{6} \mathrm{H}_{3}, 3,5-(\mathrm{MeO})_{2} \mathrm{C}_{6} \mathrm{H}_{3}, p-\mathrm{ClC}_{6} \mathrm{H}_{4}$, p- $\mathrm{MeOC}_{6} \mathrm{H}_{4}, 2$-furyl, 2-Naph, 3-thienyl

$\mathrm{R}=\mathrm{Me}$, Et

Scheme 52 1,2-Addition of dialkyl phosphites to benzalacetones.

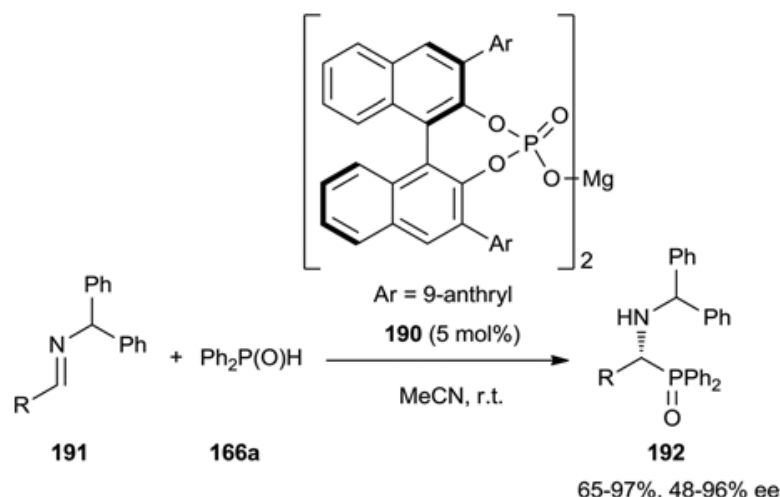

$\mathrm{R}=\mathrm{Ph}, p-\mathrm{MeOC}_{6} \mathrm{H}_{4}, o-\mathrm{Tol}, m-\mathrm{Tol}, p-\mathrm{FC}_{6} \mathrm{H}_{4}, p-\mathrm{BrC}_{6} \mathrm{H}_{4}$, $p-\mathrm{O}_{2} \mathrm{NC}_{6} \mathrm{H}_{4}, 1-\mathrm{Naph}$, 2-furyl, $\mathrm{Cy}, i-\mathrm{Pr}, n-\mathrm{Pr}, n-\mathrm{Bu}, \mathrm{BnCH}_{2}$

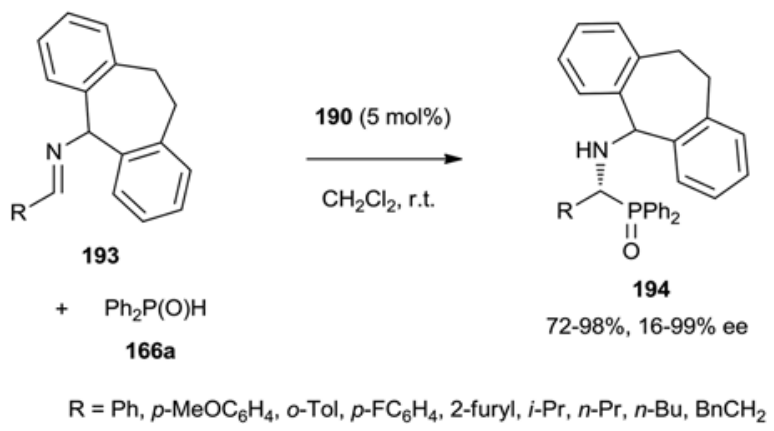

Scheme 53 Additions of diphenylphosphine oxide to aldimines.

chloromethane instead of acetonitrile as solvent (Scheme 53). Most substrates led to the corresponding products 194 with comparable yields (72-98\%) and slightly better enantioselectivities (74-99\% ee) than those derived from benzhydryl imines with the exception of para-fluorophenyl-substituted imine, which afforded the corresponding product with only $16 \%$ ee.

The Mannich reaction, ${ }^{91}$ occurring between a Schiff base and a nucleophile, constitutes one of the most powerful reactions for the construction of nitrogen-containing products. ${ }^{92}$ Over the past two decades, the catalytic asymmetric Mannich reaction, ${ }^{93}$ which allows biologically important chiral $\beta$-amino carbonyl compounds and derivatives to be easily prepared, ${ }^{94}$ has been widely investigated on the basis of using either chiral organometallic catalysts or organocatalysts. ${ }^{95}$ In 2010, Ishihara et al. developed the first enantioselective magnesium-catalyzed Mannich-type reaction of various dialkyl malonates 150 with (hetero)aryl aldimines $195 .{ }^{96}$ Remarkably, this very simple process employed a combination of $\mathrm{MgBu}_{2}$ and $(R)$-BINOL as a catalyst system in toluene at $-20^{\circ} \mathrm{C}$, as shown in Scheme 54 . It afforded a series of chiral amines 196 in almost quantitative yields (91->99\%) and high enantioselectivities (87-95\% ee) in most cases.

The asymmetric hydrocyanation of imino compounds, known as the Strecker reaction, represents an indispensable synthetic procedure for producing chiral $\alpha$-amino nitriles, which constitute highly important precursors of natural and 
<smiles>[R]N=C([18OH])[18OH]</smiles>

150
$55->99 \%, 81-95 \%$ ee

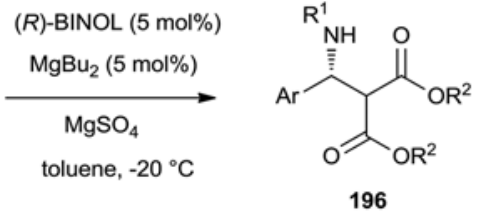

$\mathrm{Ar}=\mathrm{Ph}, p-\mathrm{ClC}_{6} \mathrm{H}_{4}, m-\mathrm{Tol}, 3,4-(\mathrm{MeO})_{2} \mathrm{C}_{6} \mathrm{H}_{3}$

2-furyl, 3-thienyl, 3-pyridyl, 1-Naph

$\mathrm{R}^{1}=\mathrm{Boc}, \mathrm{Cbz}$

$\mathrm{R}^{2}=\mathrm{Me}, n-\mathrm{Pr}$, allyl, $\mathrm{Bn}$

Scheme 54 Mannich-type reaction of aldimines with dialkyl malonates.

non-natural $\alpha$-amino acids, as well as various useful building blocks in synthesis. ${ }^{97}$ Numerous variants of this reaction have been reported based on the use of HCN or TMSCN as the cyanide source. Due to their toxicity, volatility and hazardous handling, alternative cyanide sources have been developed such as acetone cyanohydrin 197. In particular, this reagent was used in magnesium-mediated asymmetric Strecker-type reactions of nitrones 198 to give the corresponding chiral $\alpha$-amino nitrile derivatives $199 .{ }^{98}$ As shown in Scheme 55, the

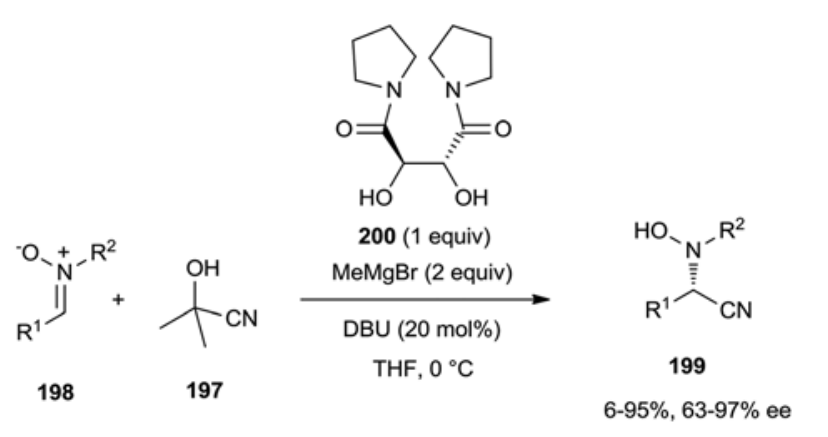

$\mathrm{R}^{1}=\mathrm{Ph}, p-\mathrm{MeOC}_{6} \mathrm{H}_{4}, p-\mathrm{ClC}_{6} \mathrm{H}_{4}, p-\mathrm{BrC}_{6} \mathrm{H}_{4}, 1-\mathrm{Naph}, 2-\mathrm{Naph}, \mathrm{Me}, \mathrm{Cy}, t-\mathrm{Bu}$ $\mathrm{R}^{2}=\mathrm{Bn}, \mathrm{Me}, \mathrm{Ph}, \mathrm{Ph}_{2} \mathrm{CH}$

possible mechanism:

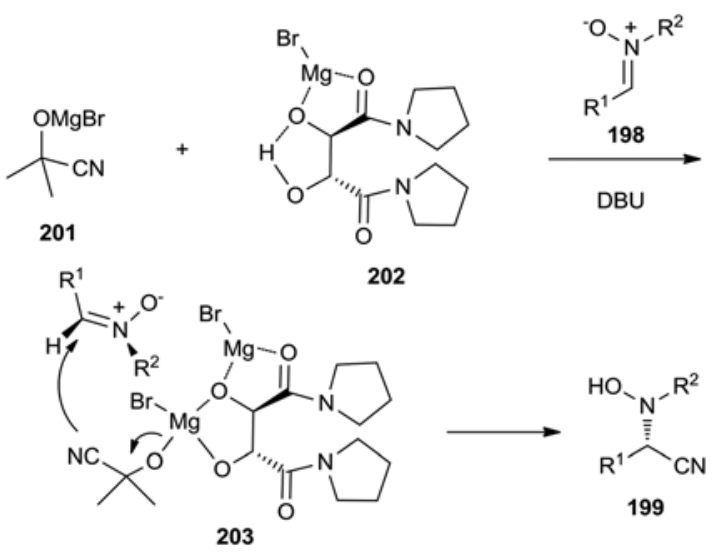

Scheme 55 Strecker-type reaction of nitrones. process was mediated by a magnesium complex derived from one equivalent of tartramide $\mathbf{2 0 0}$ and two equivalents of $\mathrm{MeMgBr}$ in $\mathrm{THF}$ at $0{ }^{\circ} \mathrm{C}$ in the presence of DBU as a base. Various $N$-benzyl nitrones were compatible with the process. While $N$-benzyl aryl nitrones $\left(\mathrm{R}^{1}=\right.$ aryl, $\left.\mathrm{R}^{2}=\mathrm{Bn}\right)$ provided higher enantioselectivities (85-96\% ee vs. $73-87 \%$ ee) than $N$-benzyl alkyl nitrones $\left(\mathrm{R}^{1}=\right.$ alkyl, $\left.\mathrm{R}^{2}=\mathrm{Bn}\right)$, the latter gave higher yields than the former (90-95\% vs. 63-89\%). The influence of the substituents on the nitrogen of the nitrones was also investigated, showing that an $N$-benzyl nitrone $\left(\mathrm{R}^{2}=\mathrm{Bn}\right)$ led to the corresponding product in 58\% yield and $96 \%$ ee whereas an $N$-methyl $\left(\mathrm{R}^{2}=\mathrm{Me}\right)$ and an $N$-phenyl $\left(\mathrm{R}^{2}=\mathrm{Ph}\right)$ nitrones reacted with lower yields (6-47\%) and enantioselectivities $(63-72 \%$ ee). The authors have proposed a possible mechanism depicted in Scheme 55 in which bromomagnesium salts 201 and 202 were formed when acetone cyanohydrin 197 was treated with $\mathrm{MeMgBr}_{2}$ and chiral tartramide 200. In the presence of $\mathrm{DBU}$, deprotonation of 202 occurred to give tartramide-magnesium ate complex 203, to which the nitrone coordinated. A subsequent transcyanation proceeded from the $R e$-face of the nitrone to afford the final $(S)$-product 199.

\section{Magnesium-catalyzed $\alpha$-functionalizations of carbonyl compounds}

The electrophilic amination reaction constitutes a direct method to stereoselectively form $\mathrm{C}-\mathrm{N}$ bonds, a fundamental process in both organic chemistry and biochemistry. In particular, the asymmetric $\alpha$-amination of carbonyl compounds is an efficient route to important chiral $\alpha$-amino acid derivatives. ${ }^{99}$ Consequently, much progress has been made in the enantioselective $\alpha$-amination of carbonyl compounds, such as aldehydes, ketones, $\alpha$-ketoesters, $\alpha$-cyano esters, and other compounds, using azodicarboxylates as the nitrogen source since the pioneering work reported by Evans and Nelson in $1997 .^{100}$ It dealt with the reaction between $\mathrm{N}$-acyloxazolidinones and di-tert-butyl azodicarboxylate to give the corresponding chiral hydrazides in remarkable enantioselectivities ( $96 \%->99 \%$ ee) by using a chiral bis(sulfonamide) ligand. More recently, Yamamoto and Maji reported the first example of a Lewis acid-catalyzed asymmetric hydroamination of $\beta$-ketoesters with nitrosocarbonyl compounds generated in situ. ${ }^{101}$ Among the various Lewis acids investigated, including $\mathrm{Ni}(\mathrm{OTf})_{2}, \mathrm{Zn}(\mathrm{OTf})_{2}, \mathrm{Ca}(\mathrm{OTf})_{2}, \mathrm{Sr}(\mathrm{OTf})_{2}, \mathrm{Sc}(\mathrm{OTf})_{3}, \mathrm{Cu}(\mathrm{OTf})_{2}$, $\mathrm{Mg}\left(\mathrm{ClO}_{4}\right)_{2}, \mathrm{Mg}(\mathrm{NTf})_{2}$ and $\mathrm{Mg}(\mathrm{OTf})_{2}$, the latter allowed the best results to be achieved when combined with chiral $N, N^{\prime}$-dioxide ligand 45 in dichloromethane at $23{ }^{\circ} \mathrm{C}$. Under these conditions, the reaction of the nitrosocarbonyl compound, in situ generated from $N$-Boc-hydroxylamine 204 through oxidation with $\mathrm{MnO}_{2}$, with cyclic $\beta$-ketoesters 205 bearing a 1-indanone $(n=0)$ or a 1-tetralone $(n=1)$ subunit led to the corresponding chiral highly substituted quaternary $\beta$-keto amino acid derivatives 206 in both high yields (89-95\%) and enantioselectivities 
(86-95\% ee), as shown in Scheme 56. Remarkably, the regioselectivity ( $\mathrm{N}-v$ s. O-attack) was uniformly high for all substrates $(>20: 1)$. The scope of the process was extended to cyclic $\beta$-ketoesters 207 possessing sensitive cyclohexene and cyclopentene subunits which also delivered the corresponding $\alpha$-aminated products 208 in high yields (83-97\%) with even higher enantioselectivities $(93-96 \%$ ee). Furthermore, very good results were obtained with a range of acyclic $\beta$-ketoesters 209 which led to the corresponding amines 210 in high yields (82-95\%) and enantioselectivities (86-94\% ee). Even the presence of labile functionalities, such as allyl and propargyl groups, did not affect the results, thus demonstrating the mildness of the oxidation/catalytic system.

In 2013, Feng et al. described a rare example of asymmetric magnesium-catalyzed $\alpha$-hydroxylation reactions. ${ }^{102}$ As shown in Scheme 57, the reaction involved the $\alpha$-hydroxylation of $\beta$-ketoesters with tert-butyl hydroperoxide (TBHP) as the oxidant performed in the presence of $10 \mathrm{~mol} \%$ of $\mathrm{Mg}(\mathrm{OTf})_{2}$ and chiral $N, N^{\prime}$-dioxide ligand 45 in dichloromethane at $30^{\circ} \mathrm{C}$ with TMEDA as additive. When 1-tetralone-derived $\beta$-ketoesters $211(n=1)$ were used, the corresponding tertiary alcohols 212 were obtained in moderate to quantitative yields (67-99\%) and

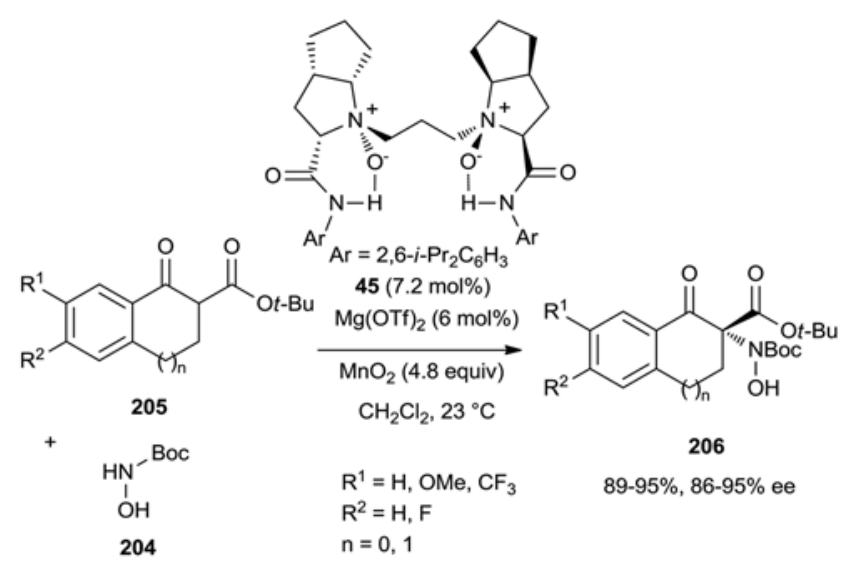

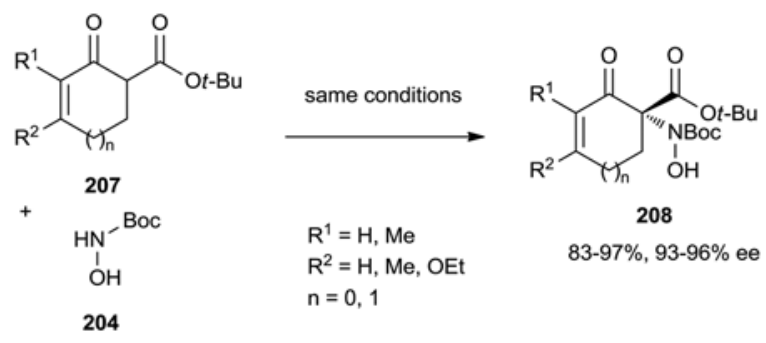

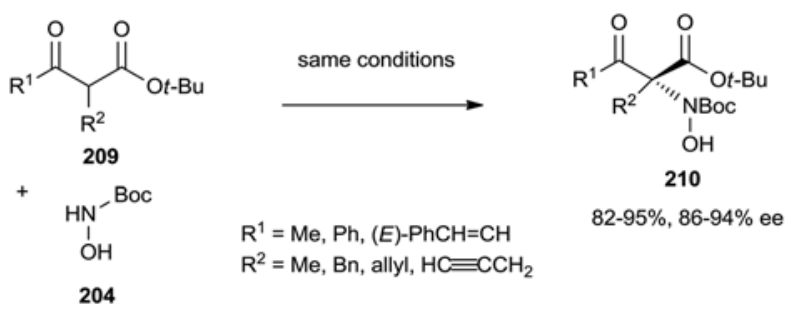

Scheme $56 \alpha$-Amination of $\beta$-ketoesters with $N$-Boc-hydroxylamine.

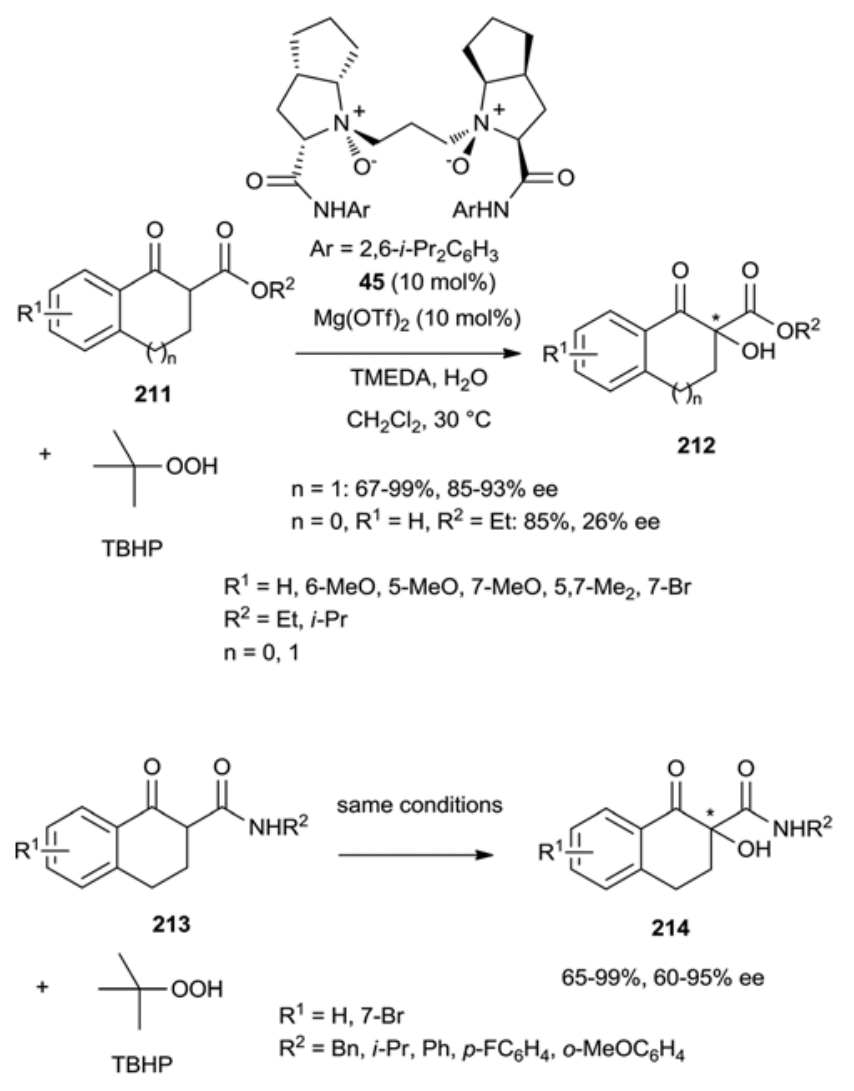

Scheme $57 \alpha$-Hydroxylations of $\beta$-ketoesters and $\beta$-ketoamides with tert-butyl hydroperoxide.

high enantioselectivities (85-93\% ee). Various electron-donating as well as electron-withdrawing substituents $\left(\mathrm{R}^{1}\right)$ were tolerated on the phenyl ring of the tetralone. On the other hand, the reaction of a 1-indanone-derived $\beta$-ketoester $(n=0)$ provided a much lower enantioselectivity (26\% ee) albeit with good yield (85\%). The scope of the methodology was extended to related 1-tetralone-derived $\beta$-ketoamides 213 which afforded the corresponding products $\mathbf{2 1 4}$ in moderate to quantitative yields (65-99\%) and enantioselectivities (60-95\% ee), as shown in Scheme 57 . The best enantioselectivities (92-95\% ee) were achieved with amides bearing an aliphatic substituent on the nitrogen atom $\left(\mathrm{R}^{2}\right)$ while lower enantioselectivities (60-90\% ee) were obtained in the reaction of amides bearing aromatic substituents. In both cases, the yields were comparable $(71-99 \%$ for the former vs. $65-99 \%$ for the latter). The synthetic utility of this simple novel methodology was demonstrated in the synthesis of an important precursor of the antibiotic daunomycin.

\section{Magnesium-catalyzed hydroamination reactions}

The application of alkaline earth metal complexes as substitutes for transition-metal catalysts in alkene hydrofunctionali- 


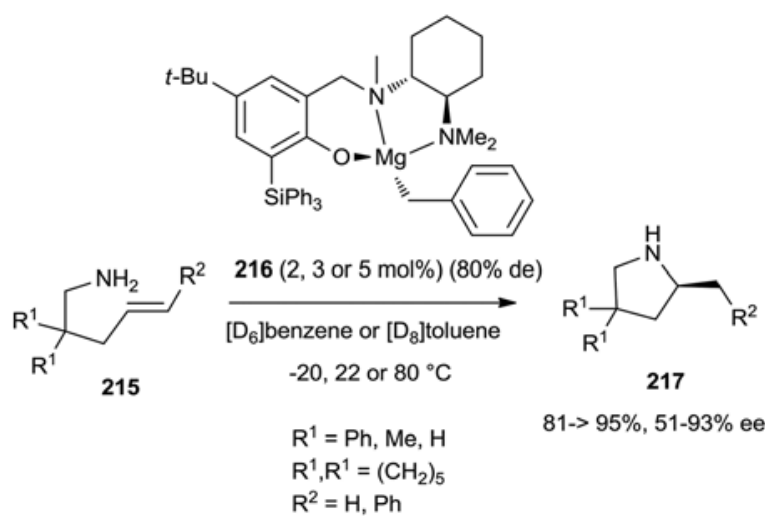

Scheme 58 Hydroamination of aminoalkenes.

zations has drawn increasing attention in recent years. ${ }^{103}$ However, only rare examples dealing with asymmetric versions have been reported. Among them, Hultzsch et al. have developed enantioselective intramolecular magnesiumcatalyzed hydroamination of aminoalkenes 215 performed in the presence of preformed chiral catalyst 216 derived from a chiral phenoxyamine. ${ }^{104}$ As illustrated in Scheme 58, the corresponding chiral pyrrolidines 217 were formed in high yields (81->95\%) and moderate to high enantioselectivities (51-93\% ee). The lowest enantioselectivity of $51 \%$ ee was observed in the case of a non-substituted aminoalkene $\left(\mathrm{R}^{1}=\right.$ $\mathrm{R}^{2}=\mathrm{H}$ ) requiring a reaction temperature of $80{ }^{\circ} \mathrm{C}$ while enantioselectivities of $74-93 \%$ ee were achieved for substituted substrates $\left(\mathrm{R}^{1} \neq \mathrm{H}\right)$ generally reacting below room temperature $\left(-20{ }^{\circ} \mathrm{C}\right)$.

Earlier, enantioselectivities not exceeding $36 \%$ ee were reported by using other chiral magnesium complexes. For example, Sadow et al. previously developed asymmetric hydroamination of C-(1-allyl-cyclohexyl)-methylamine 218 in the presence of chiral tris(oxazolinyl)borate magnesium complex $\mathbf{2 1 9}$ to give the corresponding bicyclic amine 220 in 93\% yield and $36 \%$ ee (Scheme 59). ${ }^{105}$

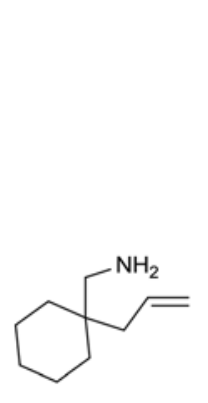

218
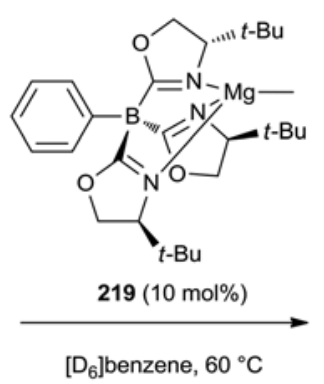

$\left[\mathrm{D}_{6}\right]$ benzene, $60^{\circ} \mathrm{C}$

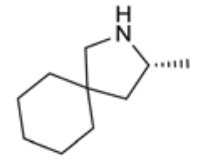

220

$93 \%, 36 \%$ ee

\section{Magnesium-catalyzed miscellaneous reactions}

In 2011, Antilla et al. demonstrated the utility of $(R)$-VAPOLderived phosphate magnesium catalyst 221 to promote an enantioselective aza-Darzens aziridination reaction between $N$-benzoyl aldimines 222 and $\alpha$-chloro-1,3-diketone $223 .{ }^{106}$ The corresponding chiral aziridines $\mathbf{2 2 4}$ were obtained in good yields (52-78\%) and moderate to high enantioselectivities (57-92\% ee), as shown in Scheme 60. A theoretical study of the active catalytic species was undertaken by the authors to explain the stereoselectivity of the process. It showed coordination of the magnesium to the carbonyl groups of the imine and diketone's enol form, as shown in the transition state depicted in Scheme 60. Additionally, the enol could hydrogen bond to an oxygen atom of the catalyst. Indeed, the latter could simultaneously stabilize the nucleophile and electro-<smiles></smiles>

222<smiles>CC(=O)C(Cl)C(C)=O</smiles>

1)

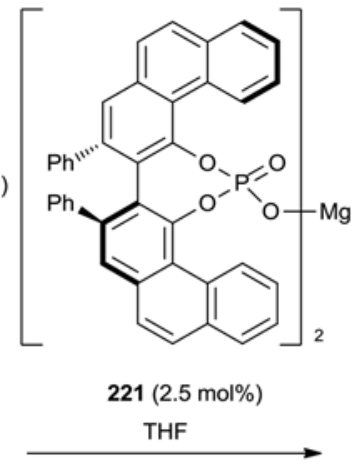

2) DMF, DMAP

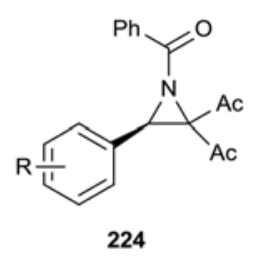

$52-78 \%, 57-92 \%$ ee

\footnotetext{
$\mathrm{R}=\mathrm{H}, 3-\mathrm{Me}, 4-\mathrm{Me}, 2-\mathrm{MeO}, 3-\mathrm{MeO}, 4-\mathrm{MeO}, 4-\mathrm{F}, 4-\mathrm{Cl}, 4-\mathrm{Br}$
}

proposed transition state:

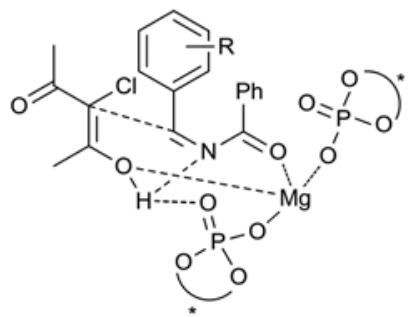

Scheme 59 Hydroamination of an aminoalkene.

Scheme 60 Aza-Darzens aziridination reaction. 


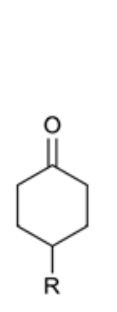

226
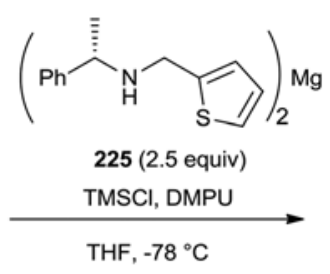

$68-83 \%, 66-74 \%$ ee

$\mathrm{R}=t-\mathrm{Bu}, i-\mathrm{Pr}, n-\mathrm{Pr}, \mathrm{Ph}$, OTBS, Me

Scheme 61 Deprotonation reaction of 4-substituted cyclohexanones.

phile, while providing the chiral requirement for asymmetric induction.

In 2011, Kerr et al. reported the synthesis of novel chiral secondary amines, incorporating a five- or six-membered heterocycle, which were used to prepare new chiral magnesium bisamide complexes. ${ }^{107}$ The latter were investigated in the asymmetric deprotonation of prochiral ketones. For example, a superstoichiometric quantity of thiophene-derived magnesium complex 225 was applied to the asymmetric deprotonation of 4-substituted cyclohexanones 226, which afforded in the presence of TMSCl the corresponding chiral trimethylsilyl ethers 227 in moderate to good yields (68-83\%) and enantioselectivities (66-74\% ee), as shown in Scheme 61.

While numerous enolate transformations, including Michael, Mannich, aldol and $\alpha$-functionalization reactions, may be carried out under catalytic enantioselective conditions, the simple alkylation with an unactivated alkyl halide is often performed using stoichiometric amounts of metal enolates. In the past few years, chiral catalysts have been successfully applied to these reactions including magnesium chiral complexes. For example, a catalyst in situ generated from chiral pybox 228 and $\mathrm{MgBr}_{2}\left(\mathrm{Et}_{2} \mathrm{O}\right)$ was used in chloroform at room
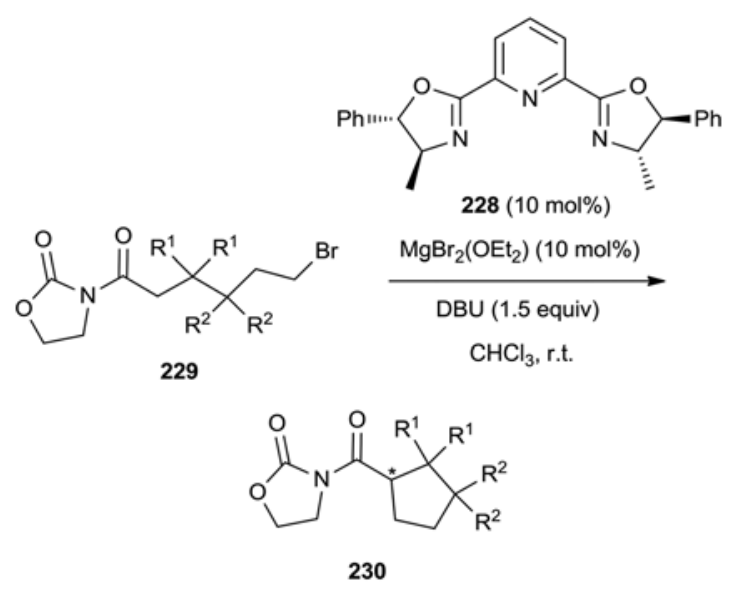

$R^{1}=M e, R^{2}=H: 98 \%, 46 \%$ ee $R^{1}=H, R^{2}=M e: 81 \%, 37 \%$ ee

Scheme 62 Alkylation of oxazolidinone bromoalkanoate imides. temperature by Gleason et al. in the asymmetric intramolecular alkylation of oxazolidinone bromoalkanoate imides 229 performed in the presence of DBU as a base. ${ }^{108}$ As shown in Scheme 62, the process afforded the corresponding functionalized cyclopentanes 230 in high yields (81-98\%) albeit with moderate enantioselectivities (37-46\% ee).

\section{Conclusions}

Even if transition metal chemistry still constitutes the heart of catalysis, environmentally friendly chemical processes are now strongly preferred from the point of view of green sustainable chemistry. In this context, the use of readily available, cheap, and non-toxic alkaline earth metal catalysts, such as magnesium complexes, is highly promising owing to their milder Lewis acidity in comparison with traditional transition metals. This review illustrates how much enantioselective magnesium catalysis has contributed to the development of a wide variety of enantioselective highly efficient ecological and economical reactions. It updates the major progress in the field of enantioselective transformations promoted by chiral magnesium catalysts, illustrating the power of these mild Lewis acid catalysts to provide many novel reactions. Especially in the last decade, a variety of chiral magnesium complexes derived from bis(oxazoline), $N, N^{\prime}$-dioxides, Schiff bases, cinchona alkaloids, BINOL derivatives, and phosphates, among other ligands, have become catalysts of the first choice for many types of asymmetric reactions generally performed under mild reaction conditions. Among them, a number of them have been reported for the first time, including cycloadditions, domino and tandem reactions, ring-opening reactions, Michael reactions, 1,2-nucleophilic additions to carbonyl compounds and imines, $\alpha$-functionalizations of carbonyl compounds, hydroaminations of alkenes, etc., allowing many chiral cyclic as well as acyclic products to be achieved in generally remarkable enantioselectivities. For example, in the area of cycloadditions Ding has reported the first asymmetric magnesium-catalyzed hetero-Diels-Alder reactions of aldehydes and Danishefsky's diene with 99\% ee. Comparable excellent enantioselectivities were also achieved by Feng in the first catalytic asymmetric hetero-Diels-Alder reaction of Brassard's type dienes and isatins. Other than Diels-Alder cycloadditions have encountered success on the basis of asymmetric magnesium catalysis. For example, enantioselectivities of $94 \%$ ee were obtained by Wang in the first enantioselective 1,3-dipolar cycloaddition of 3-isothiocyanato oxindoles with alkynyl ketones. Moreover, several asymmetric magnesium-catalyzed carbonyl ene reactions of trifluoropyruvate with alkenes, 1,2dicarbonyl compounds such as isatins with alkyl enol ethers, or $\beta, \gamma$-unsaturated $\alpha$-ketoesters with 5 -methyleneoxazolines have been reported for the first time by Feng, all providing up to $99 \%$ ee. Furthermore, it is only recently that the first enantioselective magnesium-catalyzed domino reactions have been developed, such as Michael-initiated domino reactions reported by Feng with $96 \%$ ee. A range of other types of highly 
enantioselective domino reactions have also been developed, including domino Mannich/cyclization reactions with 95-99\% ee by Willis and Shibasaki, domino aldol/cyclization reactions by Shibasaki with $99 \%$ ee, and domino $\gamma$-deprotonation/ Michael/cyclization reactions with $99 \%$ ee by Wang, among others. Several multicatalyzed domino reactions have also been very recently described, such as those by Scheidt and Gong, among others, in which magnesium complexes interact with organocatalysts, such as phosphoric acids or $\mathrm{N}$-heterocyclic carbene catalysts. In addition, highly efficient tandem ring-opening/ring-closing reactions have been described by Wang with $>99 \%$ ee. Another type of highly enantioselective magnesium-catalyzed tandem reaction was developed by this author, involving 3-isothiocyanato oxindoles and $N$-(2-picolinoyl)aziridines as substrates and constituting the first asymmetric formal $[3+3]$ cycloaddition with aziridines. In the last decade, a range of chiral magnesium catalysts derived from different types of ligands, including $N, N^{\prime}$ dioxides, cinchona alkaloids, amino alcohols, phosphates and BINOL derivatives, have also been successfully applied to ringopening reactions of meso-aziridines with a variety of nucleophiles, yielding many valuable chiral nitrogen-containing products. In the area of Michael additions, many interesting results have been recently reported. Thus, heterogeneous Michael additions of malonates to $\alpha, \beta$-unsaturated ketones were achieved with $96 \%$ ee by Kantam. Moreover, Michael additions of alkenylboronic acids to indole-appended $\alpha, \beta$-unsaturated ketones were developed with $99 \%$ ee by May, Michael additions of a $\alpha, \beta$-unsaturated $\gamma$-butyrolactam to $\alpha, \beta$-unsaturated ketones and $\alpha, \beta$-unsaturated $N$-acylpyrroles with $98 \%$ ee by Wang, and Michael additions of diaryl phosphine oxides to $\alpha, \beta$-unsaturated esters with $96 \%$ ee by Ishihara, along with a rare example of dearomatization of naphthols described by Wang which was based on a catalytic asymmetric conjugate addition performed with $98 \%$ ee. Other types of reactions, such as various 1,2-nucleophilic additions to carbonyl compounds and imines, have been successfully described by using chiral magnesium catalysts. Among them are aldol reactions of ethyl diazoacetate with aldehydes developed with $>99 \%$ ee by Trost, a novel methodology reported by Antilla to add diphenylphosphine oxide to imines with up to $99 \%$ ee, as well as the first enantioselective magnesium-catalyzed Mannich-type reactions of various dialkyl malonates with (hetero)aryl aldimines achieved with $95 \%$ ee by Ishihara. Miscellaneous reactions have also been recently developed on the basis of magnesium asymmetric catalysis, such as $\alpha$-functionalizations of carbonyl compounds. For example, Yamamoto and Maji have reported the first example of a Lewis acid-catalyzed asymmetric hydroamination of $\beta$-ketoesters with nitrosocarbonyl compounds generated in situ, which provided up to $96 \%$ ee. All these excellent results have demonstrated the remarkable efficiency of green magnesium complexes to be substitutes of transition-metal catalysts in asymmetric catalysis, owing to their mild Lewis acidity, opening the way for developing new catalytic systems to perform reactions, such as $\mathrm{C}-\mathrm{C}$ bond formations, $\mathrm{C}-$ heteroatoms bond formations or $\mathrm{C}-\mathrm{H}$ functionalizations under more environmentally friendly conditions. Indeed, with the environmentally benign properties of magnesium as an inexpensive, non-toxic, and abundant metal, the asymmetric magnesium catalysis is expected to become an unavoidable tool in the near future.

\section{References}

1 (a) R. Noyori, Asymmetric Catalysts in Organic Synthesis, Wiley-VCH, New-York, 1994; (b) M. Nogradi, Stereoselective Synthesis, Wiley-VCH, Weinheim, 1995; (c) M. Beller and C. Bolm, Transition Metals for Organic Synthesis, WileyVCH, Weinheim, 1998, vols I and II; (d) E. N. Jacobsen, A. Pfaltz and H. Yamamoto, Comprehensive Asymmetric Catalysis, Springer, Berlin, 1999; (e) I. Ojima, Catalytic Asymmetric Synthesis, Wiley-VCH, New-York, 2nd edn, 2000; $(f)$ G. Poli, G. Giambastiani and A. Heumann, Tetrahedron, 2000, 56, 5959; $(g)$ E. Negishi, Handbook of Organopalladium Chemistry for Organic Synthesis, John Wiley \& Sons, Inc., Hoboken, NJ, 2002, vol. 2, p. 1689; (h) A. de Meijere, P. von Zezschwitz, H. Nüske and B. Stulgies, J. Organomet. Chem., 2002, 653, 129; (i) M. Beller and C. Bolm, Metals for Organic Synthesis, Wiley-VCH, Weinheim, 2nd edn, 2004; $(j)$ L. F. Tietze, I. Hiriyakkanavar and H. P. Bell, Chem. Rev., 2004, 104, 3453; (k) D. J. Ramon and M. Yus, Chem. Rev., 2006, 106, 2126; (l) H. Pellissier and H. Clavier, Chem. Rev., 2014, 114, 2775; (m) H. Pellissier, Coord. Chem. Rev., 2015, 284, 93; (n) T. Yasukawa, H. Miyamura and S. Kobayashi, ACS Adv., 2016, 6, 7979; (o) H. Pellissier, Coord. Chem. Rev., 2016, 313, 1; $(p)$ J. Wencel-Delord and F. Colobert, Synthesis, 2016, 2981; (q) H. Pellissier, Enantioselective Titanium-Catalysed Transformations, Imperial College Press, London, 2016; ( $r$ ) H. Yang, X. Yang and W. Tang, Tetrahedron, 2016, 72, 6143; $(s)$ H. Pellissier, Enantioselective Nickel-Catalysed Transformations, Royal Society of Chemistry, Southampton, 2016; $(t)$ H. Groeger, Eur. J. Org. Chem., 2016, 4116; (u) H. Pellissier, Adv. Synth. Catal., 2016, 358, 2194; (v) H. Pellissier, Coord. Chem. Rev., 2016, 324, 17; (w) H. Pellissier, Chem. Rev., 2016, 116, 14868; (x) X. Chen and Z. Lu, Org. Biomol. Chem., 2017, 15, 2280; (y) C. G. Newton, S.-G. Wang, C. C. Oliveira and N. Cramer, Chem. Rev., 2017, DOI: 10.1021/acs. chemrev.6b00692.

2 E. J. Corey and K. Ishihara, Tetrahedron Lett., 1992, 33, 6807.

3 M. Hatano and K. Ishihara, in Acid Catalysis in Modern Organic Synthesis, ed. H. Yamamoto and K. Ishihara, Wiley-VCH, Weinheim, 2008, p. 135.

4 Y. Motoyama and H. Nishiyama, in Lewis Acids in Organic Synthesis, ed. H. Yamamoto, Wiley, Weinheim, 2000, vol. 1 , p. 59.

5 K. Afarinkia, J. Chem. Soc., Perkin Trans. 1, 1999, 2025.

6 M. L. Kantam and V. R. Chintareddy, in Hybrid Nanomaterials: Synthesis, Characterization, and 
Applications, ed. B. P. S. Chauhan, Wiley, Hoboken, 2011, p. 139.

7 S. Harder, Alkaline-Earth Metal Compounds: Oddities and Applications, Springer, Heidelberg, 2013.

8 R. Rochat, M. J. Lopez, H. Tsurugi and K. Mashima, ChemCatChem, 2016, 8, 10.

9 L. Hong, W. Sun and R. Wang, in Sustainable Catalysis With Non-endangered Metals, Part 1, ed. M. North, Royal Society of Chemistry, Cambridge, 2016, p. 49.

10 H. B. Kagan and O. Riant, Chem. Rev., 1992, 92, 1007.

11 (a) P. Goodrich, C. Hardacre, C. Paun, A. Ribeiro, S. Kennedy, M. J. V. Lourenço, H. Manyar, C. A. Nieto de Castro, M. Besnea and V. I. Pârvulescu, Adv. Synth. Catal., 2011, 353, 995; (b) P. Goodrich, C. Hardacre, C. Paun, V. I. Pârvulescu and I. Podolean, Adv. Synth. Catal., 2008, 350, 2473.

12 S. S. Girija and Y. D. Zelalem, Chem. Rev., 2012, 112, 6104.

13 G. Li, T. Liang, L. Wojtas and J. C. Antilla, Angew. Chem., Int. Ed., 2013, 52, 4628.

14 (a) S. Danishefsky, Acc. Chem. Res., 1981, 14, 400; (b) H. Waldmann, Synthesis, 1994, 535; (c) L. F. Tietze and G. Kettschau, Top. Curr. Chem., 1997, 189, 1; (d) E. J. Corey, Angew. Chem., Int. Ed., 2002, 41, 1650; (e) K. C. Nicolaou, S. A. Snyder, T. Montagnon and G. E. Vassilikogiannakis, Angew. Chem., Int. Ed., 2002, 41, 1668; $(f)$ K. A. Jørgensen, Eur. J. Org. Chem., 2004, 2093; $(g)$ H. Pellissier, Tetrahedron, 2012, 68, 2197; (h) M. M. Heravi, T. Ahmadi, M. Ghavidel, B. Heidari and H. Hamidi, RSC Adv., 2015, 5, 101999; (i) G. Blond, M. Gulea and V. Mamane, Curr. Org. Chem., 2016, 20, 2161; (j) F. Gallier, Curr. Org. Chem., 2016, 20, 2222.

15 S. Bromidge, P. C. Wilson and A. A. Whiting, Tetrahedron Lett., 1998, 39, 8905.

16 H. Du, X. Zhang, Z. Wang, H. Bao, T. You and K. Ding, Eur. J. Org. Chem., 2008, 2248.

17 M. Hatano, T. Horibe, K. Yamashita and K. Ishihara, Asian J. Org. Chem., 2013, 2, 952.

18 J. Zheng, L. Lin, Y. Kuang, J. Zhao, X. Liu and X. Feng, Chem. Commun., 2014, 50, 994.

19 J. Zheng, L. Lin, K. Fu, Y. Zhang, X. Liu and X. Feng, Chem. - Eur. J., 2014, 20, 14493.

20 R. Huisgen, Angew. Chem., Int. Ed. Engl., 1963, 75, 604.

21 (a) K. V. Gothelf and K. A. Jørgensen, Chem. Rev., 1998, 98, 863; (b) G. Pandey, P. Banerjee and S. R. Gadre, Chem. Rev., 2006, 106, 4484; (c) H. Pellissier, Tetrahedron, 2007, 63, 3235; (d) L. M. Stanley and M. P. Sibi, Chem. Rev., 2008, 108, 2887; (e) C. Najera and J. M. Sansano, Org. Biomol. Chem., 2009, 7, 4567; ( $f$ ) M. Kissane and A. R. Maguire, Chem. Soc. Rev., 2010, 39, 845; (g) J. Adrio and J. C. Carretero, Chem. Commun., 2011, 47, 6784; (h) A. Moyano and R. Rios, Chem. Rev., 2011, 111, 4703; (i) Y. Xing and N. X. Wang, Coord. Chem. Rev., 2012, 256, 938; (j) A. D. Lim, J. A. Codelli and S. E. Reisman, Chem. Sci., 2013, 4, 650; (k) C. Najera and J. M. Sansano, J. Organomet. Chem., 2014, 771, 78; (l) E. E. Maroto, M. Izquierdo, S. Reboredo, J. Marco-Martinez, S. Filippone and N. Martin, Acc. Chem. Res., 2014, 47, 2660; (m) J. Adrio and J. C. Carretero, Chem. Commun., 2014, 50, 12434; (n) T. Hashimoto and K. Maruoka, Chem. Rev., 2015, 115, 5366.

22 K. V. Gothelf, R. G. Hazell and K. A. Jørgensen, J. Org. Chem., 1996, 61, 346.

23 H. Yamamoto, S. Hayashi, M. Kubo, M. Harada, M. Hasegawa, M. Noguchi, M. Sumimoto and K. Hori, Eur. J. Org. Chem., 2007, 2859.

24 A. T. Parsons and J. S. Johnson, J. Am. Chem. Soc., 2009, 131, 3122.

25 A. T. Parsons, A. G. Smith, A. J. Néel and J. S. Johnson, J. Am. Chem. Soc., 2010, 132, 9688.

26 A. L. Gerten, M. C. Slade, K. M. Pugh and L. M. Stanley, Org. Biomol. Chem., 2013, 11, 7834.

27 L. Wang, D. Yang, F. Han, D. Li, D. Zhao and R. Wang, Org. Lett., 2015, 17, 176.

28 L. Wang, D. Yang, D. Li, X. Liu, Q. Zhao, R. Zhu, B. Zhang and R. Wang, Org. Lett., 2015, 17, 4260.

29 X. Liu, K. Zheng and X. Feng, Synthesis, 2014, 2241.

30 K. Zheng, Y. Yang, J. Zhao, C. Yin, L. Lin, X. Liu and X. Feng, Chem. - Eur. J., 2010, 16, 9969.

31 K. Zheng, C. Yin, X. Liu, L. Lin and X. Feng, Angew. Chem., Int. Ed., 2011, 50, 2573.

32 W. Luo, J. Zhao, J. Ji, L. Lin, X. Liu, H. Mei and X. Feng, Chem. Commun., 2015, 51, 10042.

33 (a) L. F. Tietze and U. Beifuss, Angew. Chem., Int. Ed. Engl., 1993, 32, 131; (b) L. F. Tietze, Chem. Rev., 1996, 96, 115; (c) L. F. Tietze, G. Brasche and K. Gericke, Domino Reactions in Organic Synthesis, Wiley-VCH, Weinheim, 2006; (d) L. F. Tietze, Domino Reactions, Concepts for Efficient Organic Synthesis, Wiley-VCH, Weinheim, 2014.

34 (a) D. J. Ramon and M. Yus, Angew. Chem., Int. Ed., 2005, 44, 1602; (b) J. Zhu and H. Bienaymé, Multicomponent Reactions, Wiley-VCH, Weinheim, 2005; (c) D. Enders, C. Grondal and M. R. M. Hüttl, Angew. Chem., Int. Ed., 2007, 46, 1570; (d) D. M. D'Souza and T. J. J. Müller, Chem. Soc. Rev., 2007, 36, 1095; (e) C. J. Chapman and C. G. Frost, Synthesis, 2007, 1; (f) A.-N. Alba, X. Companyo, M. Viciano and R. Rios, Curr. Org. Chem., 2009, 13, 1432; $(g)$ J. E. Biggs-Houck, A. Younai and J. T. Shaw, Curr. Opin. Chem. Biol., 2010, 14, 371; (h) R. V. A. Orru and E. Ruijter, Synthesis of Heterocycles via Multicomponent Reactions, Topics in Heterocyclic Chemistry, Springer, Berlin, 2010, vols. I and II; (i) M. Ruiz, P. Lopez-Alvarado, G. Giorgi and J. C. Menéndez, Chem. Soc. Rev., 2011, 40, 3445; (j) L. Albrecht, H. Jiang and K. A. Jørgensen, Angew. Chem., Int. Ed., 2011, 50, 8492; (k) C. De Graaff, E. Ruijter and R. V. A. Orru, Chem. Soc. Rev., 2012, 41, 3969.

35 (a) C. Hulme and V. Gore, Curr. Med. Chem., 2003, 10, 51; (b) H. Pellissier, Tetrahedron, 2006, 62, 1619; (c) H. Pellissier, Tetrahedron, 2006, 62, 2143; (d) A. Padwa and S. K. Bur, Tetrahedron, 2007, 63, 5341; (e) G. Guillena, D. J. Ramon and M. Yus, Tetrahedron: Asymmetry, 2007, 18, 693; $(f)$ M. Colombo and I. Peretto, Drug Discovery 
Today, 2008, 13, 677; (g) B. B. Touré and D. G. Hall, Chem. Rev., 2009, 109, 4439; (h) K. C. Nicolaou and J. S. Chen, Chem. Soc. Rev., 2009, 38, 2993; (i) C. Grondal, M. Jeanty and D. Enders, Nat. Chem., 2010, 2, 167; (j) H. Pellissier, Adv. Synth. Catal., 2012, 354, 237; (k) H. Clavier and H. Pellissier, Adv. Synth. Catal., 2012, 354, 3347; (l) H. Pellissier, Chem. Rev., 2013, 113, 442; (m) H. Pellissier, Asymmetric Domino Reactions, Royal Society of Chemistry, Cambridge, 2013; (n) P. Chauhan, S. Mahajan, U. Kaya, D. Hack and D. Enders, Adv. Synth. Catal., 2015, 357, 253; (o) V. Michelet, Top. Curr. Chem., 2015, 357, 95; ( $p$ ) G. Eppe, D. Didier and I. Marek, Chem. Rev., 2015, 115, 9175; (q) S. A. Snyder, Applications of Domino Transformations in Organic Synthesis, Thieme, Stuttgart, 2016, vols 1 and 2.

36 X. Zhao, X. Liu, H. Mei, J. Guo, L. Lin and L. Feng, Angew. Chem., Int. Ed., 2015, 54, 4032.

37 X. Zhao, X. Liu, Q. Xiong, H. Mei, B. Ma, L. Lin and X. Feng, Chem. Commun., 2015, 51, 16076.

38 W. Luo, X. Yuan, L. Lin, P. Zhou, X. Liu and X. Feng, Chem. Sci., 2016, 7, 4736.

39 G. A. Cutting, N. E. Stainforth, M. P. John, G. KociokKöhn and M. C. Willis, J. Am. Chem. Soc., 2007, 129, 10632.

40 G. Lu, T. Yoshino, H. Morimoto, S. Matsunaga and M. Shibasaki, Angew. Chem., Int. Ed., 2011, 50, 4382.

41 R. Mahrwald, Modern Aldol Reactions, Wiley-VCH, Weinheim, 2004.

42 T. Yoshino, H. Morimoto, G. Lu, S. Matsunaga and M. Shibasaki, J. Am. Chem. Soc., 2009, 131, 17082.

43 C. Taillier and M. Lautens, Org. Lett., 2007, 9, 591.

44 S. Murarka, I. Deb, C. Zhang and D. Seidel, J. Am. Chem. Soc., 2009, 131, 13226.

45 L. Chen, L. Zhang, J. Lv, J.-P. Cheng and S. Luo, Chem. Eur. J., 2012, 18, 8891.

46 D. Yang, L. Wang, F. Han, D. Zhao, B. Zhang and R. Wang, Angew. Chem., Int. Ed., 2013, 52, 6739.

47 (a) J.-A. Ma and D. Cahard, Angew. Chem., Int. Ed., 2004, 43, 4566; (b) M. Kanai, N. Kato, E. Ichikawa and M. Shibasaki, Synlett, 2005, 1491; (c) D. H. Paull, C. J. Abraham, M. T. Scerba, E. Alden-Danforth and T. Leckta, Acc. Chem. Res., 2008, 41, 655; (d) Z. Shao and H. Zhang, Chem. Soc. Rev., 2009, 38, 2745; (e) C. Zhong and X. Shi, Eur. J. Org. Chem., 2010, 2999; ( $f$ ) M. Rueping, R. M. Koenigs and I. Atodiresei, Chem. - Eur. J., 2010, 16, 9350; (g) J. Zhou, Chem. - Asian J., 2010, 5, 422; (h) L. M. Ambrosini and T. H. Lambert, ChemCatChem, 2010, 2, 1373; (i) S. Piovesana, D. M. Scarpino Schietroma and M. Bella, Angew. Chem., Int. Ed., 2011, 50, 6216; (j) N. T. Patil, V. S. Shinde and B. Gajula, Org. Biomol. Chem., 2012, 10, 211; (k) A. E. Allen and D. W. C. MacMillan, Chem. Sci., 2012, 3, 633; (l) Z. Du and Z. Shao, Chem. Soc. Rev., 2013, 42, 1337.

48 (a) J. Zhou, Chem. - Asian J., 2010, 5, 422; (b) A. E. Allen and D. W. C. MacMillan, Chem. Sci., 2012, 10, 211; (c) H. Pellissier, Tetrahedron, 2013, 69, 7171; (d) Z. Du and Z. Shao, Chem. Soc. Rev., 2013, 42, 1337; (e) H. Pellissier, Enantioselective Multicatalyzed Tandem Reactions, Royal Society of Chemistry, Cambridge, 2014; $(f)$ X.-P. Zeng and J. Zhou, in Multicatalyst System in Asymmetric Catalysis, ed. J. Zhou, Wiley, New York, 2015.

49 D. E. A. Raup, B. Cardinal-David, D. Holte and K. A. Scheidt, Nat. Chem., 2010, 2, 766.

50 L. Ren, T. Lei, J.-X. Ye and L.-Z. Gong, Angew. Chem., Int. Ed., 2012, 51, 771.

51 D. Yang, L. Wang, F. Han, D. Zhao and R. Wang, Chem. Eur. J., 2014, 20, 8584.

52 Z. Mao, F. Mo and X. Lin, Synlett, 2016, 546.

53 (a) Z. Zhang and J. C. Antilla, Angew. Chem., Int. Ed., 2012, 51, 11778; (b) C. Vaxelaire, P. Winter and M. Christmann, Angew. Chem., Int. Ed., 2011, 50, 3605.

54 S. K. Nimmagadda, Z. Zhang and J. C. Antilla, Org. Lett., 2014, 16, 4098.

55 L. Wang, D. Yang, D. Li and R. Wang, Org. Lett., 2015, 17, 3004 .

56 C. Wang, L. Luo and H. Yamamoto, Acc. Chem. Res., 2016, 49, 193.

57 H. Bao, J. Wu, H. Li, Z. Wang, T. You and K. Ding, Eur. J. Org. Chem., 2010, 6722.

58 H. Bao, Z. Wang, T. You and K. Ding, Chin. J. Chem., 2013, 31, 67.

59 (a) A. Padwa, in Comprehensive Organic Synthesis, ed. B. M. Trost and I. Fleming, Pergamon, Oxford, 1991, vol. 4, ch. 4.9, p. 1069; (b) W. McCoull and F. A. Davis, Synthesis, 2000, 1347; (c) B. Zwanenburg and P. ten Holte, in Stereoselective Heterocyclic Synthesis III, ed. P. Metz, Topics in Current Chemistry, Springer, Berlin, 2001, vol. 216, pp. 93-124; (d) J. B. Sweeney, Chem. Soc. Rev., 2002, 31, 247; (e) X. E. Hu, Tetrahedron, 2004, 60, 2701; (f) A. Yudin, in Aziridines and Epoxides in Organic Synthesis, ed. A. K. Yudin, Wiley-VCH, Weinheim, 2006; (g) S. Florio and R. Luisi, Chem. Rev., 2010, 110, 5128; (h) P. Lu, Tetrahedron, 2010, 66, 2549.

60 J. Li, Y. Liao, Y. Zhang, X. Liu, L. Lin and X. Feng, Chem. Commun., 2014, 50, 6672.

61 D. Yang, L. Wang, F. Han, D. Li, D. Zhao, Y. Cao, Y. Ma, W. Kong, Q. Sun and R. Wang, Chem. - Eur. J., 2014, 20, 16478.

62 D. Yang, L. Wang, F. Han, D. Li, D. Zhao and R. Wang, Angew. Chem., Int. Ed., 2015, 54, 2185.

63 D. Li, L. Wang, D. Yang, B. Zhang and R. Wang, ACS Catal., 2015, 5, 7432.

64 L. Wang, D. Li, D. Yang, K. Wang, J. Wang, P. Wang, W. Su and R. Wang, Chem. - Asian J., 2016, 11, 691.

65 D. Li, Y. Wang, L. Wang, J. Wang, P. Wang, K. Wang, L. Lin, D. Liu, X. Jiang and D. Yang, Chem. Commun., 2016, 52, 9640.

66 G. Della Sala, Tetrahedron, 2013, 69, 50.

67 (a) O. Lifchits, D. Alberico, I. Zakharian and A. B. Charette, J. Org. Chem., 2008, 73, 6838; (b) K. Sapeta and M. A. Kerr, Org. Lett., 2009, 11, 2081. 
68 S. M. Wales, M. M. Walker and J. S. Johnson, Org. Lett., 2013, 15, 2558.

69 T. Komnenos, Justus Liebigs Ann. Chem., 1884, 218, 145.

70 (a) P. Perlmutter, Conjugate Addition Reactions in Organic Synthesis, Pergamon Press, Oxford, 1992; (b) M. P. Sibi and S. Manyem, Tetrahedron, 2000, 56, 8033; (c) M. Kanai and M. Shibasaki, in Catalytic Asymmetric Synthesis, Wiley, New York, 2000, 2nd edn, p. 569; (d) N. Krause and A. Hoffmann-Roder, Synthesis, 2001, 171; (e) J. Comelles, M. Moreno-Manas and A. Vallribera, ARKIVOC, 2005, ix, 2078; (f) J. Christoffers, G. Koripelly, A. Rosiak and M. Rössle, Synthesis, 2007, 1279; $(g)$ C. Hui, F. Pu and J. Xu, Chem. - Eur. J., 2017, 23, 4023.

71 M. P. Sibi and J. Ji, J. Org. Chem., 1997, 62, 3800.

72 M. P. Sibi, J. J. Shay, M. Liu and C. P. Jasperse, J. Am. Chem. Soc., 1998, 120, 6615.

73 J. Ji, D. M. Barnes, J. Zhang, S. A. King, S. J. Wittenberger and H. E. Morton, J. Am. Chem. Soc., 1999, 121, 10215.

74 M. L. Kantam, K. V. S. Ranganath, K. Mahendar, L. Chakrapani and B. M. Choudary, Tetrahedron Lett., 2007, 48, 7646.

75 B. J. Lundy, S. Jansone-Popova and J. A. May, Org. Lett., 2011, 13, 4958.

76 L. Lin, J. Zhang, X. Ma, X. Fu and R. Wang, Org. Lett., 2011, 13, 6410.

77 (a) S. Sobhani and Z. Tashrifi, Tetrahedron, 2010, 66, 1429; (b) M. Benaglia and S. Rossi, Org. Biomol. Chem., 2010, 8, 3824.

78 D. Zhao and R. Wang, Chem. Soc. Rev., 2012, 41, 2095.

79 M. Hatano, T. Horibe and K. Ishihara, Angew. Chem., Int. Ed., 2013, 52, 4549.

80 J. Zhang, X. Liu and R. Wang, Chem. - Eur. J., 2014, 20, 4911.

81 C. Dong, T. Song, X.-F. Bai, Y.-M. Cui, Z. Xu and L.-W. Xu, Catal. Sci. Technol., 2015, 5, 4755.

82 D. Yang, L. Wang, M. Kai, D. Li, X. Yao and R. Wang, Angew. Chem., Int. Ed., 2015, 54, 9523.

83 L. Wang, D. Yang, D. Li, P. Wang, K. Wang, J. Wang, X. Jiang and R. Wang, Chem. - Eur. J., 2016, 22, 8483.

84 J. Lv, X. Li, L. Zhong, S. Luo and J.-P. Cheng, Org. Lett., 2010, 12, 1096.

85 E. J. Corey and Z. Wang, Tetrahedron Lett., 1993, 34, 4001.

86 S. Mukherjee, J. W. Yang, S. Hoffmann and B. List, Chem. Soc. Rev., 2010, 39, 1600.

87 M. C. Willis, G. A. Cutting, V. J. D. Piccio, M. J. Durbin and M. P. John, Angew. Chem., Int. Ed., 2005, 44, 1543.

88 B. M. Trost, S. Malhotra and B. A. Fried, J. Am. Chem. Soc., 2009, 131, 1674.

89 B. M. Trost, S. Malhotra, P. Koschker and P. Ellerbrock, J. Am. Chem. Soc., 2012, 134, 2075.

90 G. K. Ingle, Y. Liang, M. G. Mormino, G. Li, F. R. Fronczek and J. C. Antilla, Org. Lett., 2011, 13, 2054.

91 C. Mannich and W. Krosche, Arch. Pharm., 1912, 250, 647.
92 (a) M. Arend, B. Westermann and N. Risch, Angew. Chem., Int. Ed., 1998, 37, 1044; (b) S. E. Denmark and O. J.-C. Nicaise, in Comprehensive Asymmetric Catalysis, ed. E. N. Jacobsen, A. Pfaltz and H. Yamamoto, Springer, Heidelberg, 1999, p. 923.

93 (a) S. Kobayashi and H. Ishitani, Chem. Rev., 1999, 99, 1069; (b) A. Cordova, Acc. Chem. Res., 2004, 37, 102; (c) G. K. Friestad and A. K. Mathies, Tetrahedron, 2007, 63, 2541; (d) R. G. Arrayas and J. C. Carretero, Chem. Soc. Rev., 2009, 38, 1940; (e) B. Weiner, W. Szymanski, D. B. Janssen, A. J. Minnaard and B. L. Feringa, Chem. Soc. Rev., 2010, 39, 1656; (f) S. Kobayashi, Y. Mori, J. S. Fossey and M. M. Salter, Chem. Rev., 2011, 111, 2626; (g) X.-H. Cai, G. Hui and X. Bing, Eur. J. Chem., 2012, 3, 258.

94 A. Viso, R. F. de la Pradilla, A. Garcia and A. Flores, Chem. Rev., 2005, 105, 3167.

95 (a) W. Notz, F. Tanaka and C. F. Barbas, Acc. Chem. Res., 2004, 37, 580; (b) A. Ting and S. E. Schaus, Eur. J. Org. Chem., 2007, 5797; (c) J. M. M. Verkade, L. J. C. van Hemert, P. J. L. M. Quaedflieg and F. P. J. T. Rutjes, Chem. Soc. Rev., 2008, 37, 29; (d) X.-H. Cai and X. Bing, ARKIVOC, 2013, i, 264; (e) A. Ghosh, S. Bhowmick, A. Mondal, H. Garai and K. C. Bhowmick, Curr. Organocatal., 2016, 3, 133.

96 M. Hatano, T. Horibe and K. Ishihara, Org. Lett., 2010, 12, 3502.

97 J. Wang, X. Liu and X. Feng, Chem. Rev., 2011, 111, 6947.

98 T. Sakai, T. Soeta, K. Endo, S. Fujinami and Y. Ukaji, Org. Lett., 2013, 15, 2422.

99 (a) C. Greck, B. Drouillat and C. Thomassigny, Eur. J. Org. Chem., 2004, 1377; (b) E. Erdick, Tetrahedron, 2004, 60, 8747.

100 D. A. Evans and S. G. Nelson, J. Am. Chem. Soc., 1997, 119, 6452.

101 B. Maji, M. Baidya and H. Yamamoto, Chem. Sci., 2014, 5, 3941.

102 C. Yin, W. Cao, L. Lin, X. Liu and X. Feng, Adv. Synth. Catal., 2013, 355, 1924.

103 (a) T. E. Müller, K. C. Hultzsch, M. Yus, F. Foubelo and M. Tada, Chem. Rev., 2008, 108, 3795; (b) S. Harder, Chem. Rev., 2010, 110, 3852.

104 X. Zhang, T. J. Emge and K. C. Hultzsch, Angew. Chem., Int. Ed., 2012, 51, 394.

105 S. R. Neal, A. Ellern and A. D. Sadow, J. Organomet. Chem., 2011, 696, 228.

106 S. E. Larson, G. Li, G. B. Rowland, D. Junge, R. Huang, H. L. Woodcock and J. C. Antilla, Org. Lett., 2011, 13, 2188.

107 W. J. Kerr, M. Middleditch and A. J. B. Watson, Synlett, 2011, 177.

108 N. De Rycke, J. D. St Denis, J. M. E. Hughes, K. A. Rosadiuk and J. L. Gleason, Synlett, 2014, 2802. 